NBSIR 75-918

\title{
Machine-Readable Mapping from National Network Simulation (NNS) Zones to Bureau of Economic Analysis (BEA) Areas
}

Daniel W. Lozier John R. Stiehler

Applied Mathematics Division Institute for Basic Standards National Bureau of Standards

Washington, D. C. 20234

September 1975

Final

The work reported herein was done for and Supported by the Bureau of Economic Analysis of the U.S. Department of Commerce

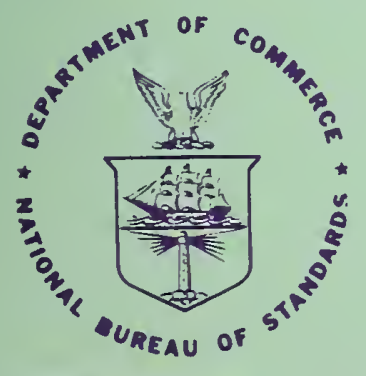

U S. DEPARTMENT OF COMMERCE

NATIONAL BUREAU OF STANDARDS 



\section{MACHINE-READABLE MAPPING \\ FROM NATIONAL NETWORK \\ SIMULATION (NNS) ZONES TO \\ BUREAU OF ECONOMIC ANALYSIS \\ (BEA) AREAS}

Daniel W. Lozier

John R. Stiehler

Applied Mathematics Division

Institute for Basic Standards

National Bureau of Standards

Washington, D. C. 20234

September 1975

Final

The work reported herein was done for and supported by the Bureau of Economic Analysis

of the U.S. Department of Commerce

U.S. DEPARTMENT OF COMMERCE, Rogers C. B. Morton, Secretary James A. Baker, III, Under Secretary

Dr. Betsy Ancker-Johnson, Assistant Secretary for Science and Technology

NATIONAL BUREAU OF STANDARDS, Ernest Ambler, Acting Director 



\section{Abstract}

This report describes the allocation of freight flow data from the National Network Simulation (NNS) zone system to the Bureau of Economic Analysis (BEA) area system. The NNS zone system was developed for use in the analysis of national modal freight flows. The BEA area system was primarily developed for the allocation of national economic data to regions of the United States. The BEA area system contains approximately 175 distinct areas and the NNS zone system, approximately 500. Assuming flows of commodities are known among the NNS zones, the NNS zone to BEA area mapping enables the determination of flows among the BEA areas. When an NNS zone is completely contained in one BEA area, flows entering and leaving the NNS zone accrue entirely to that BEA area. When an NNS zone overlaps more than one BEA area, the mapoing specifies the allocation of incoming and outgoing flows among the affected BEA areas. This report presents the NNS zone to BEA area mapping which utilizes 1970 economic data as the basis for allocating flows when an NNS zone overlaps more than one BEA area. It also presents computer programs that could be used to generate a mapping using economic data from some other year. Closely related reports are R. Schofer, "Final Report on the National Network Simulation", NBS Internal Report 75-912 and R.H.F. Jackson, "A National Network Data Base System", NBS Internal Report 75-911. 

Table of Contents

I. Introduction . . . . . . . . . . . . . . 1

II. Machine-Readable Form of the Mapping . . . . . . . 3

III. Program MAIN . . . . . . . . . . . . . . 4

IV. Method for Certain NNS zones in New England. . . . . 6

V. Preparation of Machine-Readable Input to MAIN . . . . 7

VI. Other Programs . . . . . . . . . . . . . . . . . 9

VII. Master Transmittal Tapes . . . . . . . . . . 10

VIII. Appendices . . . . . . . . . . . . . . . . . 14

App. 1 Data Sets NDX and PCT . . . . . . . . . . 14

App. 2 Listing of Program MAIN . . . . . . . . . . 30

App. 3 Data Set NNS . . . . . . . . . . . . 40

App. 4 Data Set BEA . . . . . . . . . . . . 55

App. 5 Listings of Programs CNTYLIST and INDX . . . 68

App. 6 Listings of Programs NAMELIST and FBBFC.... 71 



\section{Introduction}

The National Network Simulation (NNS) zone system was develoned for use in the analysis of national modal freight flows. The Bureau of Economic Analysis area system was primarily developed for the allocation of national economic data to regions of the United States (defined as the fifty states Dlus the District of Columbia). The BEA (Bureau of Economic Analysis) system contains approximately 175 areas and the NNS (National Network Simulation) system, approximately 500 zones.

It is desired to approximate the flows of several commodity groups among the BEA areas, starting from previously estimated flows among the NNS zones*. For this, the NNS zone to BEA area mapping is needed. The mapping specifies, for each NNS zone that lies wholly within some BEA area, the BEA area in which it lies; and for NNS zones not wholly contained in a single BEA area, it specifies the proportion of incoming and outgoing commodity flows to be allocated to each of the BEA areas that partially contain it. These commodity flow proportions are approximated by the use of two (county level) economic statistics provided by the Bureau of Economic Analysis: It is assumed that outgoing commodity flows are proportional to total earnings (eçual to the sum of wages, salaries, proprietors income, other labor income) and that incoming commodity flows are proportional to total personal income (equal to total earnings plus property income (rents) plus transfer income (welfare, gifts) minus contributions and Social Security payments).

Only the NNS zone to BEA area mapping and the methods used to determine it are of interest in this report. The distribution of county level economic statistics on which part of the mapping is based could change from year to year. Thus automated (computer) methods were developed, insofar as possible, that will ease new determinations of the mapping in the future.

The fifty states plus the District of Columbia were subdivided into approximately 500 zones in the National Network Simulation system, and into $173 \mathrm{BEA}$ areas in the Bureau of Economic Analysis. Except in four states in New England the NNS zones contain integer numbers of counties; the BEA areas always contain integer numbers of counties.

$*$

For further information see "A National Network Data Base System", NBS Internal Report 75-911, by Richard H.F. Jackson, September 1975, and "Final Report on the National Network Simulation", NBS Internal Report 75-912, by Ralph Schofer, to appear. 
THE READER SHOULD CAREFULLY NOTE THAT THE AUTOMATF.D PROCEDURE TO BE, DESCRIBED IS BASFD UPON THF, FACT THAT THERE ARE INTEGER NUMBERS OF COINTIES IN BOTH THE NNS AND THE BEA ZONES. THE SELECTED ECONOMIC STATISTICS AVAILABLE BY COUNTY IN MACHINE-READABLE FORM MAKE THIS APPROACH FEASIBLE.

Both a zone and an area are defined as a contiguous 1 and region. From here on in this report, the authors take the liberty to speak of NNS zones and BEA zones for purposes of expository clarj.ty. Readers should note that BEA zone is synonymous to BEA area.

With the exception of certain NNS zones in four New England states and Alaska, the mapping was done by creating machine-readable data sets from raw source data and a Fortran computer program for processing them. The output of the program is the zone mapping. in machine-readable form (Fortran DATA statements). Part of the basis for the computing program was selected economic statistics by county. The NNS zones that were processed by computer constituted an integral number of whole counties, or could be so construed: Certain states, notably Virginia, have "independent cities" which for our purposes could be combined with counties.

Although all BEA zones are defined as an integral number of whole counties, in four New England states some of the NNS zones are defined at the township level. Thus additional data was needed to develop the mapping in these cases and a manual approach seemed most expeditious. The manual approach was based on the distribution of population at the township level. Alaska consists of one BEA zone and nine NNS zones with no boundary complications, but for technical reasons (the BEA zone definition is in terms of "Jurisdictional Districts" rather than counties) it also was done by hand. The manual and machine-produced data are identical in format, which is described in the next section.

All economic and population data used in the mapping presented in this report are for the year 1970. Economic data was provided on magnetic tape by the BEA. Population data and detailed state and county maps were found in

County and City Data Book 1972, issued by the U.S. Dept. of Commerce

and

1970 Census of the Population

vol. 1 Characteristics of the Population part 8 (Connecticut), 23 (Massachusetts), 31 (New Hampshire) and 41 (Rhode Island), issued March 1973 by the U.S. Department of Commerce. 
Procedures for allocating commodity flows where NNS zones were contained by more than one BFA area were developed in consultation with Allan L. Olson and his colleagues at the BEA. These people also provided much helpful assistance in understanding and utilizing data files developed by other groups within the BEA.

Computer runs were made on the NBS central computer; and the programs may have some system-dependent features. This report describes duplicate Master Transmittal Tapes on which are recorded the raw source data received from BEA, refined source data, programs and output data (the NNS to BEA zone mapping).

II. Machine-Readable Form of the Mapping

The mapping of NNS zones into BEA zones is presented in Appendix 1 in the form of Fortran DATA statement which can be compiled into any Fortran program that requires the zone mapping.

The first series of DATA statements specify the contents of a table with the Fortran name NDX. The length of the table is 509 words, one word for each NNS zone. Let $v(i)$ be the (integer) $v a l u e$ found in word $i$. If $v(i)$ is positive, then NNS zone $i$ is wholly contained in BEA zone $\mathrm{v}(i)$. If $\mathrm{v}(i)$ is zero, then there is no NNS zone $i$. If $v(i)$ is negative, then NNS zone $i$ is not wholly contained in a single BEA zone, and $-v(i)$ is the starting location of a "record" of information pertaining to NNS zone i in a second table with the Fortran name PCT.

The second series of DATA statements specify the contents of the PCT table. The table is constructed in the following way: It contains one record for each NNS zone that overlaps more than one $B E A$ zone. If NNS zone $i$ is such a zone, then $-v(i)$ is the starting location (Fortran subscript of the first word) of the record for NNS zone $i$, as described above. Let $w(i)$ be the number of BEA zones that partially contain NNS zone $i$. Then the contents of word $-v(i)$ of PCT is $1000 i+w(i)$. The record is completed in $w(i)$ triplets of words immediately following word $-v(i)$. The contents of each triplet are as follows. Word 3 contains the BEA zone number, word 2 contains the fraction of total earnings in NNS zone $i$ that is to be allotted to this BEA zone, and word 1 contains the fraction of total personal income in NNS zone $i$ that is to be allotted to this BEA zone. In the commodity-flow program (not described in this report), fractional shipments into and out of parts of NNS zones that overlap more than one BEA zone are to be determined by the income and earnings fractions, respectively, in the PCT table. 
This form of storage for the PCT table permits the use of variable length records with no unused locations in the table. The DATA statements are arranged to show clearly the contents of the starting location and the following triplets. Note that the Fortran type of the constants appearing in words 1 and 2 of each triplet is REAL and that the type of constant in word 3 is INTEGER. These types will be preserved regardless of the declared type of PCT. To use the PCT table in a Fortran program, the following programming technique is needed. First declare PCT and IPCT of type REAL and INTEGER respectively, and of equal length. Then make the declaration

EQUIVALENCE (PCT (1), IPCT (1)).

In executable statements following this declaration reference to PCT or IPCT must be coded in accordance with the actual type of data stored in the Fortran array.

\section{Program MAIN}

This program, with subroutines ISL, BINSCH, CMP, SNDX and PAR, produces the NNS to BEA zone mapping in machine-readable form from three input data sets NNS, INDEX and BFA. Listings of the program and subroutines appear in Appendix 2, and listings of the data sets NNS and BEA appear in Appendices 3 and 4. The construction of these three input data sets from original source data is described in Section V; their form as roquired by program MAIN is described in the following pages.

NNS

This data set specifies the counties, by BEA county code , that comprise the NNS zones. Note that oniy NNS zones made up of whole counties can be included, so that in particular NNS zones 2-6,8,9,12-40 cannot be part of this data set. These are the NNS zones in New England that contain parts of counties. In the computer this data set is stored as a linear array of integers. For each NNS zone there is a record starting at some location in the array.

it

The term "BEA county code" refers to the 6-digit BEA state-county code in which the first three digits specify the state and the last three, the county. Similarly, the term "FIPS county code", to be introduced later, refers to the 5-digit FIPS state-county code, in which the first two digits specify the state and the last three, the county. 
The first word of the record contains the NNS zone times 1000 plus the number $N$ of counties in the zone. The following $N$ words contain the BEA county codes. The records are arranged in ascending order of NNS zones, with the record for NNS zone 1 starting in word 1 of the array. The NNS zones must be in sequence with no gaps, but the number $\mathrm{N}$ can be zero for unused NNS zones or zones, such as the ones in New England listed above, for which processing by program MAIN is to be bypassed.

INDEX

For each county (identified by the BEA county codes) this data set gives the BEA zone in which it lies plus the total personal income and the total earnings in the county in 1970. In the computer this data set is stored as a twodimensional array. The Fortran DIMENSION statement specifies the total number of counties and 4 as the first and second subscript limits. For the $i-t h$ county, the $(i, j)-t h$ array element contains the BEA county code, the BEA zone number in which the county lies, total personal income (1970) and total earnings (1970) for $j=1,2,3,4$ respectively.

BEA

This data set specifies the counties, by BEA county code, that comprise the BEA zones. In the computer this data set is stored as a linear array of integers. For each BEA zone there is a record starting at some location in the array. The first word of the record contains the BEA zone times 1000 plus the number $N$ of counties in the zone. The following $N$ words contain the BEA county codes. The records are arranged in ascending order of $\mathrm{BEA}$ zones, with the record for $\mathrm{BEA}$ zone 1 starting in word 1 of the array.

The machine-readable output of program MAIN is described in Section II. Briefly, it consists of two data sets in the form of Fortran DATA statements, listed in Appendix 1. These statements store the necessary numbers in Fortran arrays, named NDX and PCT, that specify the NNS to BEA zone mapping. 
The primary logic of program MAIN is simple. Starting and stopping NNS zone numbers are read. The input data sets INDEX, NNS and BEA are read from logical units 7, 8 and 9. Then the main loop is entered. For each NNS zone, the first county in the zone is ascertained and the BEA zone in which it lies is located. This is done by doing a binary search in the INDEX table using subroutine BINSCH. Subroutine CMP then compares the list of counties in the NNS and BEA zones to determine if the NNS zone is wholly contained in the BEA zone. If so, subroutine SNDX is called to make the appropriate entry in the NDX table.

If not, subroutine SNDX again makes the appropriate entry in NDX. Then subroutine PAR is called to determine the fractions that will specify the allocation (to the proper BEA zone) of incoming and outgoing commodity flows of the NNS zone under consideration. This allocation is done with the aid of the total personal income and total earnings data in the INDEX table: Each of these statistics is accumulated over all counties in the NNS zone. They are also accumulated for subsets of counties in the NNS zone that lie in the same BEA zone. Ratios are then formed to determine the allocation of the commodity flows of the NNS zone among the two or more BEA zones it partially overlaps, with total personal income as the surrogate for incoming flows and total earnings as the surrogate for outgoing flows. Finally, SNDX enters the fractions into the PCT table.

The output data sets NDX and PCT are written to logical units 24 and 25 by subroutines SNDX and PAR, respectively.

Note that where NNS zones comprise an integral number of counties, the procedure carried out by program MAIN works because income and earnings data are contained in the INDEX table by county. The program cannot be used for NNS zones, 2-6, 8, 9, 12-40 in four New England states because these NNS zones do not comprise an integer number of counties. For these zones, the data for the NDX and PCT tables were determined manually, as described in the next Section, and inserted into the data sets produced by program MAIN.

IV. Method for Certain NNS Zones in New England

In New England, as elsewhere, the BEA zones are made up of county units only. But in some cases the counties are too large an aggregation for the much finer system of NNS zones. Therefore, some NNS zones in New England are defined in terms of 
subdivisions of the county, such as townships ${ }^{*}$. This problem occurred only in Rhode Island, Massachusetts, Connecticut and New Hampshire. Although total personal income and total earnings data were available only at the county level, we were able to find population data at the township level in the 1970 Census of the Population, referenced in the Introduction. For NNS zones that intersect more than one BEA zone, we used population to hand-calculate percentage allotments of total NNS zone income and total NNS zone earnings for each intersected BEA zone.

The method we used was the following: We assumed the total personal income and earnings of a part of a county to be proportional to the population of that part of the county. Thus we determined income and earnings figures for NNS zones containing parts of counties, and for parts of NNS zones lying in different BEA zones. Forming the required ratios, we then determined the required percentage allotments and made appropriate entries in the NDX and PCT data sets. We used this manual method for NNS zones 1 through 40; these calculations affected only BEA zones 1 through 6 .

\section{Preparation of Machine-Readable Input to MAIN}

Machine-readable input to program MAIN consists of the data sets NNS, INDEX and BEA, described in section III.

Data set NNS was prepared by punching data on cards from an available list of NNS zones, since no machine-readable form of this data was available. Data set BEA was prepared, using simple Fortran programs, from data on a magnetic tape supplied by the Bureau of Economic Analysis. A copy of this magnetic tape exists as "File 1 " on the "Master Transmittal Tape" described in Section VII. The programs used to prepare the data set BEA have not been kept, since we anticipate that any corrections or changes in the NNS or BEA area systems will be minor.

Preparation of data set INDEX was somewhat more complicated. At first it was conceived as only specifying, for each county, the BEA zone that contained it. Program CNTYLIST, 1isted in Appendix 5, carried this out using data set BEA as the primary input. Then it was decided to include the two economic statistics total personal income (1970) and total earnings (1970). A second program INDX, also listed in Appendix 4 accomplished this using

$\star$

The exact definitions had to be deduced from maps, since only unpublished documents defining the NNS zones in terms of counties and unspecified "parts" of counties were available. 
income and earnings data provided by BEA on two magnetic tapes. Unfortunately, these tapes were arranged by FIPS county code rather than BEA county code. Being unwilling to convert previously constructed data sets to a FIPS code basis, we decided to stay with the BEA county codes, although there may be good reasons for making the opposite choice. In either case, we needed a conversion table between FIPS and BEA county codes. This was derived from a magnetic tape received from BEA which exists as "File 2" on the Master Transmittal Tape. Copies of the income and earnings tapes supplied by BEA exist as "File 3" and "File 4" on the same master tape.

The programs CNTYLIST and INDX, although listed in Appendix 5 and transmitted on the master tape, are considered primitive. But if data set INDEX were to be recreated using economic data for a year other than 1970, they could be used or could serve as a guide for development of a better single program. Three data sets named INCOME, EARNINGS and BEAFIPS were created for use as input by program INDX. A11 are included on the master tape; see Section VII.

Data sets INCOME and EARNINGS were created from the income and earnings tapes by the use of simple Fortran programs and editing sessions. The major editing task was to consolidate data for "independent cities" with appropriate counties to correspond to the BEA county definitions. The FIPS codes, but not the BEA codes, contain designations for independent cities. The following describes data sets INCOME, EARNINGS and FIPSBEA.

INCOME

This data set contains total personal income for each county in the U.S. for the years 1969 through 1973. The data is arranged by FIPS county code, and only the FIPS codes corresponding to BEA county designations are included. The format of the data is given in Section VII.

EARNINGS

This data set contains total earnings for each county in the U.S. for the years 1969 through 1973. The data is arranged by FIPS county code, and only the FIPS codes corresponding to BEA county designations are included.

FIPSBEA

This data set provides conversion from FIPS to BEA county codes. It is arranged in ascending order of the 5-digit FIPS codes, and it provides alphabetic identification and the corresponding BEA code for each FIPS county code. 
Certain anomalies arose during the preparation of the data sets NNS, INDEX and BEA. Already mentioned is the fact that "independent cities" in Virginia are given separate FIPS codes but are consolidated with counties in the BEA code list. This was important only in the creation of the INCOME and EARNINGS data sets. Other anomalies included non-uniform treatment of certain combinations of counties for BEA and FIPS codes. The counties that were at times combined and at other times listed separately included the five boroughs of New York City, Dekalb and Fulton counties in Georgia, Shawano and Menominee counties in Wisconsin, and Park County and Yellowstone National Park in Wyoming. Each of these cases was treated as a single county since not all data was available for the separate counties.

Another problem was the name and code number change from Muscogee county to Columbus City in the most recent updating of the FIPS codes for Georgia. This presented no difficulties once the mapping was changed from the old FIPS number to the new number.

\section{Other Programs}

Certain auxiliary programs are deemed useful enough to be included in this report and on the Master Transmittal Tape. They are listed in Appendix 6.

Program NAMELIST

This program prints an alphabetical listing of the counties making up either the NNS zones or the BEA zones as specified by the numerical data sets NNS and BEA; see descriptions of these data in Section III. Program NAMELIST exists solely for the purpose of listing the contents of these data sets in a form suitable for easy checking; it was used to produce Appendices 3 and 4.

Input is read from logical units 10,11, 12 and 13, as follows:

L.U. 10 FIPSBEA (alphabetic field only).

L.U. 11 An integer, the number of entries in the table to follow on L.U. 12 .

L.U. 12 Either the NNS or BEA data set.

L.U. 13 BEAFIPS 
Printed output is divided between L.U. 6 (error messages) and I.U. 15 (the alphabetical listing). After program execution, L.U. 15 can be printed using the EXEC 8 control sequence

QDATA 15.

QEND.

NAMELIST does not provide output for certain NNS zones in New England and Alaska. These zones were specially handled without the use of the computer for reasons described elsewhere. Further, the output for BEA zones will be absent for all counties that lie in these special NNS zones. A field of asterisks is printed in these cases.

It remains to describe data set BEAFIPS since FIPSBEA was described in the previous Section.

BEAFIPS This data set provides an indirect inverse for the FIPSBEA table. For each BEA zone, it gives the "record" number in the FIPSBEA table to which it corresponds. There is one record per county in FIPSBEA, arranged by FIPS code. Thus BEAFIPS provides access to county data (i.e., the name of the county) by way of BEA county code rather than FIPS county code.

Program FBBFC

This program exists solely to check the compatibility of date sets FIPSBEA and BEAFIPS. In other words, it merely verifies that no matter whether BEA or FIPS codes are specified, the same county record is retrieved from data set FIPSBEA.

\section{Master Transmittal Tapes}

There are two Master Transmittal Tapes, which are exact duplicates of each other. They exist on NBS reel numbers A019 and $A 045$ in the tape library of the NBS central computer facility, Room A27, Administration Building. They are recorded as 9 track labelled tapes, odd parity, 800 frames per inch. A rental fee of $\$ .50$ per tape per pay period (2 weeks) is being charged against the project computer account. This charge will continue until the Computer Room is told to release the tapes. The Computer Services Division will transfer the charges to another account upon request. 
The fact that the Master Transmittal Tapes are "labelled" means that the computer system will not permit them to be used (neither read nor written) unless the control card "assigning" the tape contains certain information that matches exactly the information in the tape label. The tape label is recorded on the tape and may have nothing to do with external labels appearing on the reel. The system checks every tape that is mounted to see if it has a label, and if so, to compare it against the assigning control card. This protection will last until 23 October 1978, the "expiration date" recorded as part of the tape label.

The control cards that will "assign" the Master Transmittal Tapes in "read only" mode are

$$
\begin{aligned}
& \text { @ASG, T LBEA*NNSBEA1 , 8C } 9, \text { A019 } \\
& \text { @ASG, T LBEA*NNSBEA2 . 8C9, A045 }
\end{aligned}
$$

Other forms of these cards are required if any alteration of the tapes is desired.

The tapes contain 14 "files" of information - data and programs. These files are described below.

File 1 Copy of tape received from BEA. Format: EBCDIC, logical record length 250 characters, physical record length 1250 characters ( 5 logical records), tape consists of a short header record plus 615 physical records. Each logical record is for one county in the United States; in this listing there are 3074 counties. Logical record format: cols. 9-14, BEA county code; cols. 25-30, BEA zone number; cols. 64-100, county and state name; other columns contain information of no interest.

File 2 Copy of tape received from BEA. Format: EBCDIC, logical record length 110 characters, physical record length 1100 characters (10 logical records), tape consists of 34 physical records. Each logical record corresponds to a state, county or independent city; in this listing there are a 
total of 3332 entries. Logical records format: cols. 1-5, FIPS state-county code; cols. 7-20, state and county name; cols. 60-65, BEA statecounty code; other columns contain information of no interest.

File 3 Copy of tape received from BEA. Format: EBCDIC, logical record length 63 characters, physical record length 2016 characters (32 logical records), tape consists of a short header record plus 98 physical records. Except for the first logical record, which is for the whole United States, each logical record is for one county or one independent city in the United States; in this listing there are 3133 of them. Logical record format: cols. 2-6, FIPS state-county code; total personal income for the county or city in the years 1969-1973 is given in cols. 14-23, 24-33, 34-43, 44-53 and 54-63.

File 4 Copy of tape received from BEA. Identical to File 3 in logical record and physical record format, but contains total earnings data instead of total personal income for the years 1969-1973.

Nine of the remaining 10 files are "data files" (SDF format on the NBS computer system). Of these, File 9 is in binary format and the others are in character format (Fieldata). File 14 is the "program file" (containing Fortran source and relocatable "elements"). All were written on tape using the "(COPY,GM" control card; to retrieve one of them into a mass storage file requires appropriate use of "QCOPY, G" after "assigning" a mass storage file and positioning the tape. For example,

QASG, T PROGFILE.

QASG, T LBEA*NNSBEAI , 8C 9, A019

QMOVE LBEA*NNSBEA1., 13

@COPY, G LBEA*NNSBEA1., PROGFILE.

will (i) assign a mass storage file PROGFILE, (ii) assign the tape, (iii) position the tape at the beginning of the 14-th file, and (iv) copy the 14-th tape file into the mass storage file. Since all of the remaining files have been described in earlier sections of this report, the following will give only the necessary additional information. 
File 5 FIPSBEA There is one record per county. Cols. 1-5 contain the FIPS county code, cols. 7-20 contain the state and county name, cols. 60-65 contain the BEA county code.

File 6 BEAFIPS This is in 10 Ilo format and is used by program NAMELIST. See Section VI.

File 7 INCOME There is one record per county. Cols. 2-6 contain the FIPS county code; total personal income for each county in the years 1969-1973 is given in cols. 14-23, 24-33, 34-43, 44-53 and 54-63. This file is an edited version of File 3 .

File 8 EARNINGS There is one record per county. Identical to File 7 in format, but gives total earnings by county instead of total personal income. This file is an edited version of File 4.

File 9 INDEX This file is in binary format and is used by program MAIN. See Section III.

File 10

NNS This file is in 10110 format and is used by program MAIN. See Section III.

File 11 BEA This file is in 10 Il0 format and is used by program MAIN. See Section III.

File 12 NDX See Appendix 1 for a listing.

File 13 PCT See Appendix 2 for a listing.

File 14 This is the program file containing all programs and subroutines described in this report. 
$14-$

Appendix 1

Data Sets NDX and PCT 


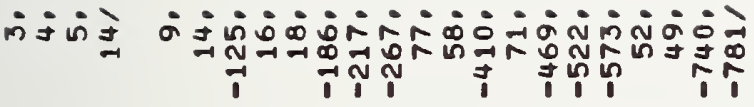

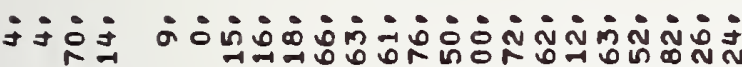
1 $\rightarrow$ न

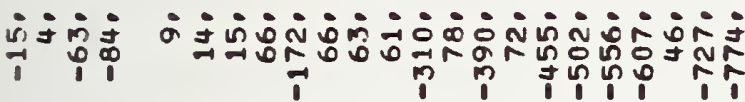

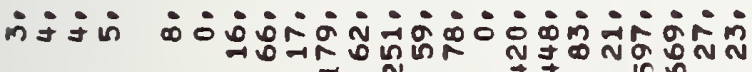

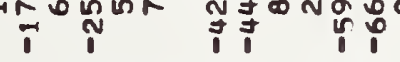

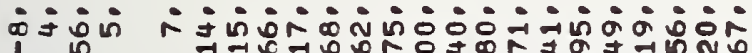

फ न न

就充

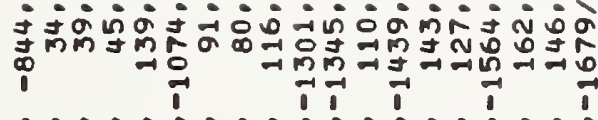

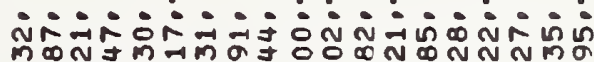

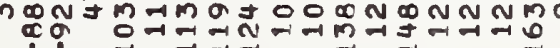
: $\div$

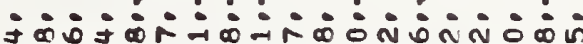

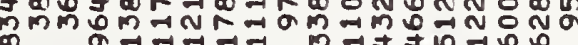
i

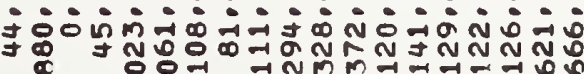
i iो

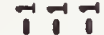
$\because 1$ ヘ

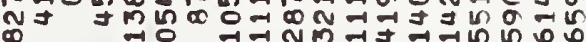
!

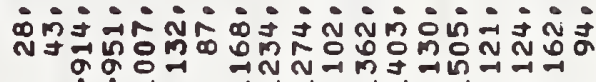
I:0

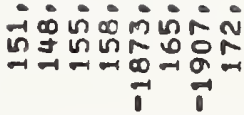

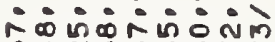
กรกง -1

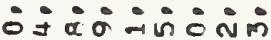
แn

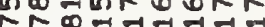
$\overrightarrow{1} \overrightarrow{1}$

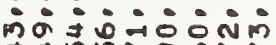

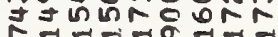
$\overrightarrow{1}$

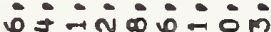
manz⿻上丨 ヘ $\infty \infty_{-1}=-$ 1-1

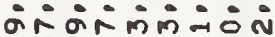
Nog

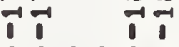

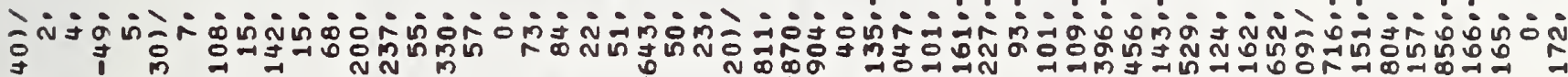

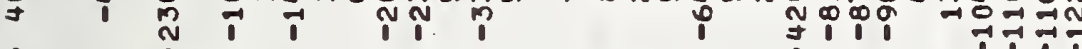

1ज्ञ

í II I II A-

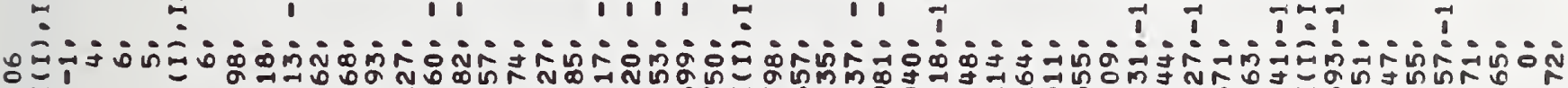

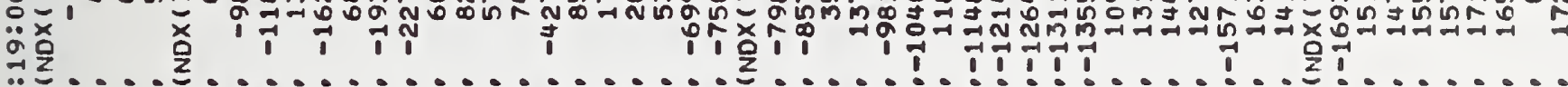

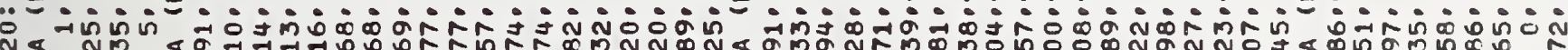
NEN $\rightarrow$ -Nm 


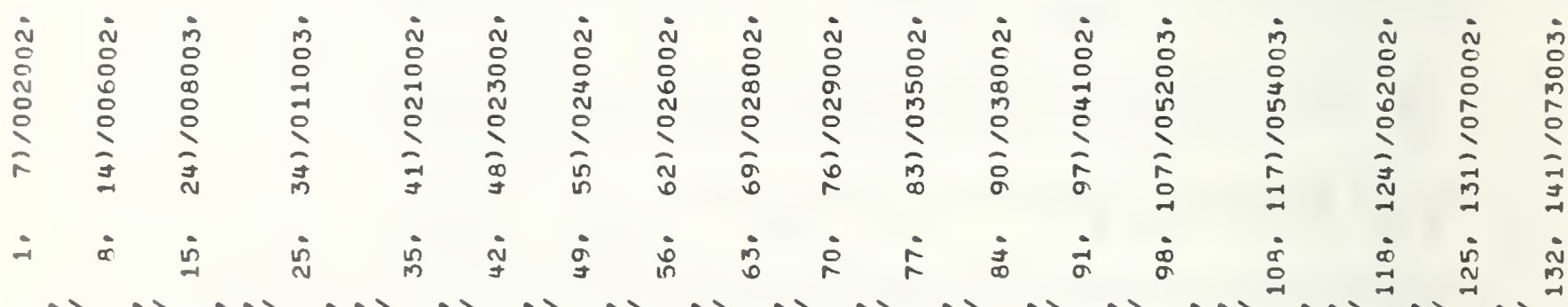

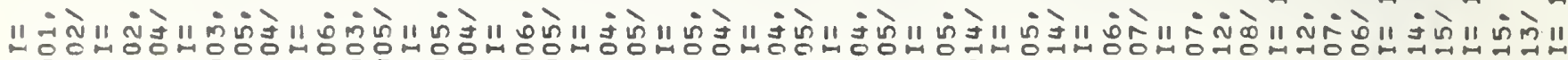

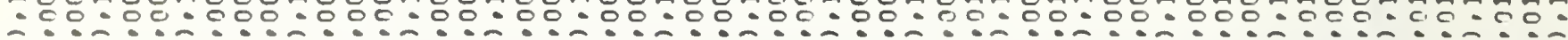

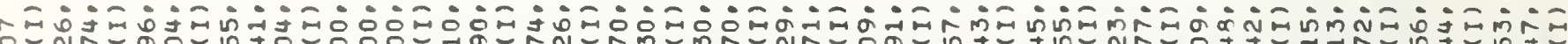
-

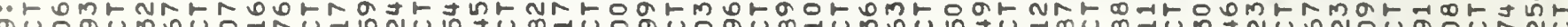

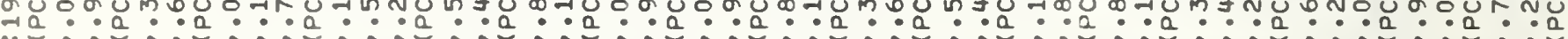

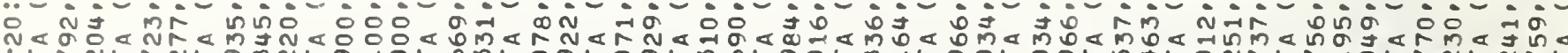
IF N o< o o

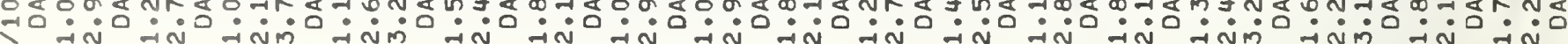
은

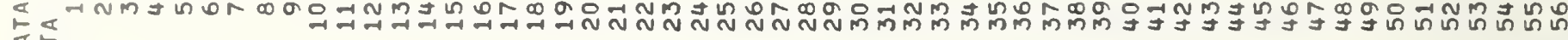
옹 


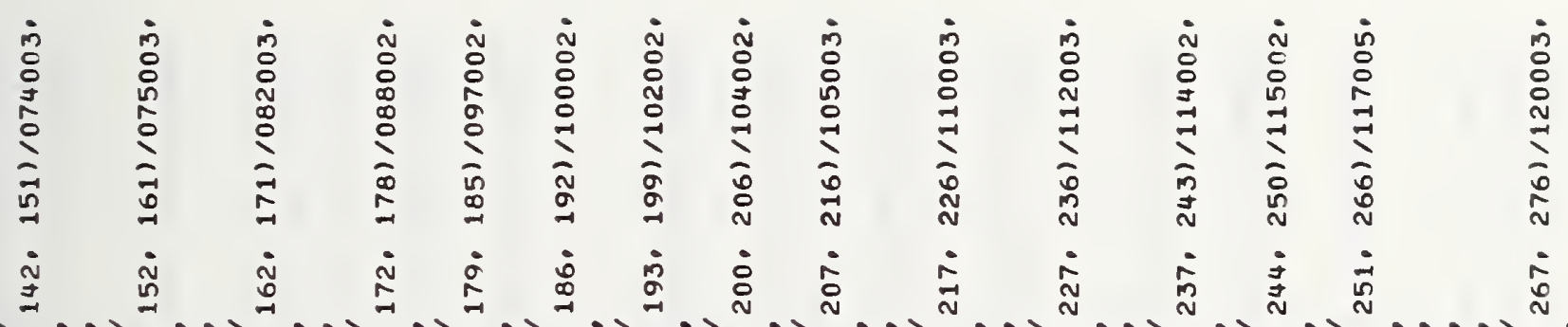
خَخ

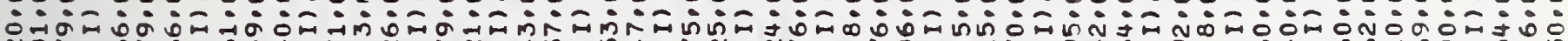

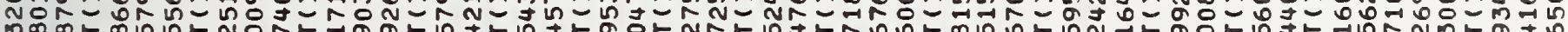

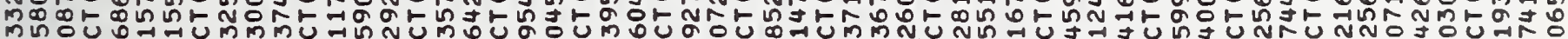

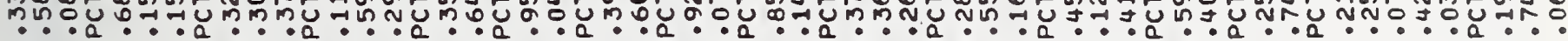
Dón

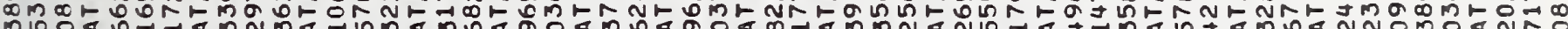

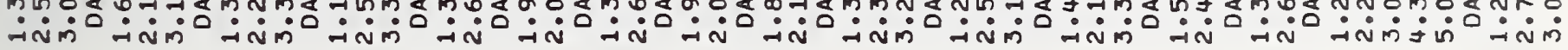




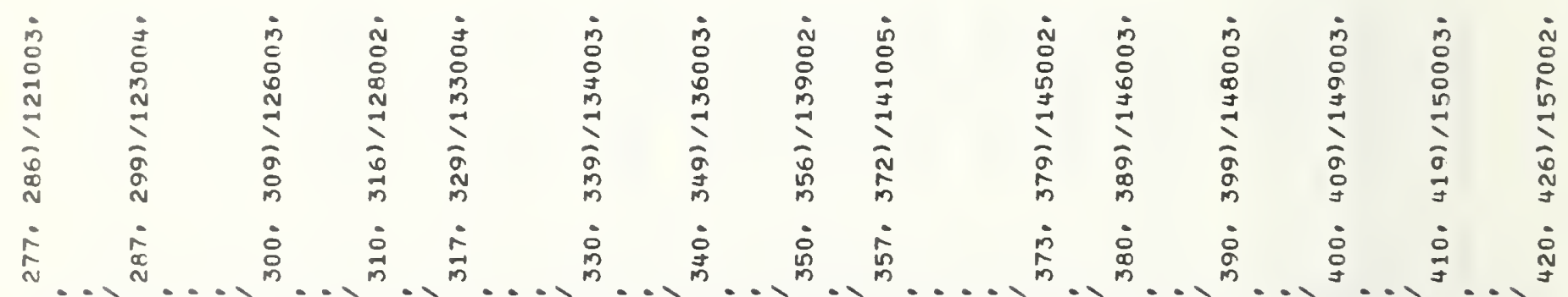

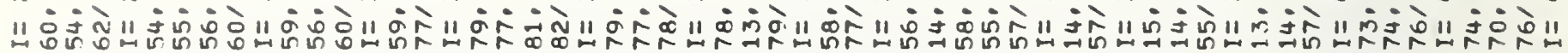

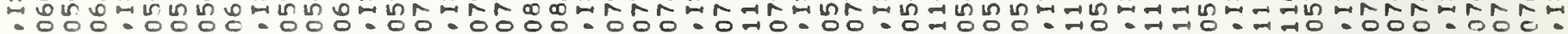

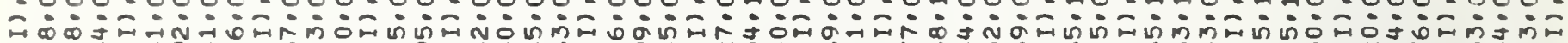

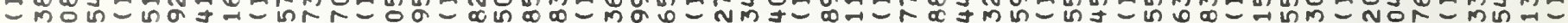

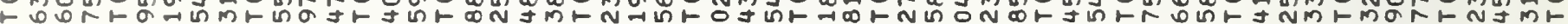

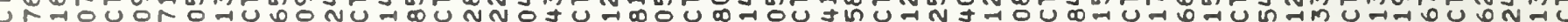
$a \cdots a \cdots a$

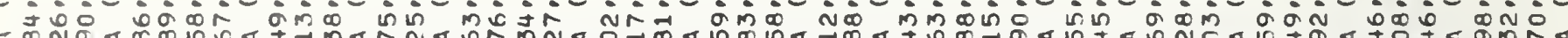

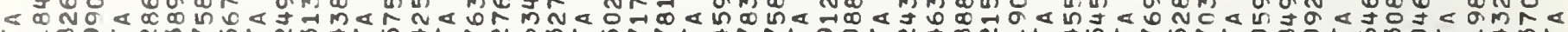

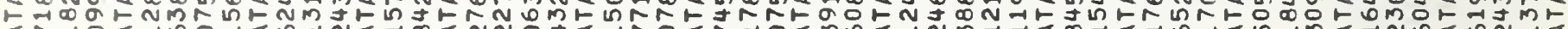

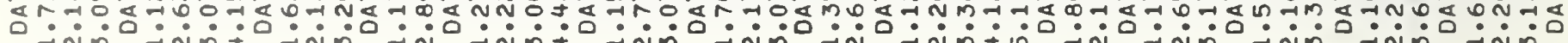




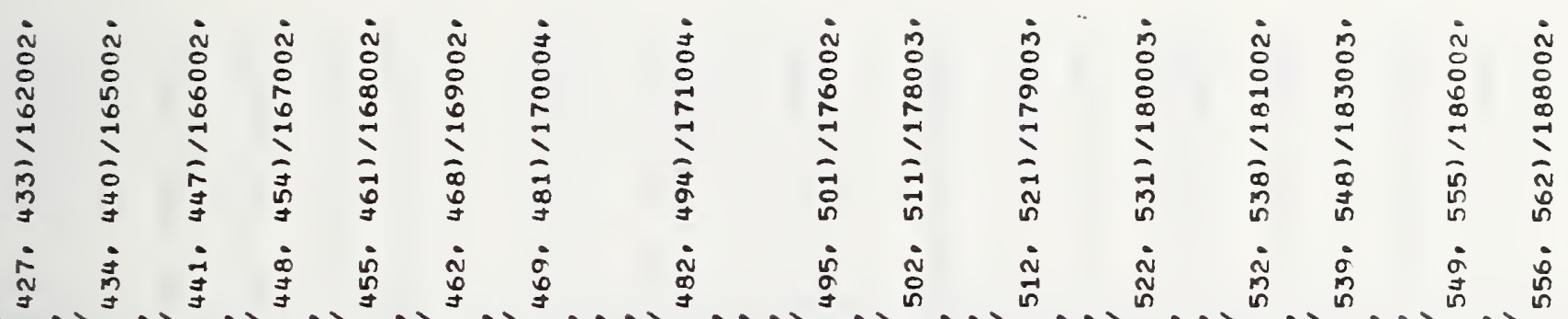

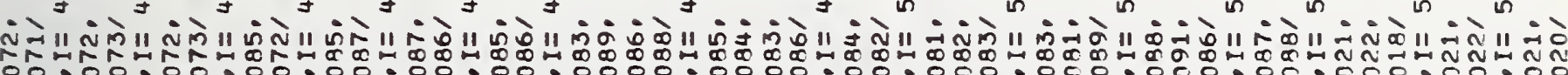

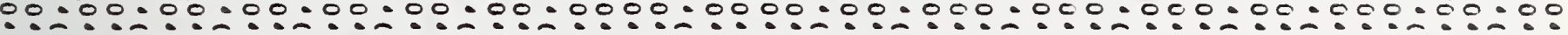

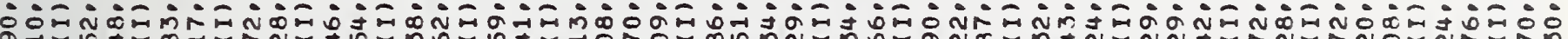

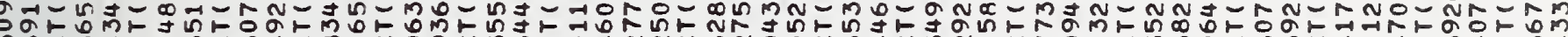

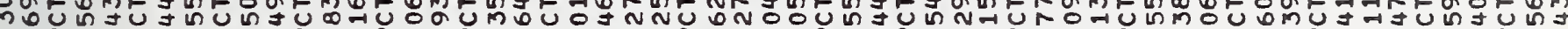

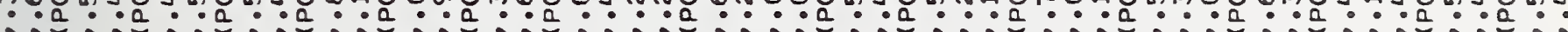
a

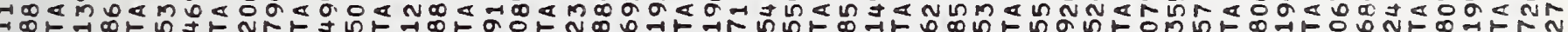
70

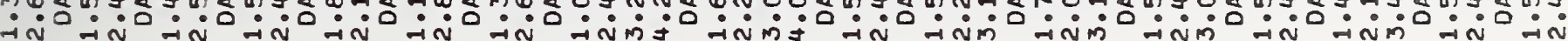




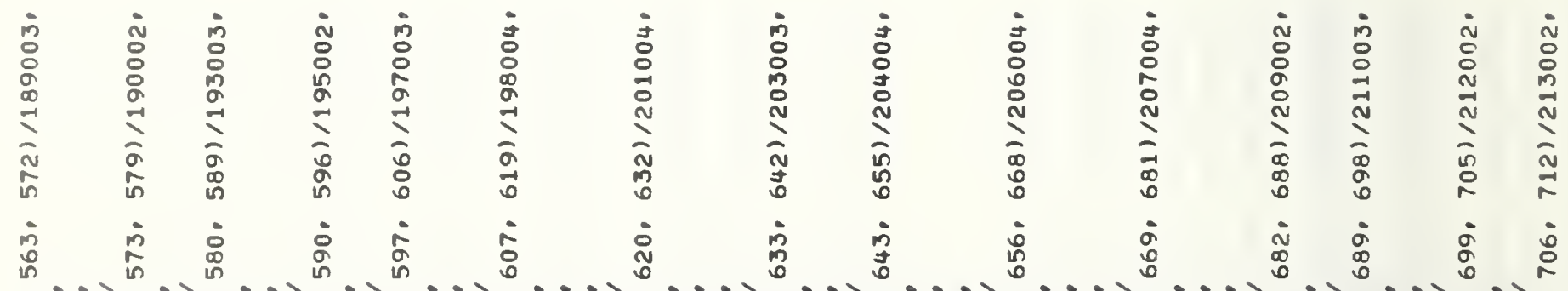
"1ळ்

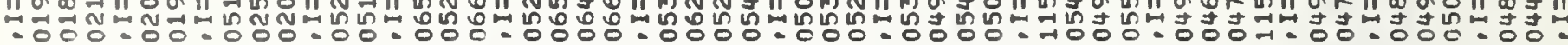

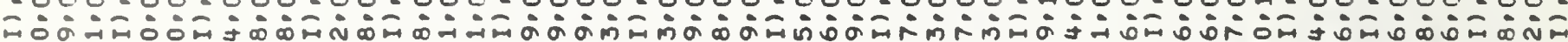
ー

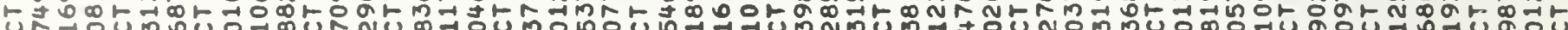

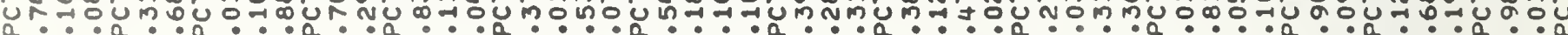
$a$

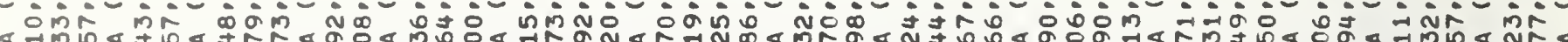

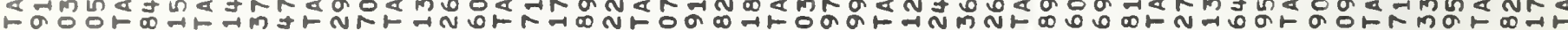

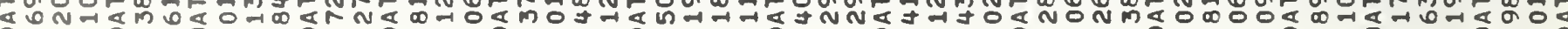

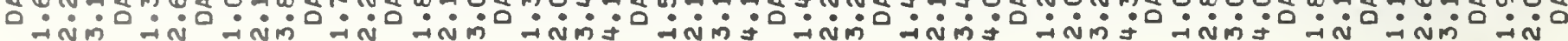




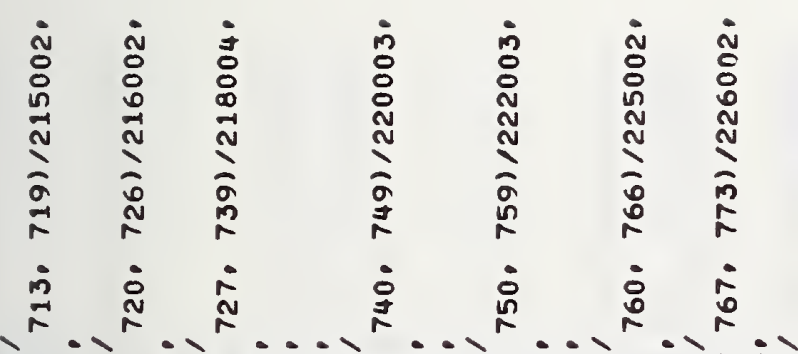

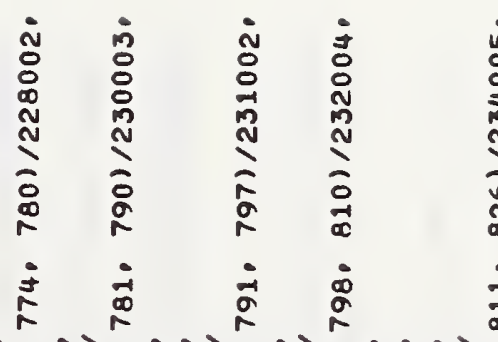

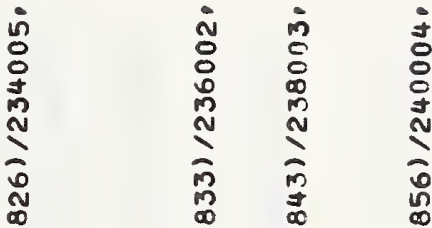

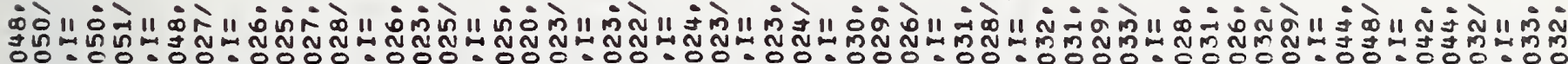

$-\infty$

少

竞

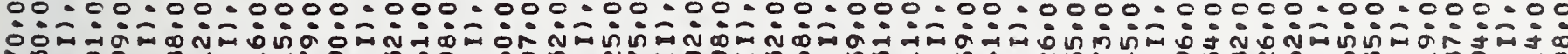

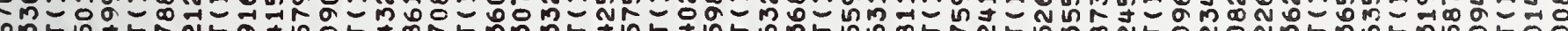

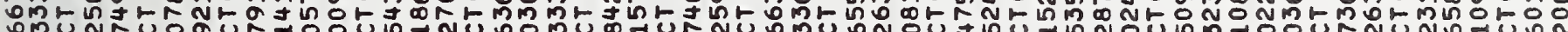
M?

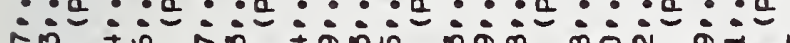

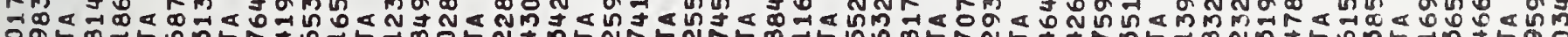

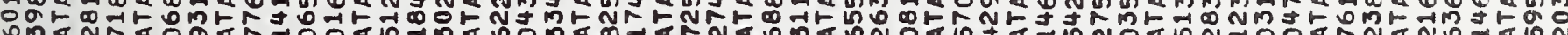

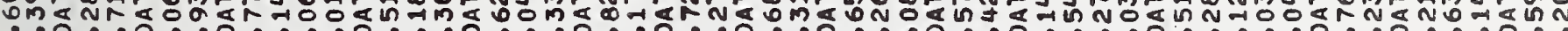

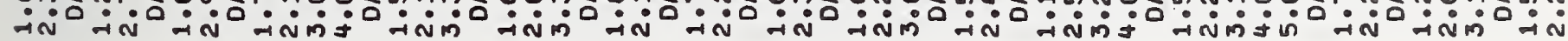




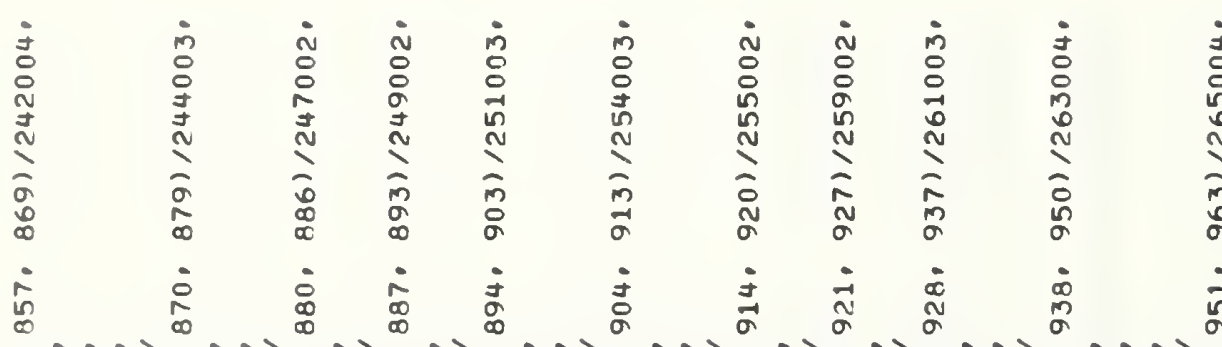

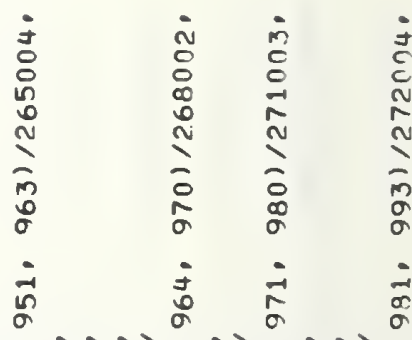

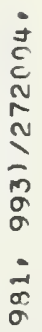

政" ón.

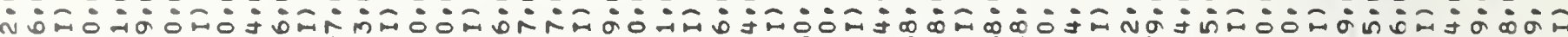

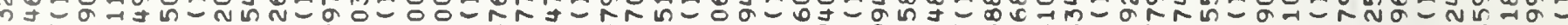

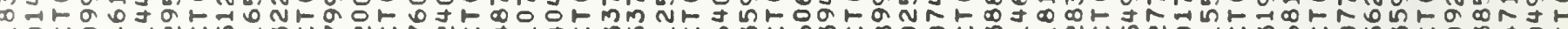

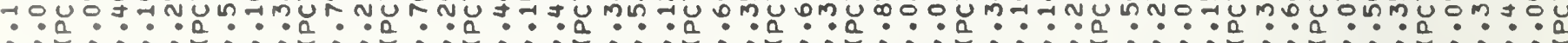

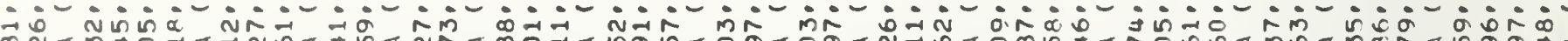

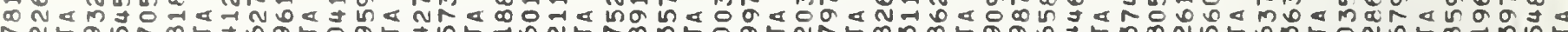

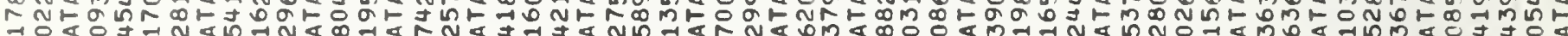

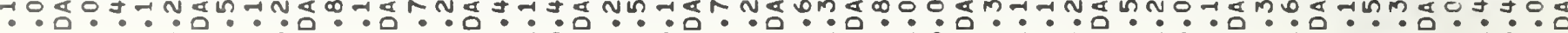

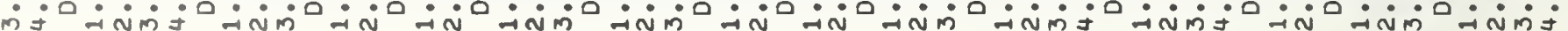




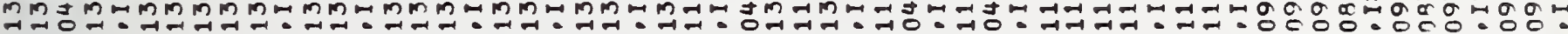

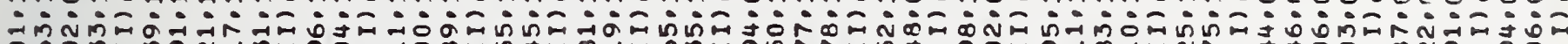

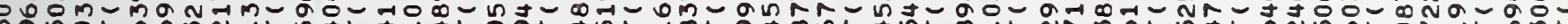

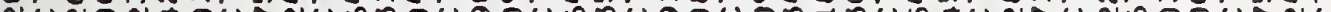

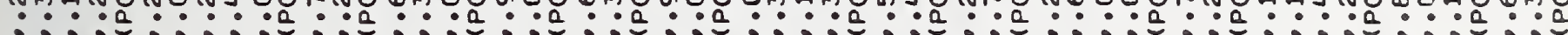

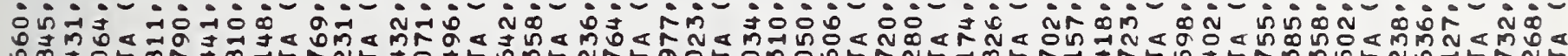

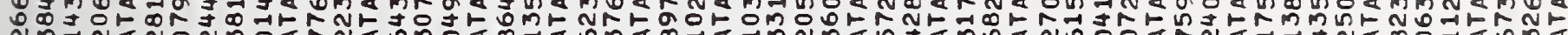
N

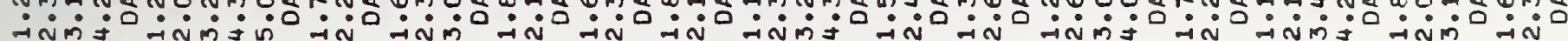




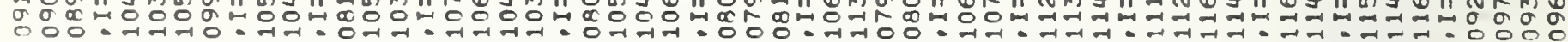

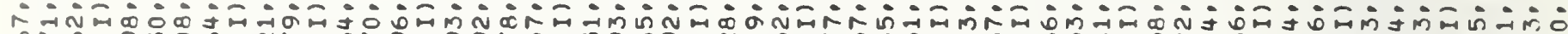

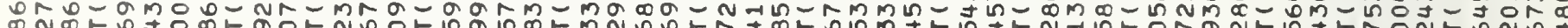

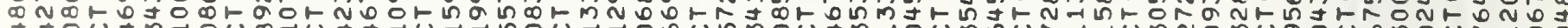

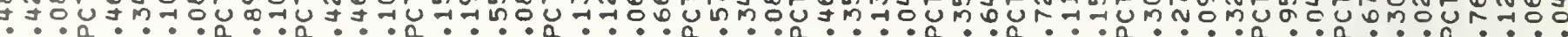

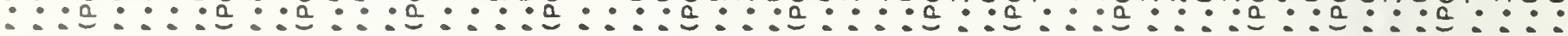

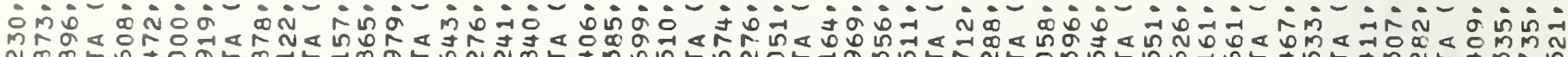

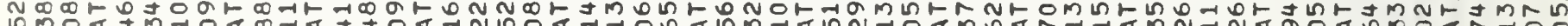

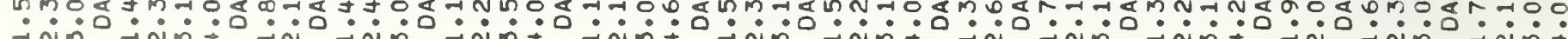
$\rightarrow N M$ INM $\neg N$ - 


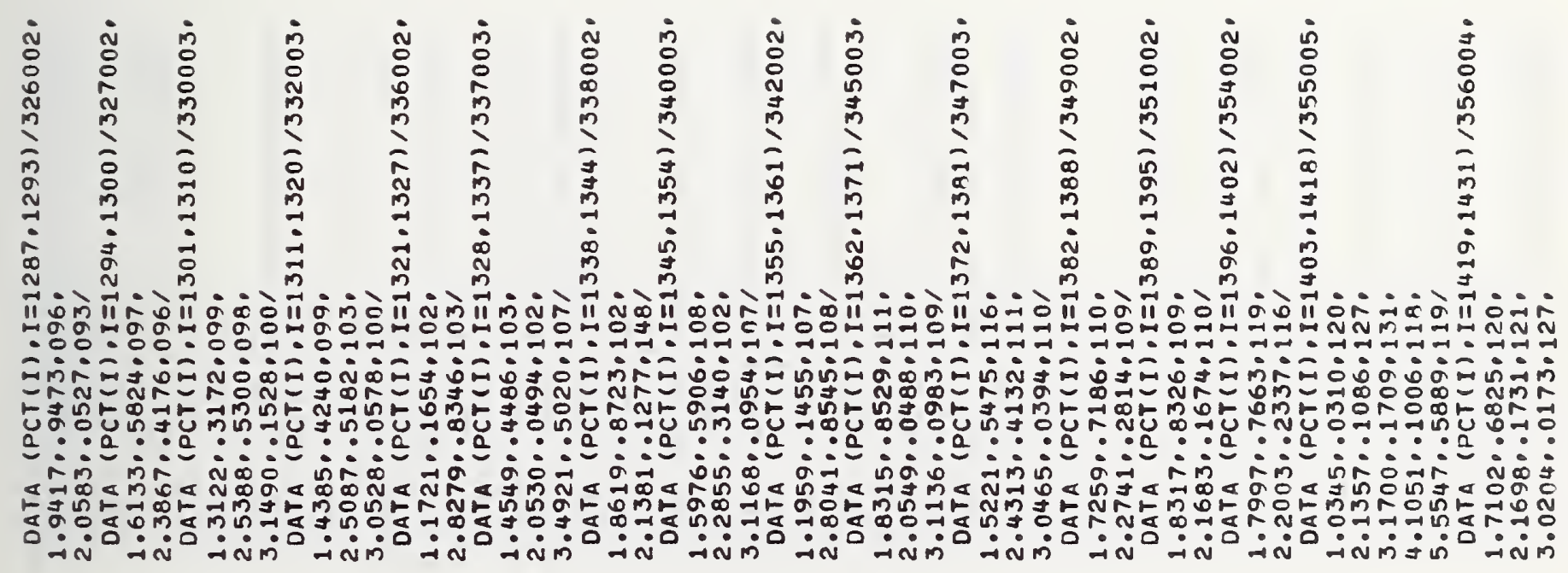

ลำผ

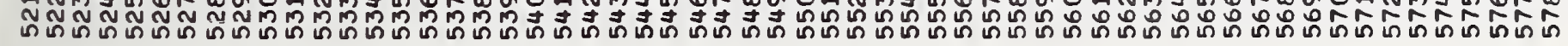




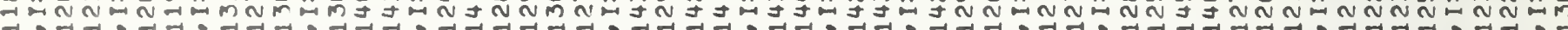

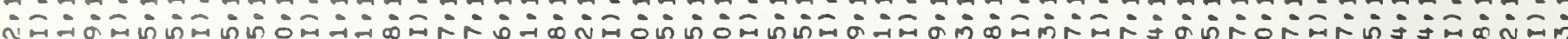

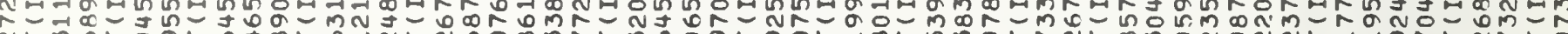

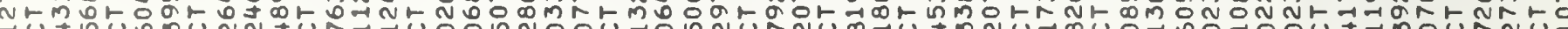

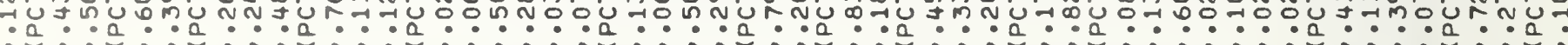
Con

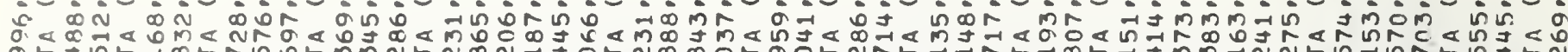

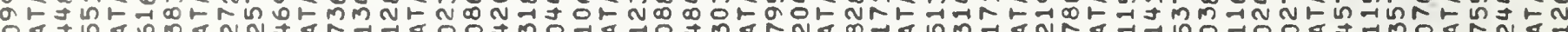

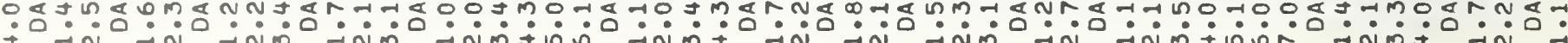




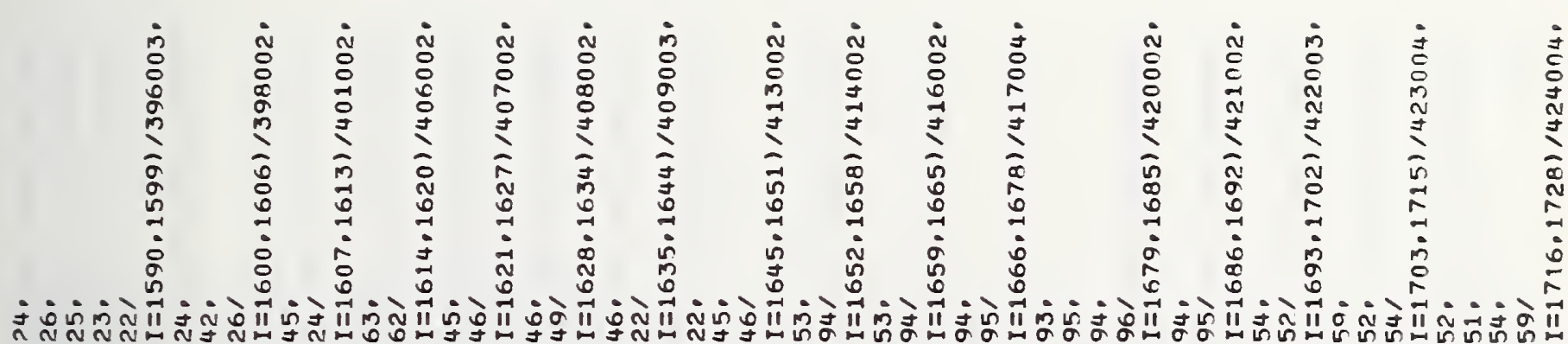

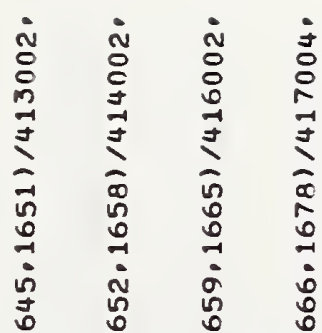

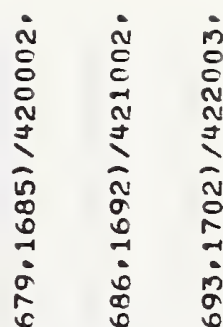

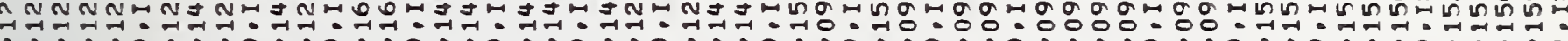

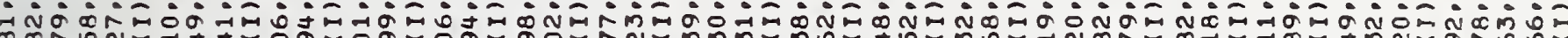

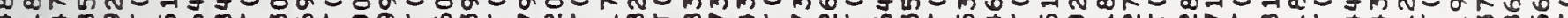
?ำ:ㄴ.?

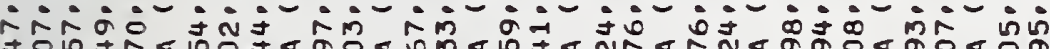

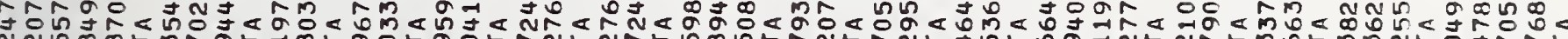

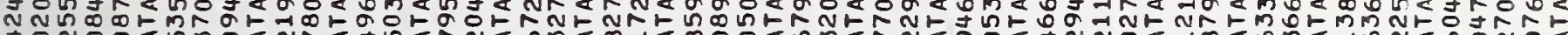

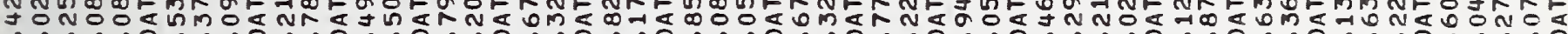

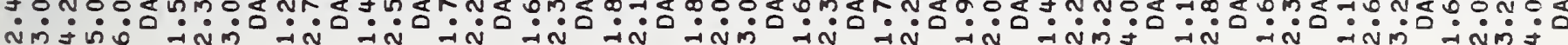




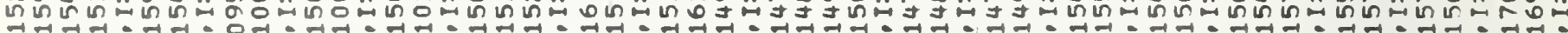

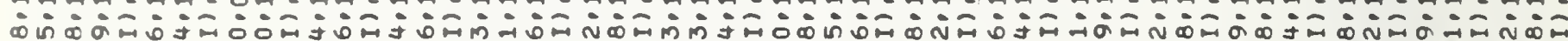

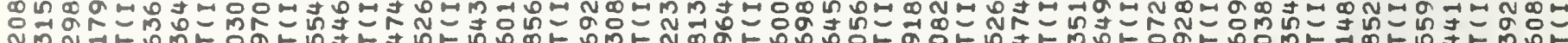
NmN-1 m 00 0. $\therefore$ -

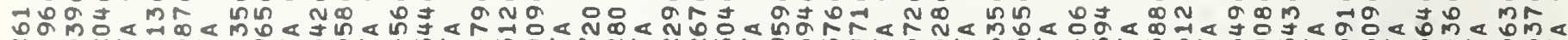

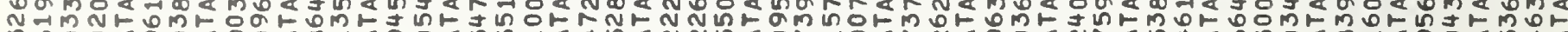

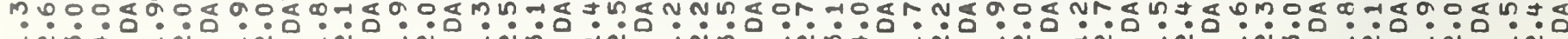

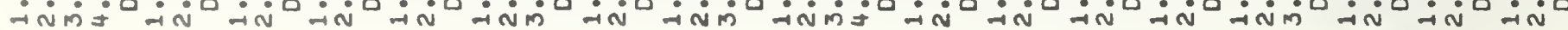




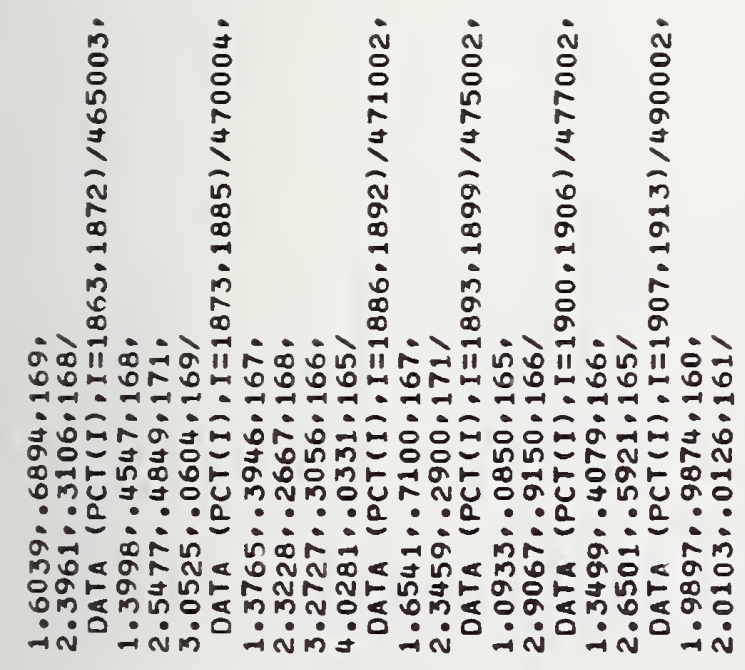


$-30-$

Appendix 2

Listing of Program MAIN 


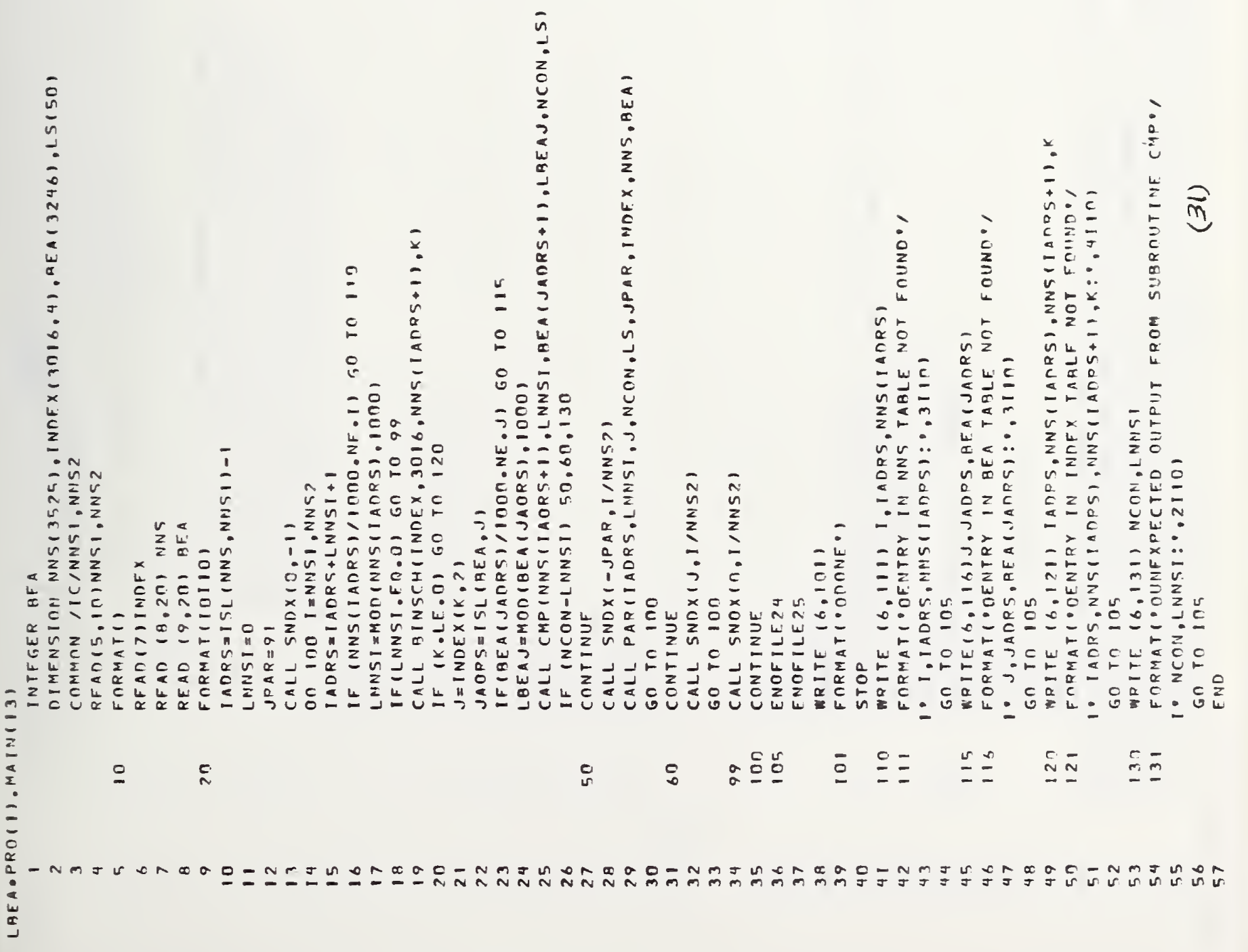




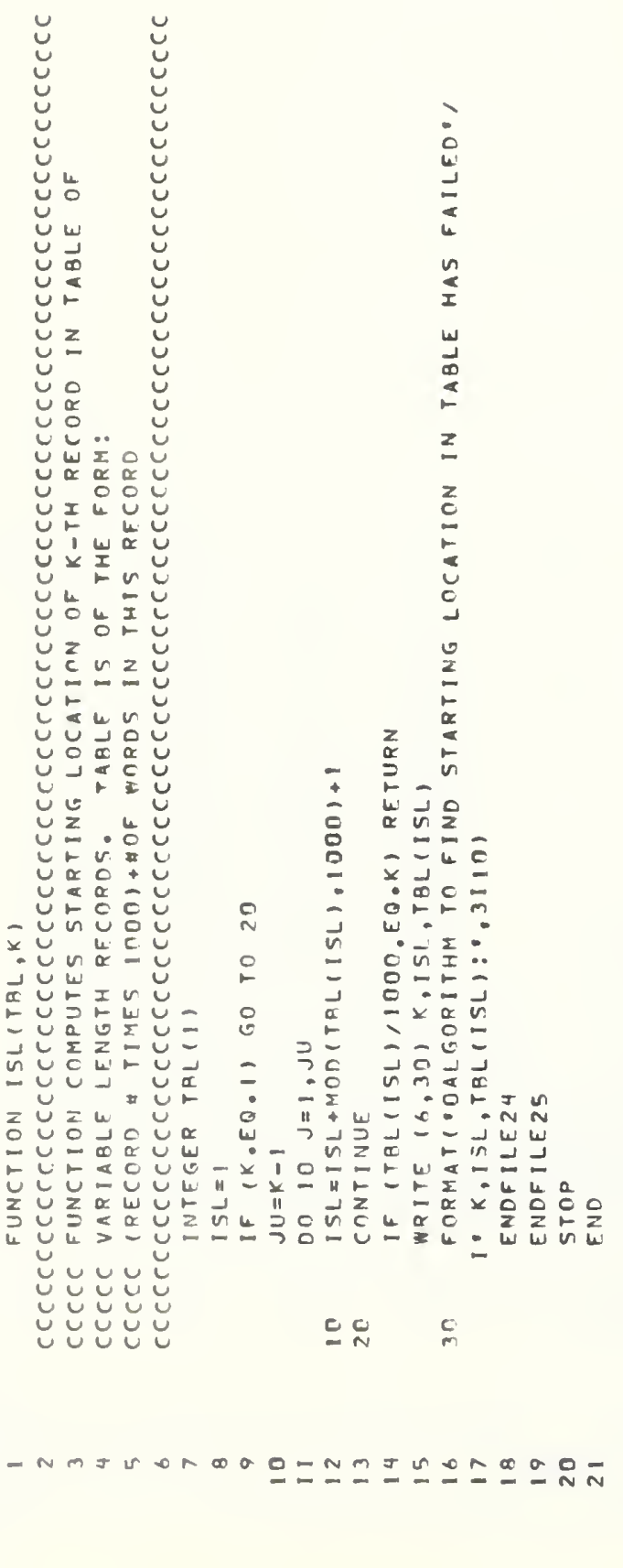




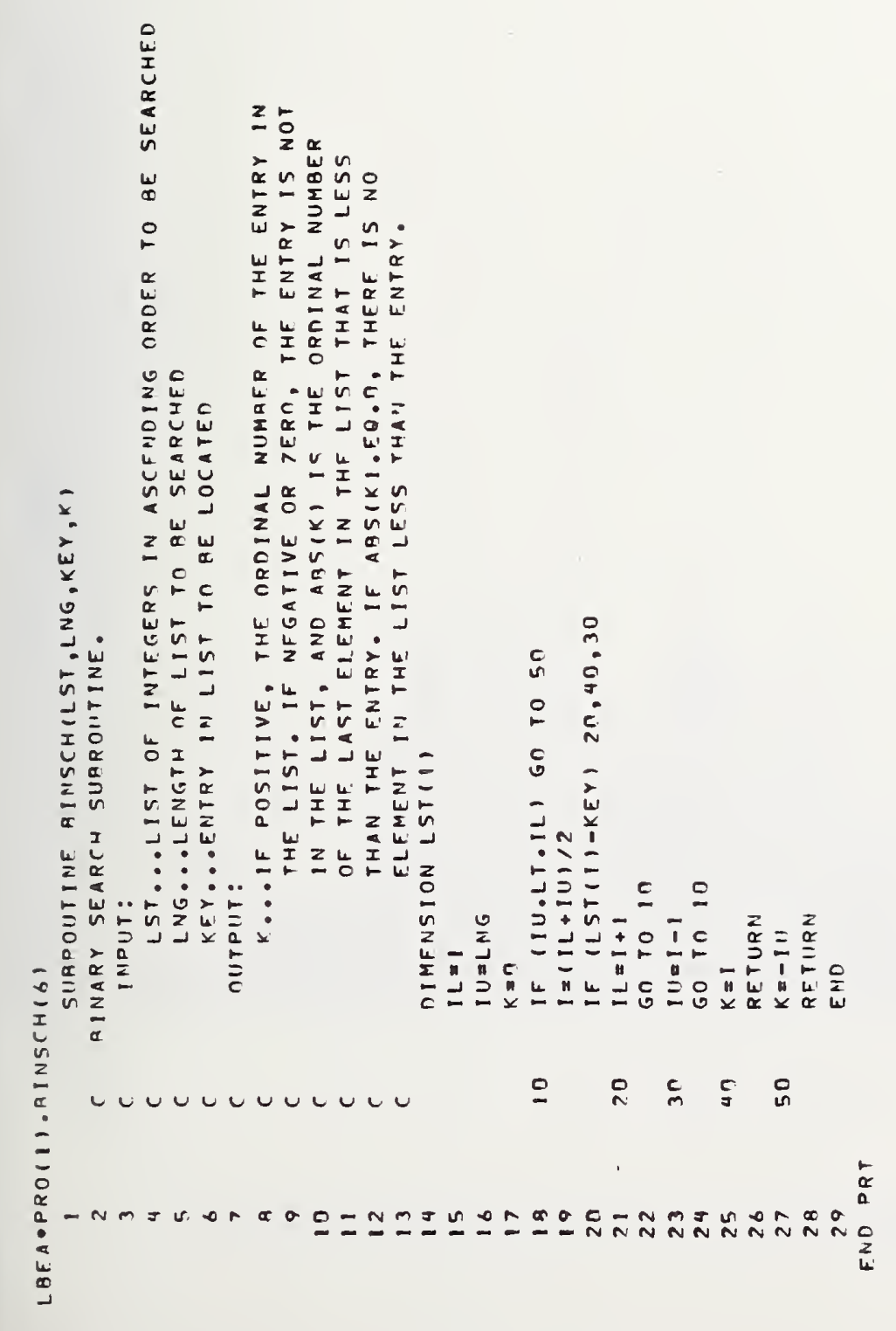




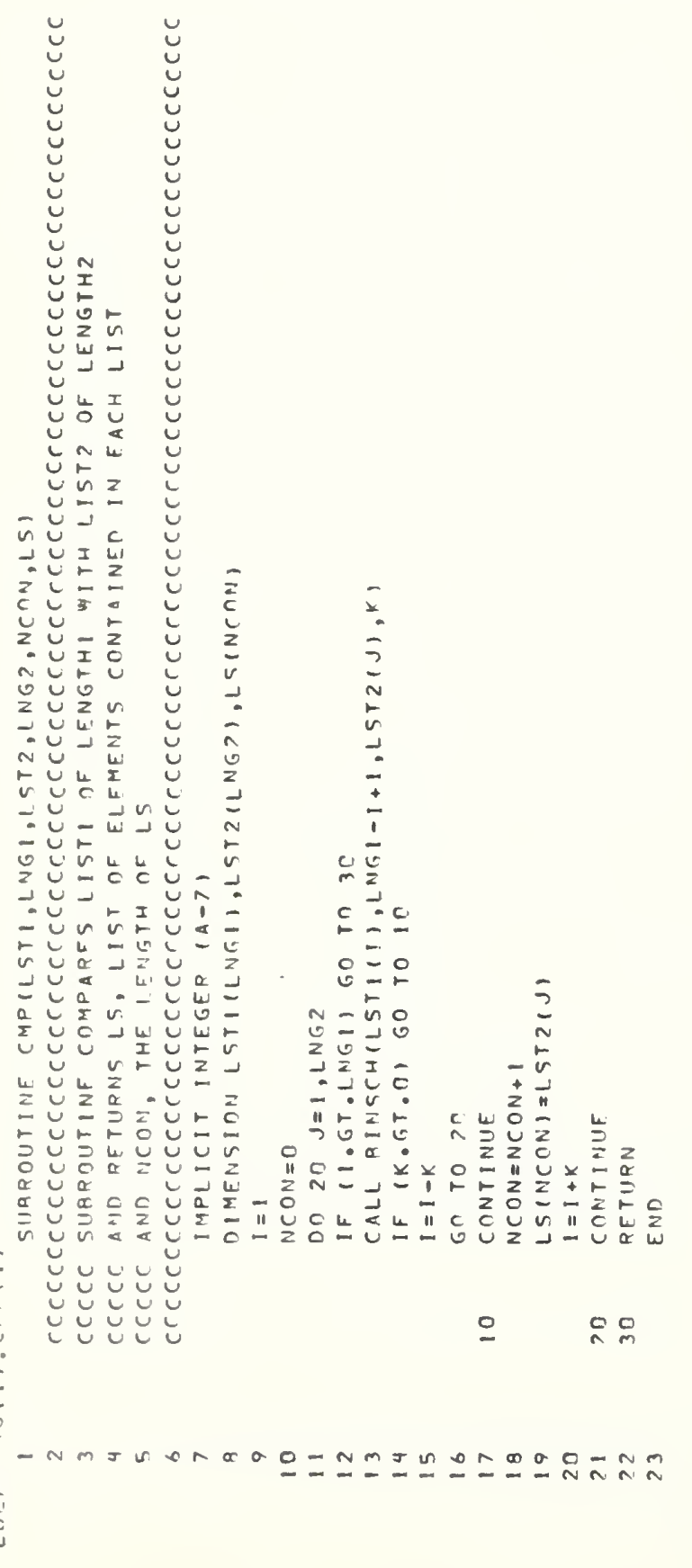

尒 


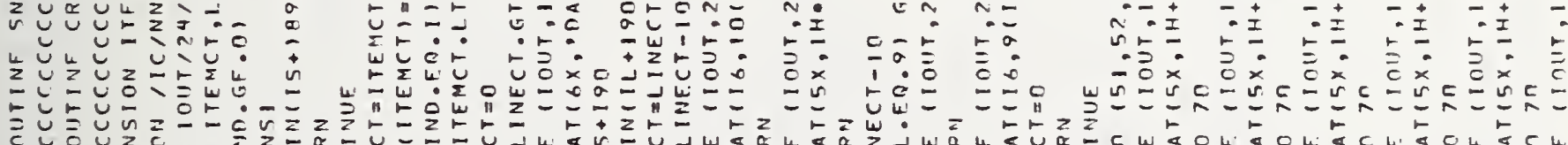

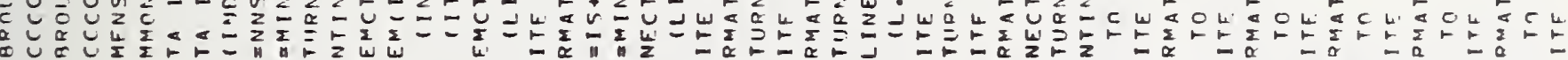

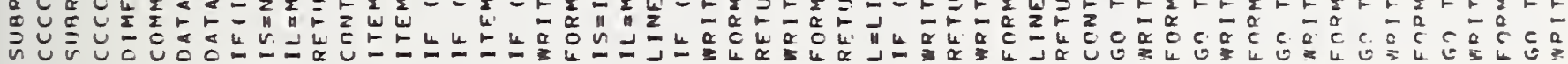

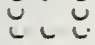




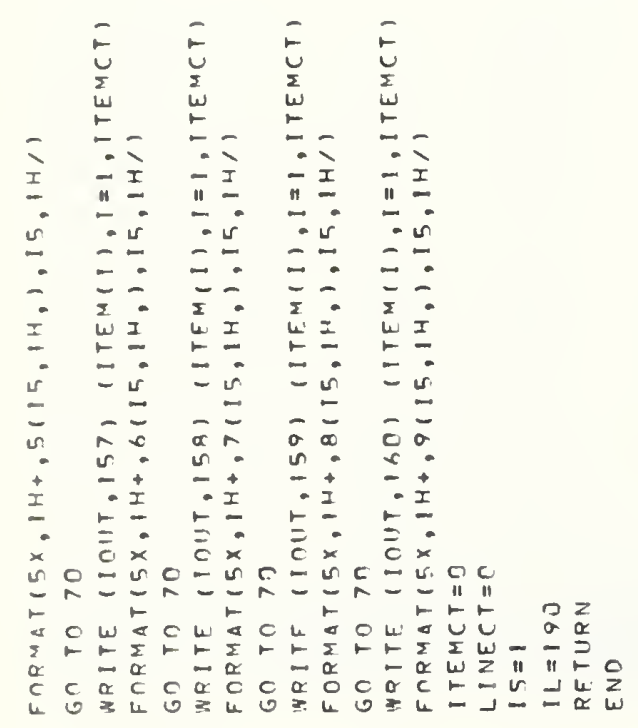

는 


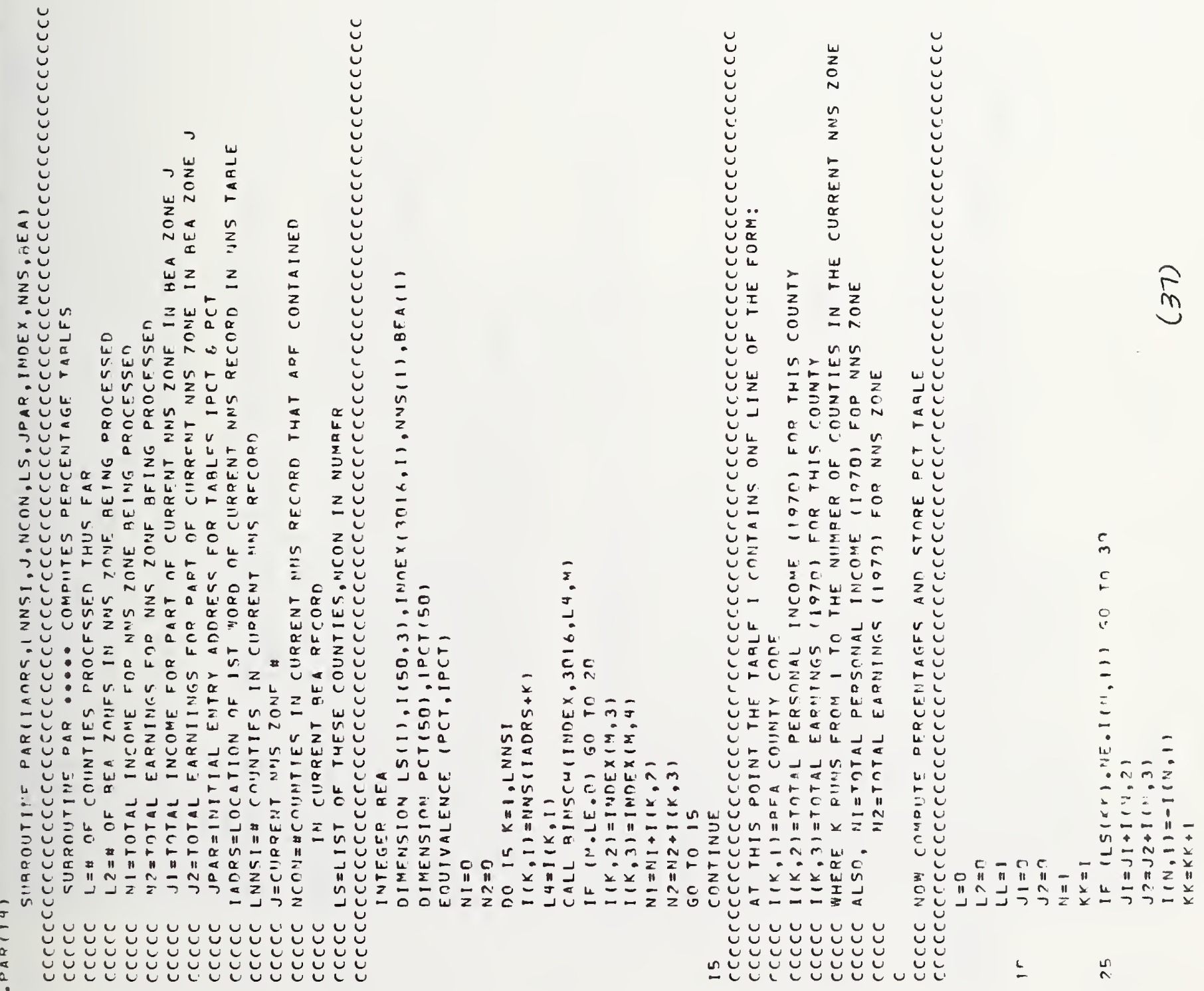

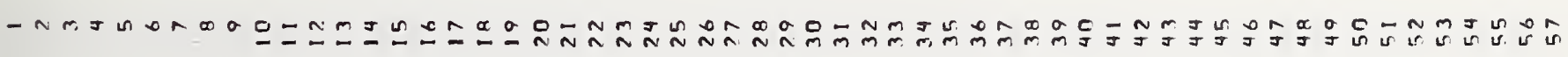




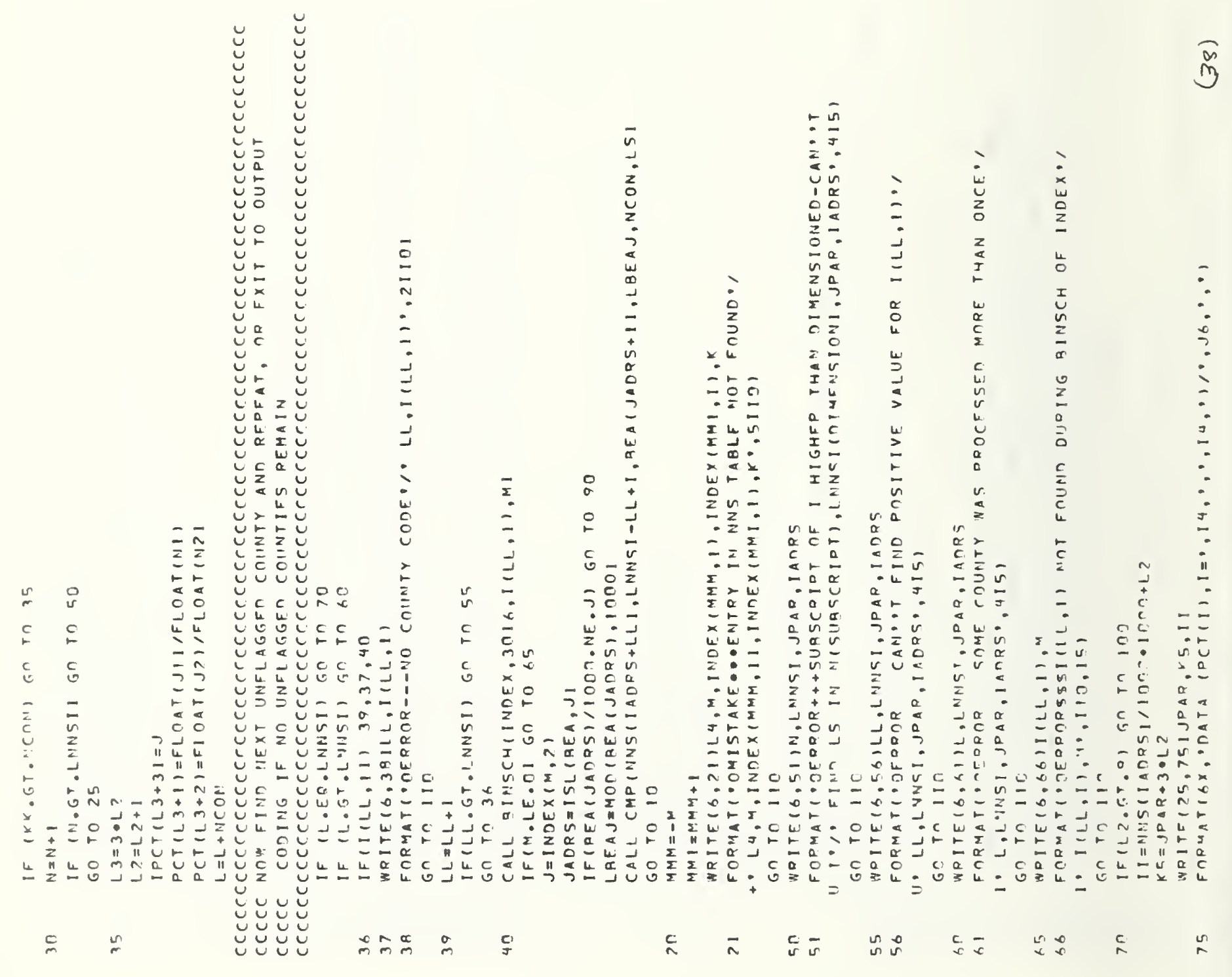




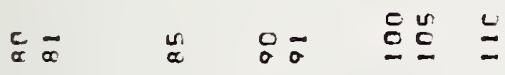


Appendix 3

Data Set NNS

The first column gives the NNS zone number times 1000 plus the number of counties in the zone. In the next six columns, for as many lines as are needed, the county names (with state name abbreviations) are listed. For example, lines 1 and 2 list the 10 counties that comprise NNS zone 10. NNS zones 1-9 and 12-40 do not appear in the listing because they are part of the special New England zones for which the NNS to BEA zone mapping was manually determined. NNS zones 10 and 11 appear in spite of the fact that they were treated manually. Other omissions in the list, such as NNS zone 147, are due to the fact that certain NNS zones are not currently defined. 


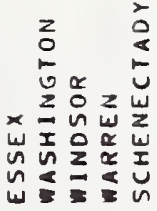

アトロン゙

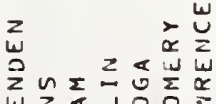

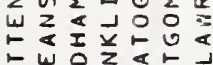

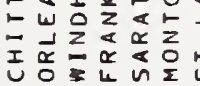

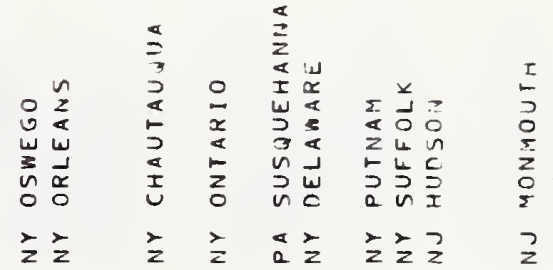

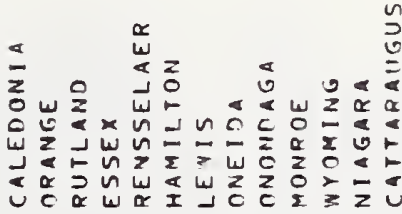

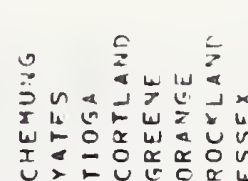

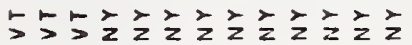

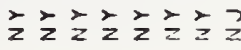

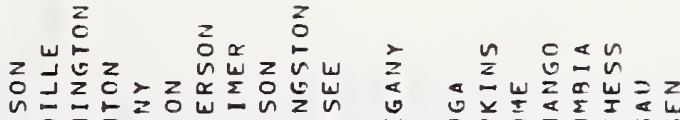

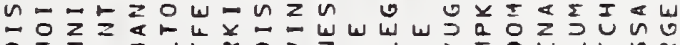

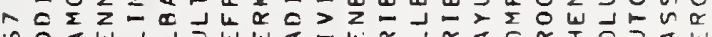

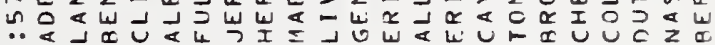

o

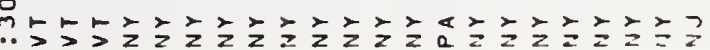

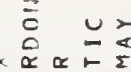

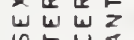

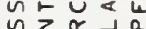

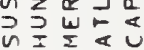
a

j

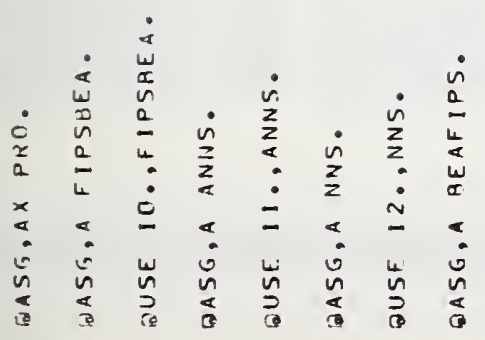

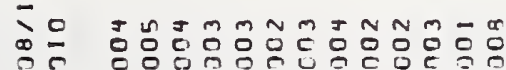

ํำำำกี

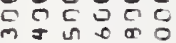
?ำㄱํㄹ 
in

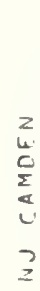

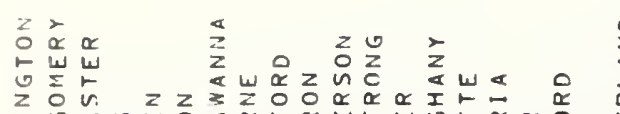

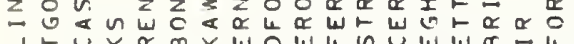

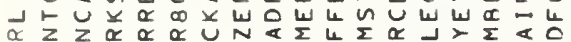

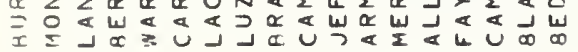
?a\&a

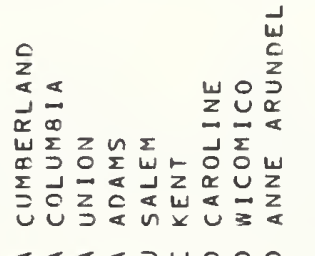
产是高

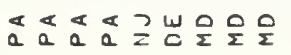

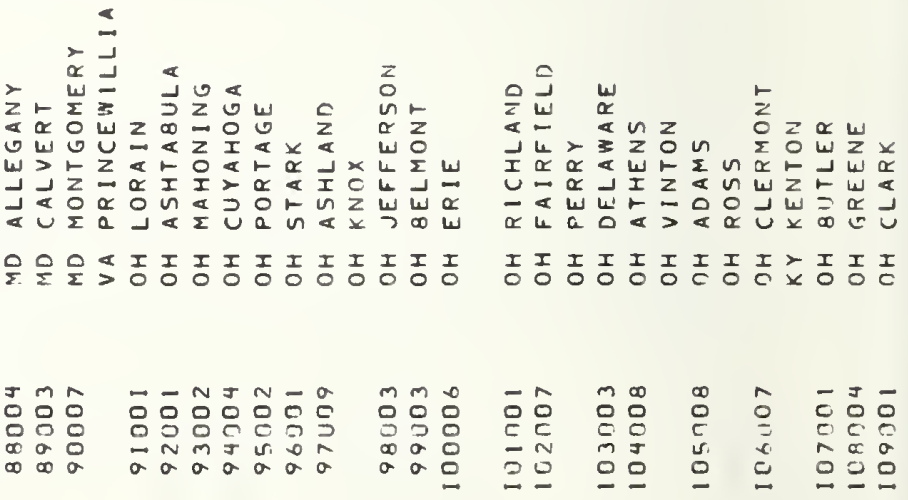

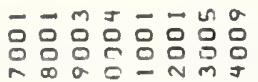

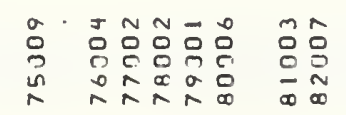

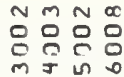
intion

\section{:}




\begin{tabular}{|c|c|c|c|c|c|c|c|c|c|c|c|c|c|c|c|c|}
\hline 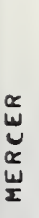 & & 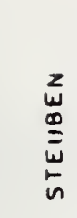 & 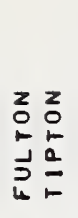 & $\frac{z}{0}$ & 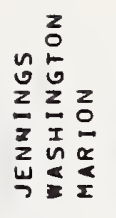 & $\begin{array}{l}z \\
0 \\
n \\
0 \\
a \\
a \\
\alpha \\
\alpha \\
\alpha \\
a \\
a \\
a\end{array}$ & & $\begin{array}{l}w \\
w \\
\alpha \\
a \\
⺊ \\
n\end{array}$ & $\vec{J}$ & $\begin{array}{l}z \\
0 \\
n \\
z \\
w \\
\frac{1}{1} \\
0 \\
\omega \\
n\end{array}$ & $\begin{array}{l}z \\
a \\
z \\
5 \\
0 \\
a\end{array}$ & $\begin{array}{l}a \\
w \\
u \\
\alpha \\
w \\
w \\
\Sigma\end{array}$ & & 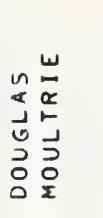 & $\begin{array}{l}z \\
a \\
a \\
c \\
u \\
\vdots \\
\Sigma\end{array}$ & 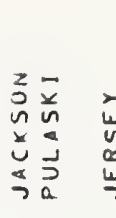 \\
\hline I & & $z$ & $z z$ & $z$ & $z \geq z$ & $\underline{z} z$ & & $z$ & $\doteq$ & $=$ & $\Rightarrow$ & $\Rightarrow$ & & $\Rightarrow\lrcorner$ & $=$ & \lrcorner$\lrcorner$ \\
\hline $\begin{array}{l}z \\
0 \\
n \\
0 \\
\vdots \\
\Sigma\end{array}$ & $\begin{array}{l}5 \\
0 \\
0 \\
2 \\
2 \\
2 \\
3\end{array}$ & 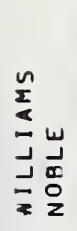 & 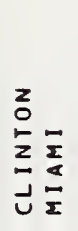 & $\underset{\sim}{\stackrel{I}{\sim}}$ & 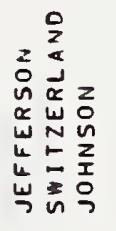 & 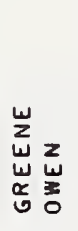 & $\begin{array}{l}z \\
w \\
\alpha \\
\alpha \\
\alpha \\
a \\
a\end{array}$ & $\begin{array}{l}\bar{v} \\
u \\
n \\
5 \\
j \\
a \\
a\end{array}$ & 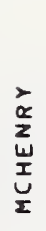 & لـ & 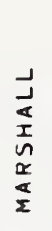 & $\begin{array}{l}I \\
0 \\
O \\
0 \\
Z \\
0 \\
0 \\
\frac{U}{2}\end{array}$ & $\begin{array}{l}\bar{a} \\
\bar{j} \\
\bar{z} \\
\alpha \\
\dot{\alpha} \\
\nu\end{array}$ & 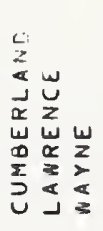 & $\begin{array}{l}z \\
0 \\
0 \\
a \\
w \\
u \\
4 \\
w \\
u\end{array}$ & 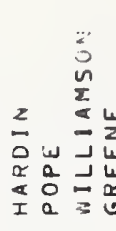 \\
\hline I & I & I $z$ & $z \geq$ & $z$ & $z \geq z$ & $\geq z$ & $z$ & 2 & $\doteq$ & $=$ & $=$ & $\beth$ & $\doteq$ & \lrcorner$\lrcorner\lrcorner$ & $\Rightarrow$ & \lrcorner$\lrcorner\lrcorner=$ \\
\hline
\end{tabular}
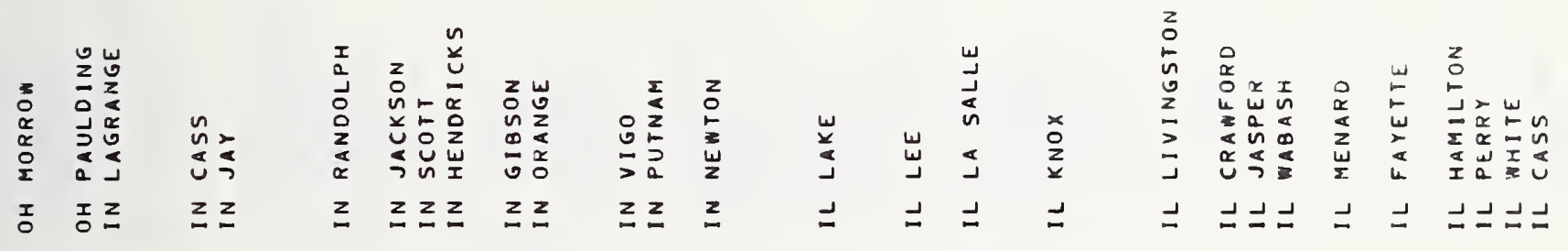

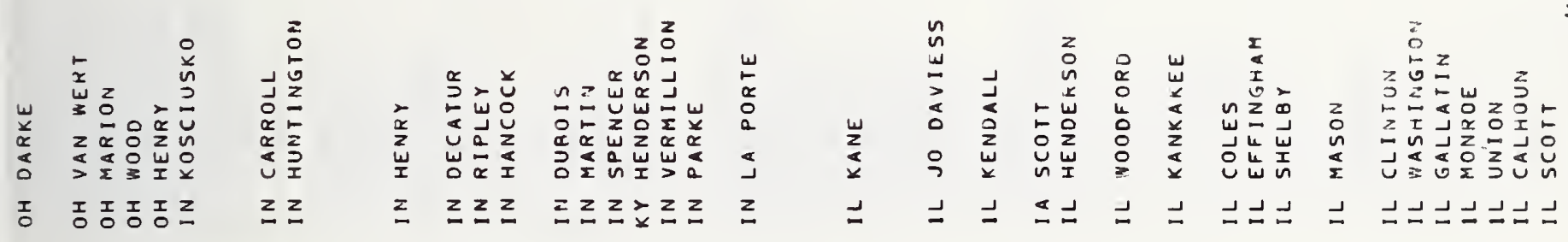

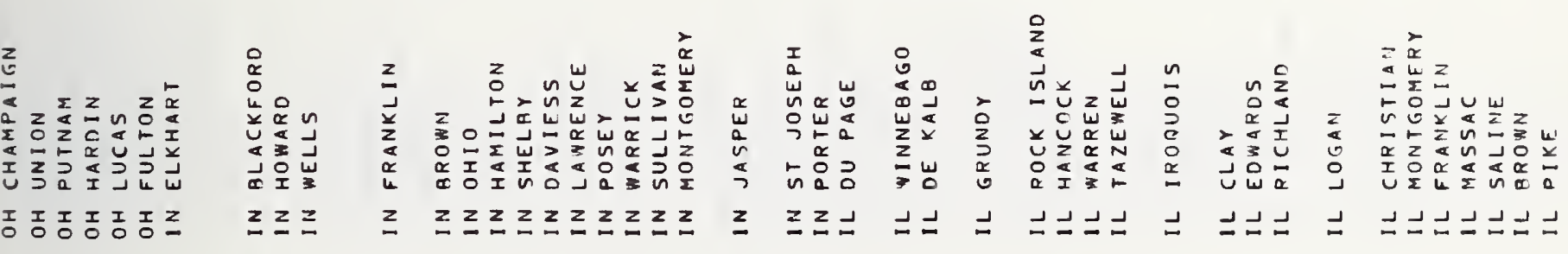

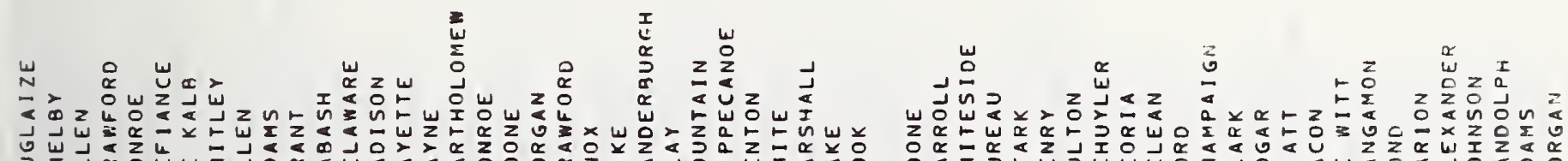

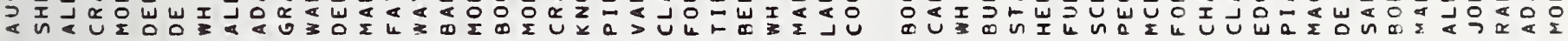

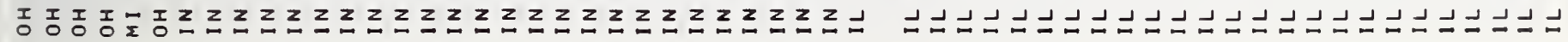

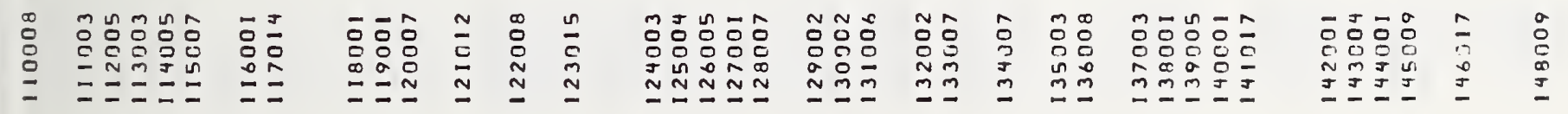




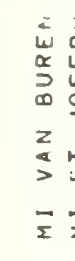

$n$
$n$
$\vdots$
$\vdots$
$\Sigma$

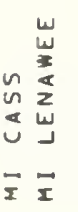

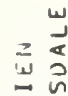

$\vec{\alpha} v$

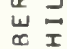

$\vec{\Sigma} \bar{\Sigma}$

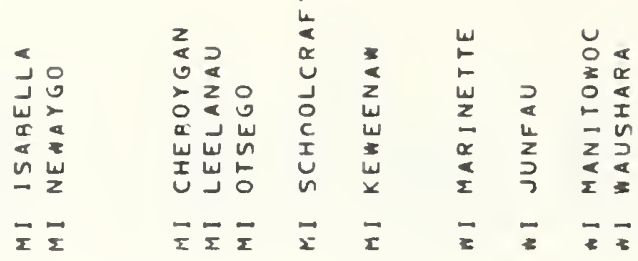

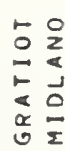

$\vec{\Sigma} \vec{x}$

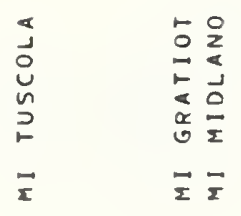

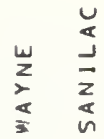

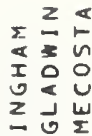

$\vec{\Sigma} \bar{\Sigma}$

立立 $\sum \frac{x}{a}$

$-\frac{1}{2}$

J?

茨

$\stackrel{a}{a}$

z

$-1$

$\$$

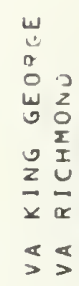

岀

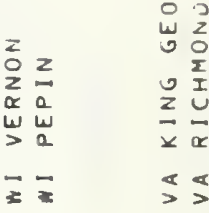

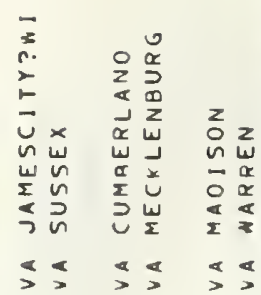
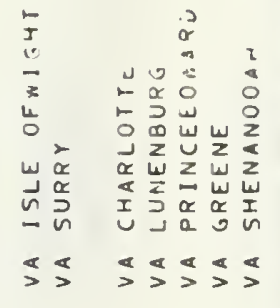

$\underset{0}{\alpha} \frac{\alpha}{\alpha}$

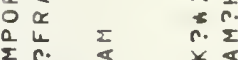

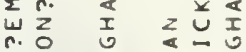

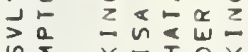

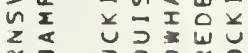
贡 小夕\$s\$s

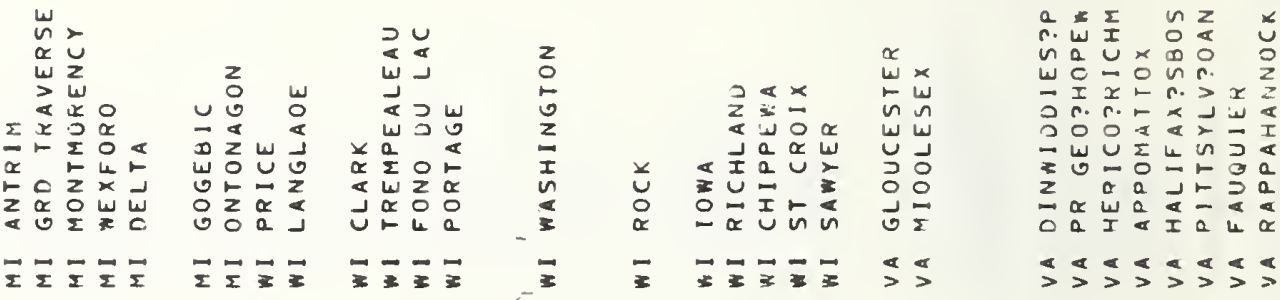

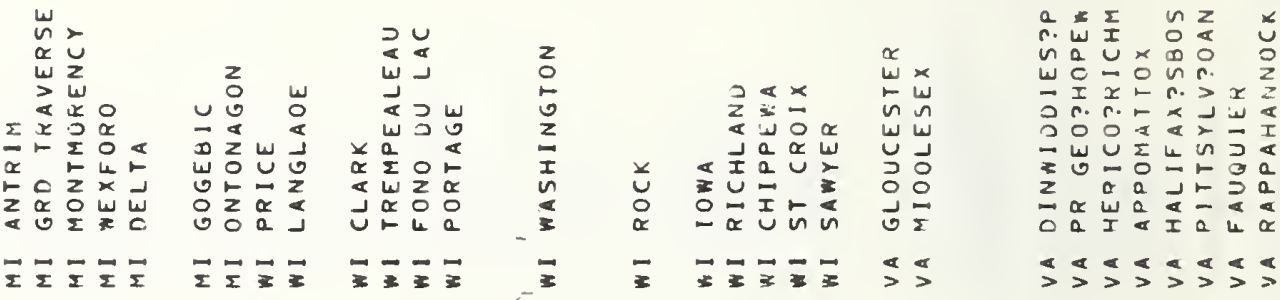

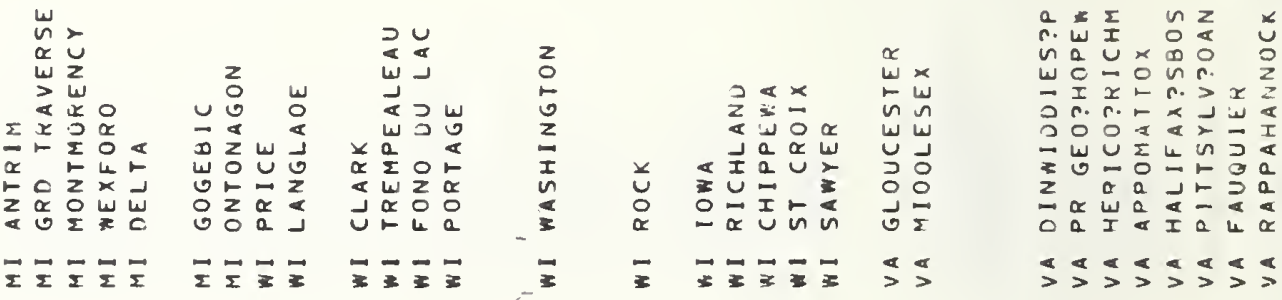

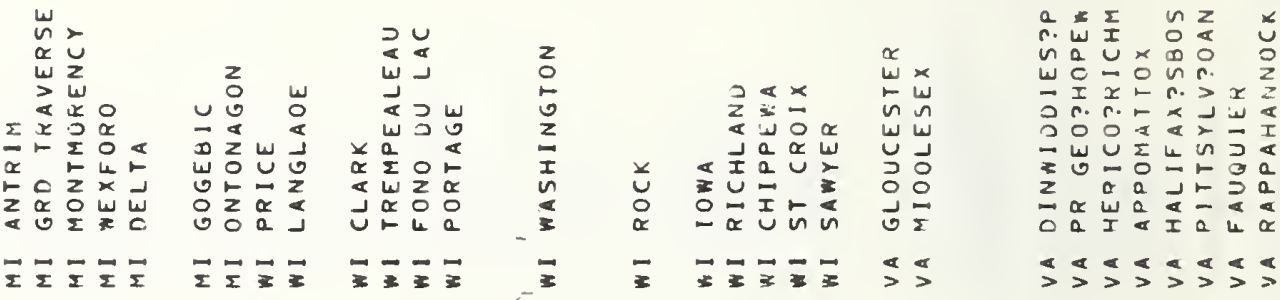

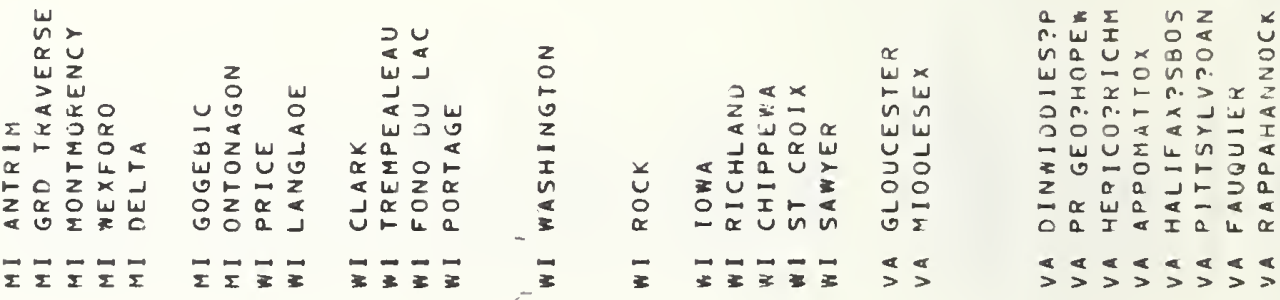

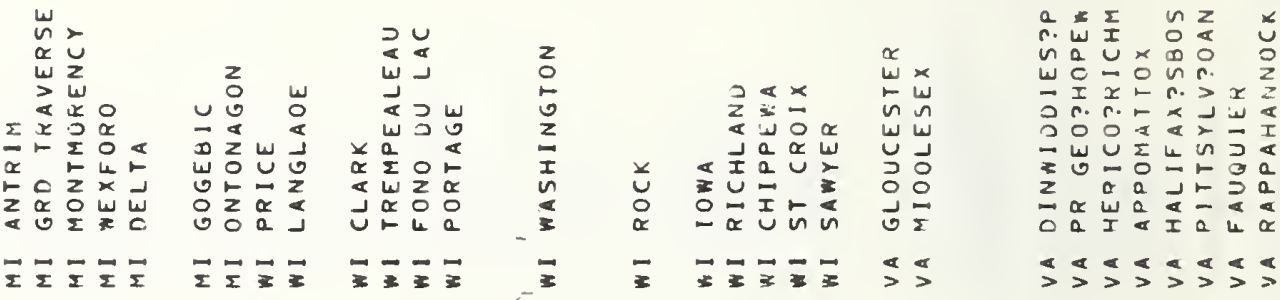

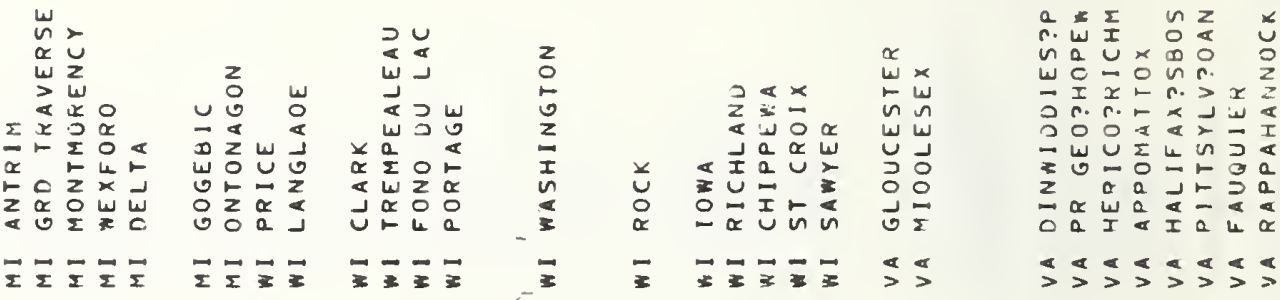

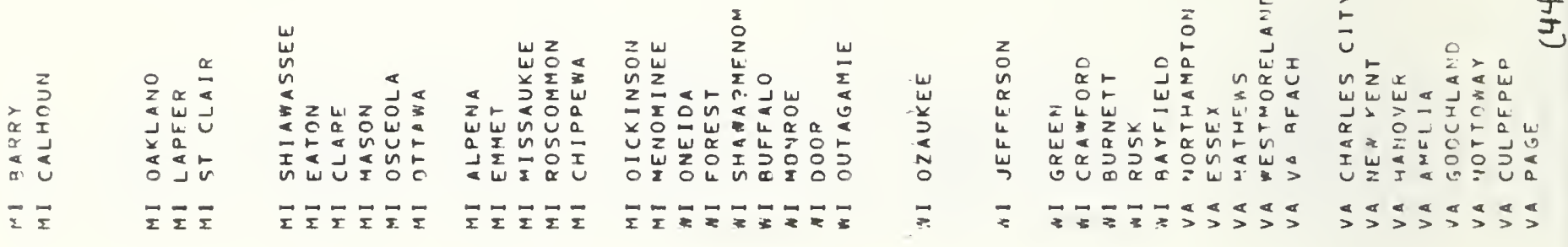

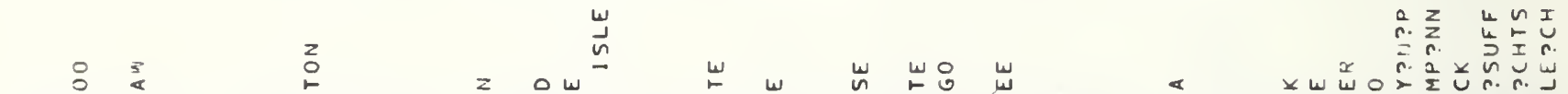

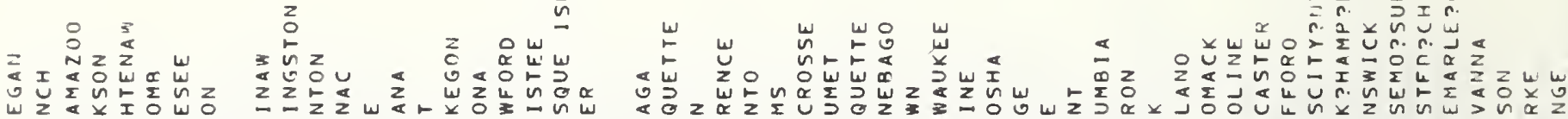

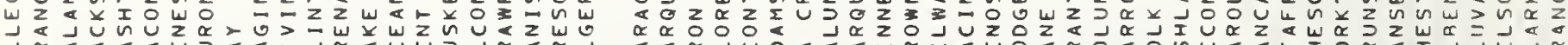

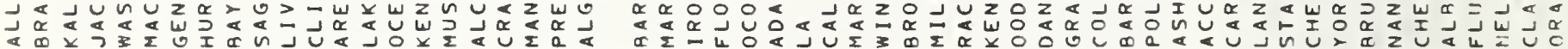

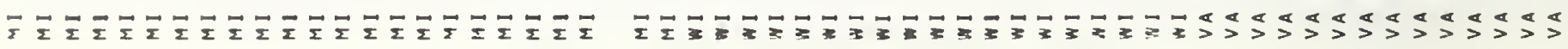

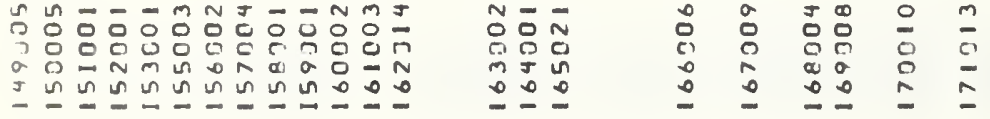

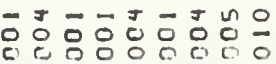
minorán

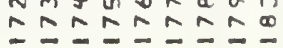

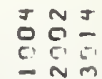

a) $w$

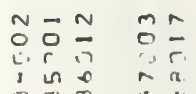

$\begin{array}{llll}1 & 0 & 0 & a \\ 0 & -\infty & -1 & -1\end{array}$ 


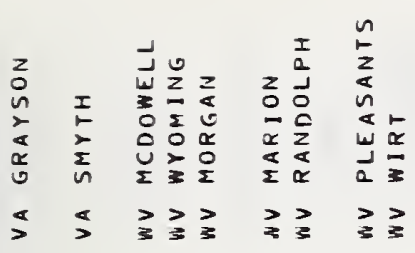

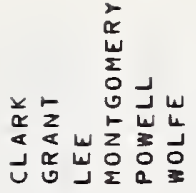

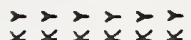

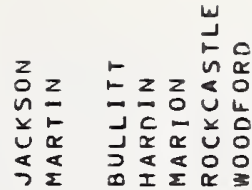

文文

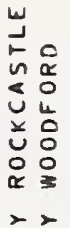

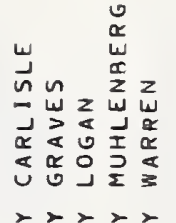

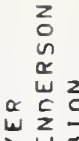
㐫岌。

$z z z$

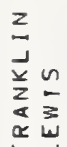

ه

$z z z$

z w

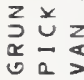

$z \geq z \quad z$

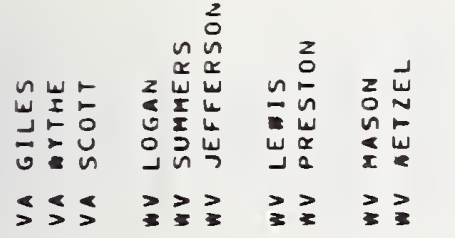

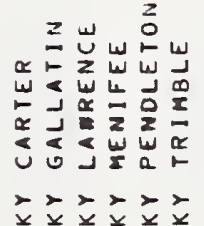

$x y y$
$y$
$y$

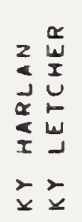

$\vec{x} \vec{z} \quad \vec{z}$ 山 2 㟧 类

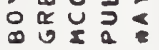

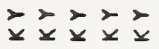

인

J上

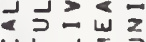
U⿺乚一

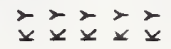

$\begin{array}{lll}x & 0 & z \\ 5 & 0 & 0\end{array}$

$\leftarrow 0$ n

$u>0$

$\omega_{0} \leq$

$z z z$

\begin{tabular}{|c|c|}
\hline 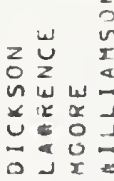 & 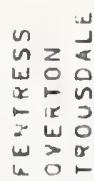 \\
\hline$\leftarrow \leftarrow$ & $\geq z$ \\
\hline
\end{tabular}

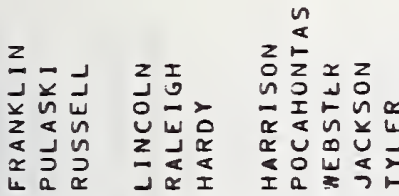

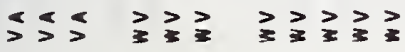

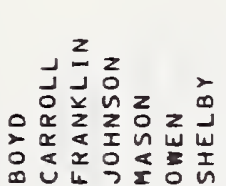

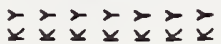

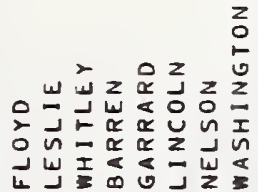

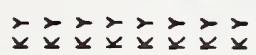

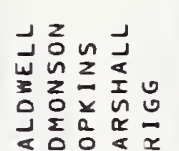

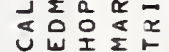

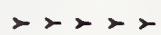

w $z \stackrel{2}{a}$

溇

O० $0 \begin{array}{ll}0 \\ 0\end{array}$

U⿺

$z \geq z$

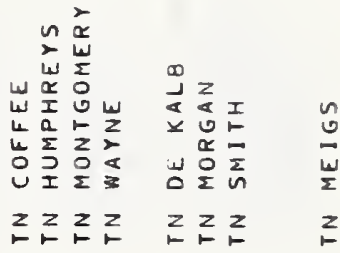

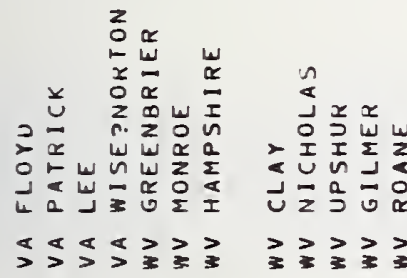

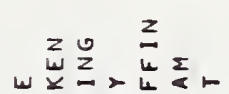

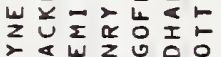

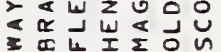

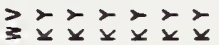

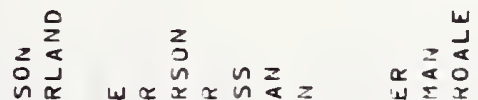

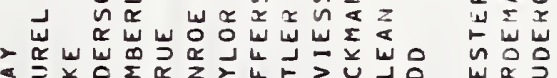

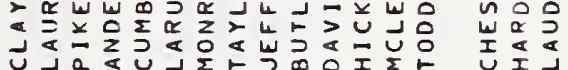

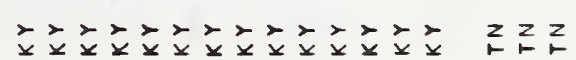

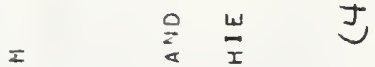

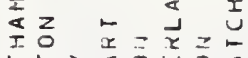
r 山ڤ

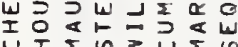

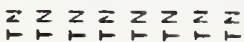

药

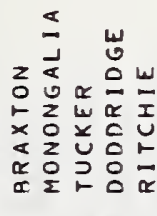
$\vec{z} \geq \geq$

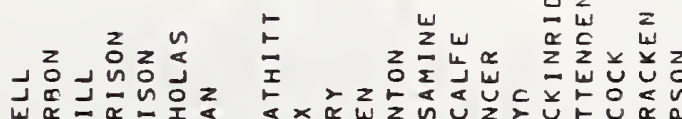

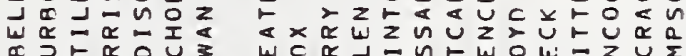

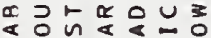

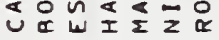

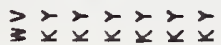

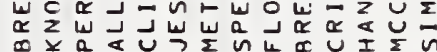

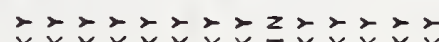

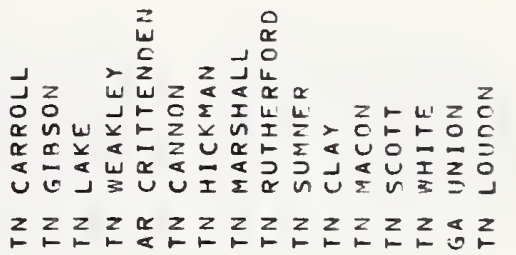

$\ddot{U}$

a.

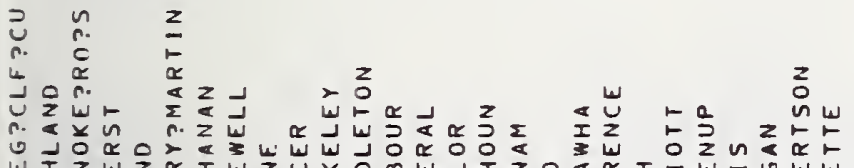

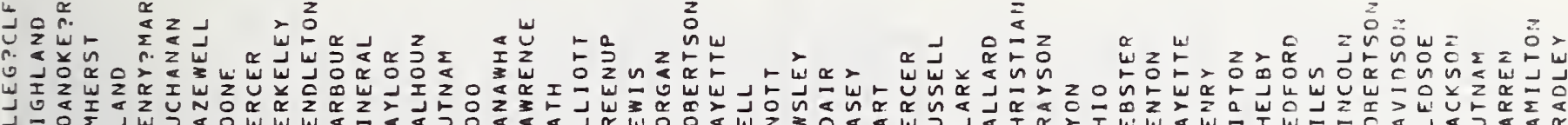
存 I

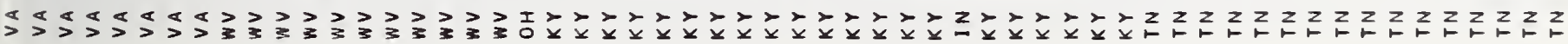

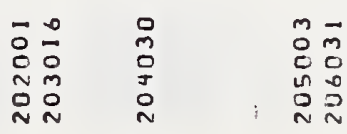

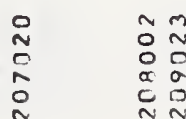

$m=$
$0 \approx$
$0=$
$0=$
$\sim=$
$\begin{array}{ll}N & 0 \\ 0 & 0 \\ 0 & 0 \\ N & m \\ & \sim\end{array}$ 


\begin{tabular}{|c|c|c|c|c|c|c|c|c|c|c|c|}
\hline $\begin{array}{lll}w & \alpha & z \\
z & w & n \\
w & \vdots & z \\
w & z & 0 \\
\alpha & w & \vdots \\
v & n & j\end{array}$ & 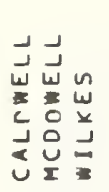 & 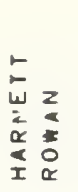 & 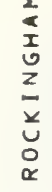 & 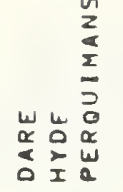 & $\begin{array}{l}z \\
0 \\
1 \\
n \\
0\end{array}$ & 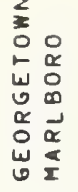 & لَّ & 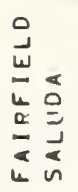 & 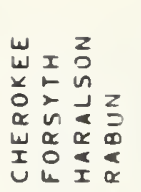 & 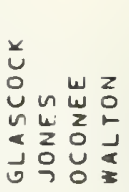 & 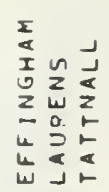 \\
\hline$z=\tilde{z}$ & UYU & $\underline{z}$ & $\ddot{z}$ & 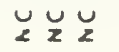 & $\ddot{z}$ & $\ddot{n} \tilde{n}$ & $n$ & $\dot{u} u_{n}$ & 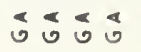 & گુ & $4<$ \\
\hline
\end{tabular}

\begin{tabular}{|c|c|c|c|c|c|c|c|c|c|c|c|}
\hline 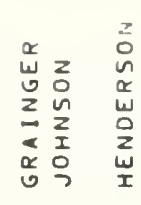 & 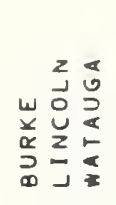 & 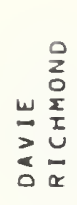 & $\begin{array}{l}z \\
0 \\
n \\
\alpha \\
w \\
a\end{array}$ & 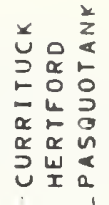 & $\begin{array}{l}\frac{\alpha}{0} \\
2 \\
w \\
J\end{array}$ & 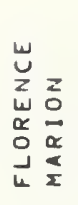 & $\begin{array}{l}z \\
3 \\
0 \\
1 \\
1 \\
\vdots \\
u\end{array}$ & 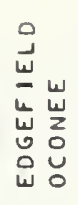 & 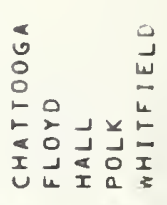 & 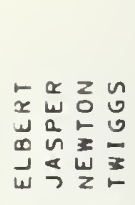 & $\begin{array}{lll}\alpha & z & z \\
w & 0 & w \\
0 & n & z \\
0 & z & w \\
z & 1 & \alpha \\
0 & 0 \\
u & j & n\end{array}$ \\
\hline$z \geq \quad y$ & $\breve{z} \breve{z}$ & $\breve{z}$ & $\underline{z}$ & UYZ & z & $\ddot{n} \tilde{n}$ & $\ddot{n}$ & $u_{n} u_{n}$ & 过范范 & ك & 0 \\
\hline
\end{tabular}

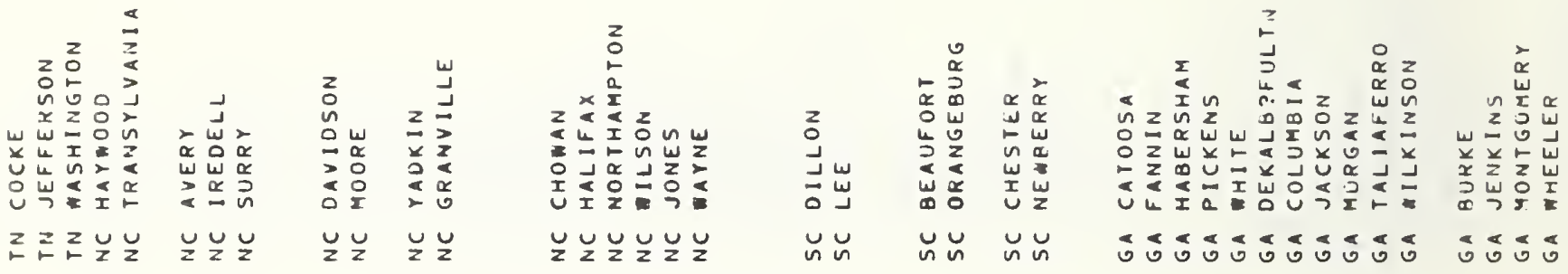

\begin{tabular}{|c|c|c|c|c|c|c|c|c|c|c|}
\hline 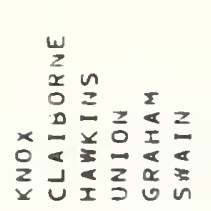 & 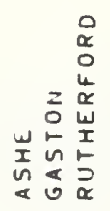 & 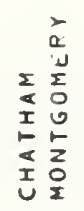 & 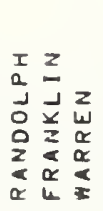 & 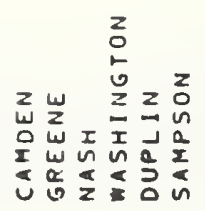 & $\begin{array}{l}z \\
0 \\
\sim \\
w \\
0 \\
0 \\
\alpha\end{array}$ & 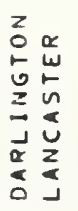 & 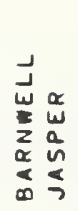 & 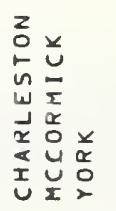 & 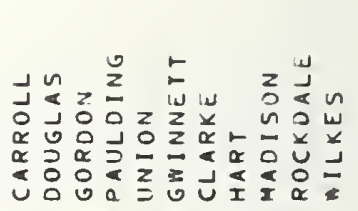 & 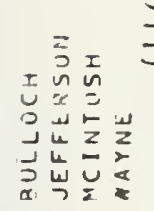 \\
\hline ZzZ는 & $\cong z$ & $\underline{z} \tilde{z}$ & $\because U_{z}$ & $\breve{Z}_{Z} U_{Z} U_{Z} U_{Z}$ & $\underline{z}$ & & 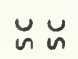 & $\tilde{n} u \tilde{n}$ & 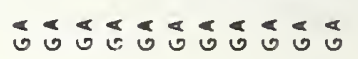 & 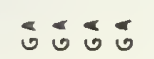 \\
\hline
\end{tabular}

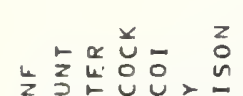

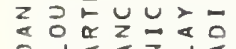
\&

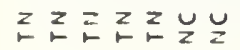

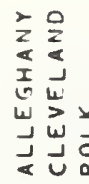

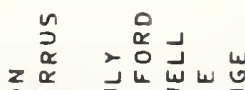

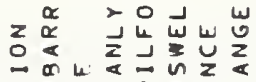

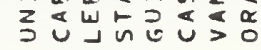

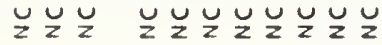

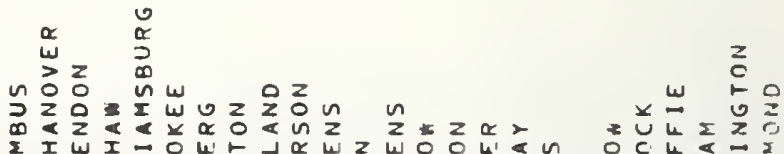

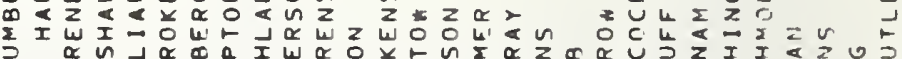

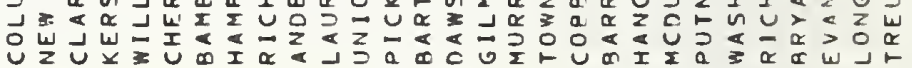

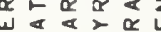

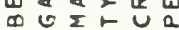
$\breve{z} u \dot{z} u \dot{z} u$

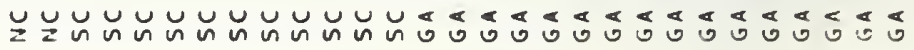

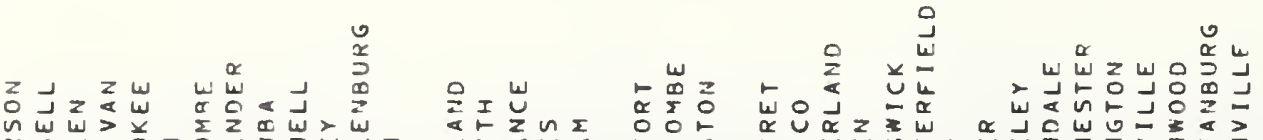

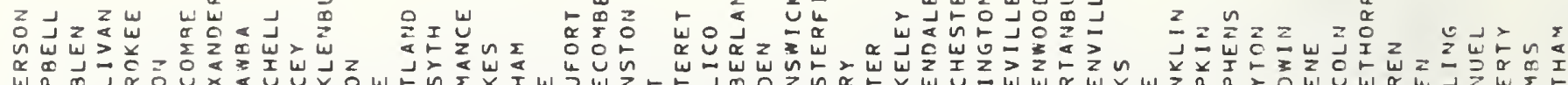

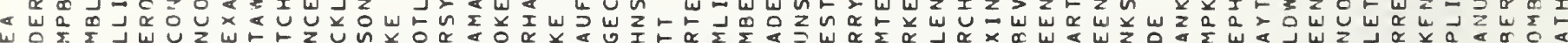

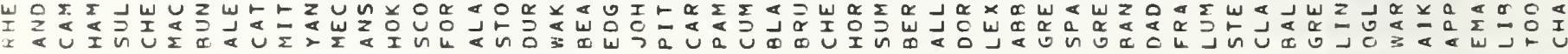

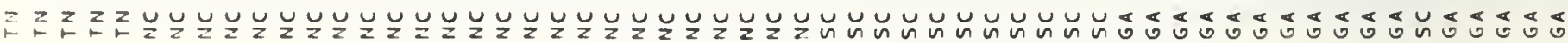

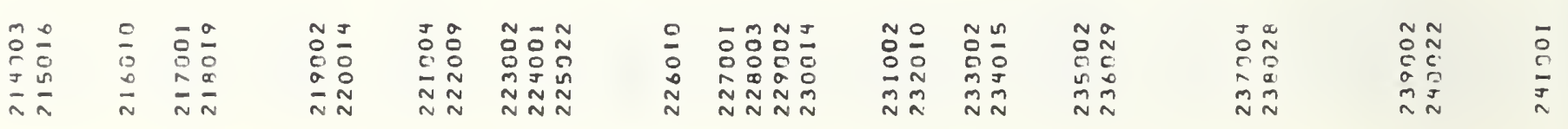




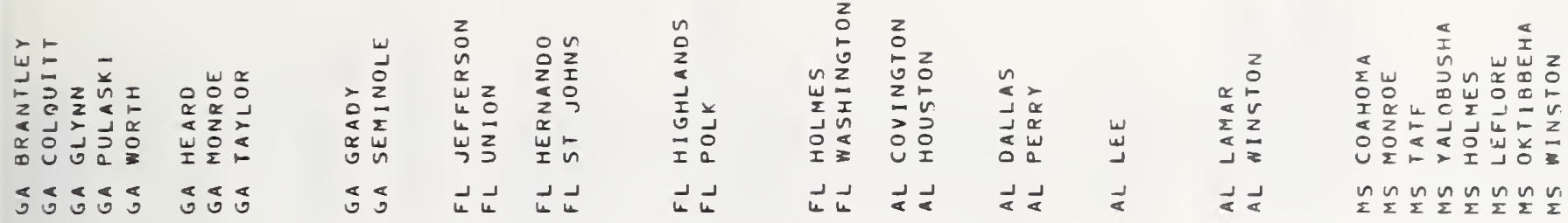

\begin{tabular}{|c|c|c|c|c|c|c|c|c|c|}
\hline 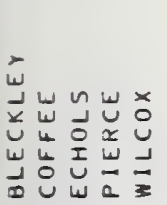 & 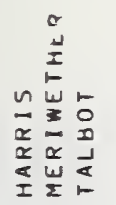 & 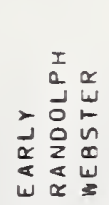 & 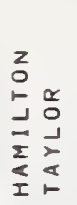 & 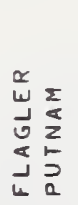 & 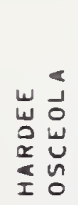 & $\begin{array}{l}z \\
\vdots \\
4 \\
\vdots \\
0 \\
0 \\
0 \\
\vdots\end{array}$ & 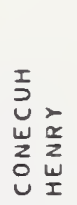 & 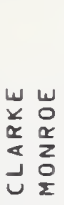 & $\begin{array}{r} \\
0 \\
0 \\
0 \\
0 \\
0 \\
0 \\
0 \\
0\end{array}$ \\
\hline కత్రీత & 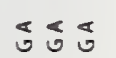 & 过过 & لد & $\vec{\omega} \vec{\omega}$ & $\vec{L}_{L}$ & لد الثا & $\overrightarrow{<} \vec{\alpha}$ & \& & $\vec{\alpha}$ \\
\hline
\end{tabular}

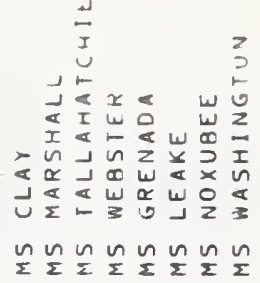

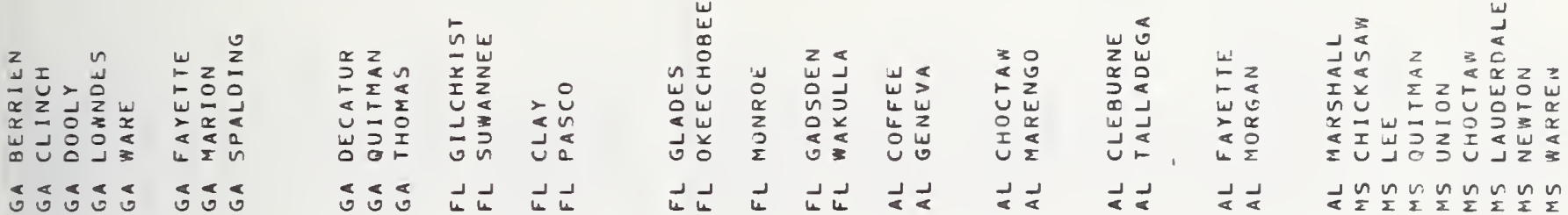

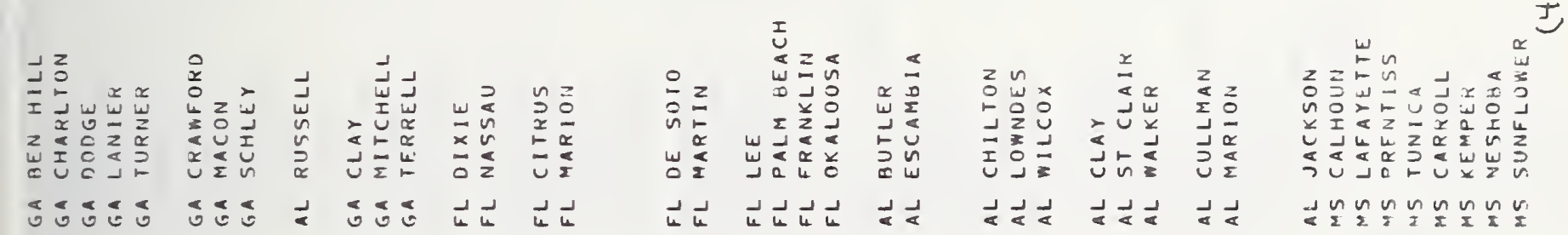

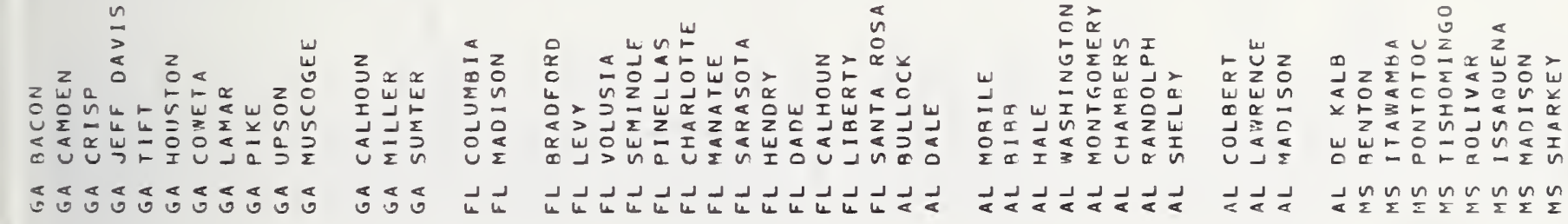

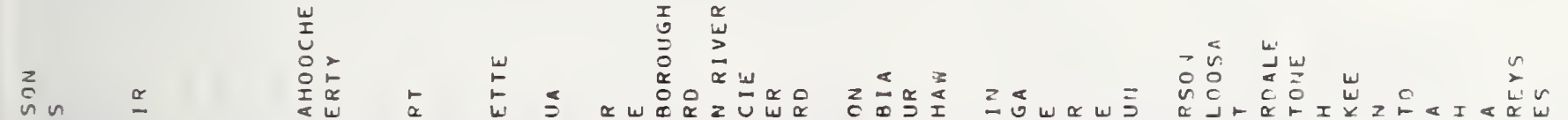

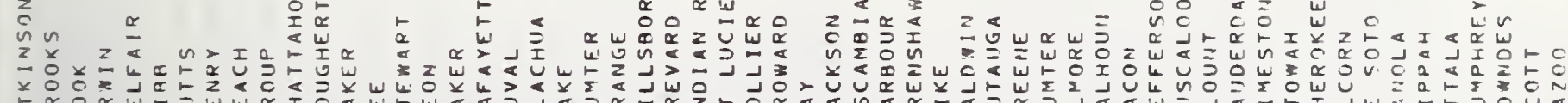

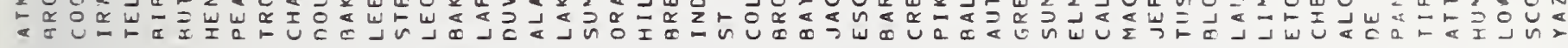

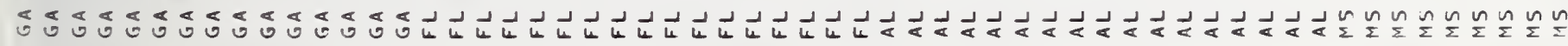

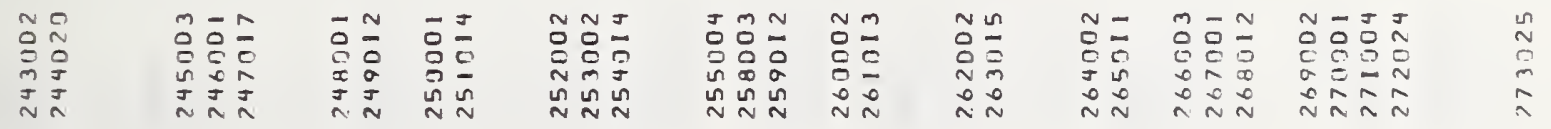




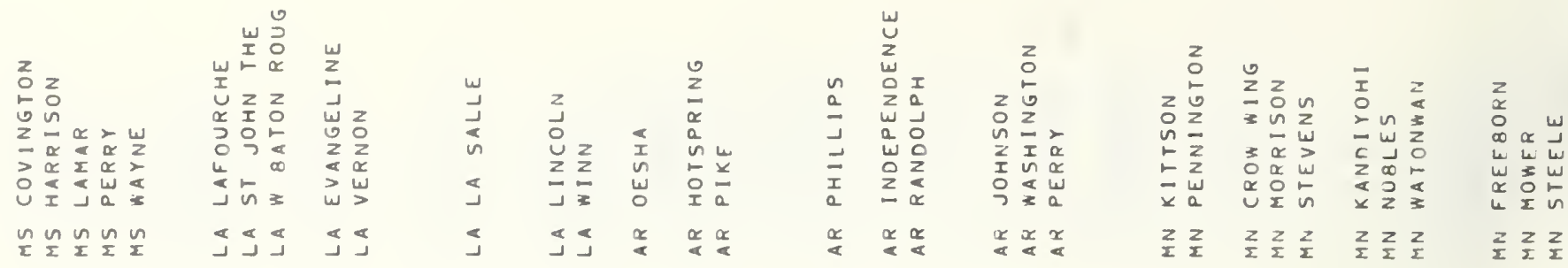

\begin{tabular}{|c|c|c|c|c|c|}
\hline 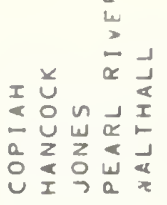 & 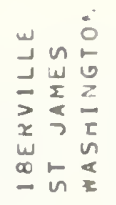 & 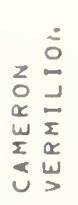 & 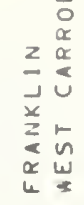 & 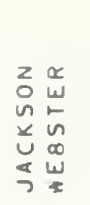 & 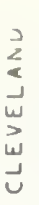 \\
\hline$u_{\Sigma}^{n} \backsim n_{\Sigma}^{n} \tilde{\Sigma}$ & s & $\pm s$ & 5 & ذَ & \\
\hline
\end{tabular}
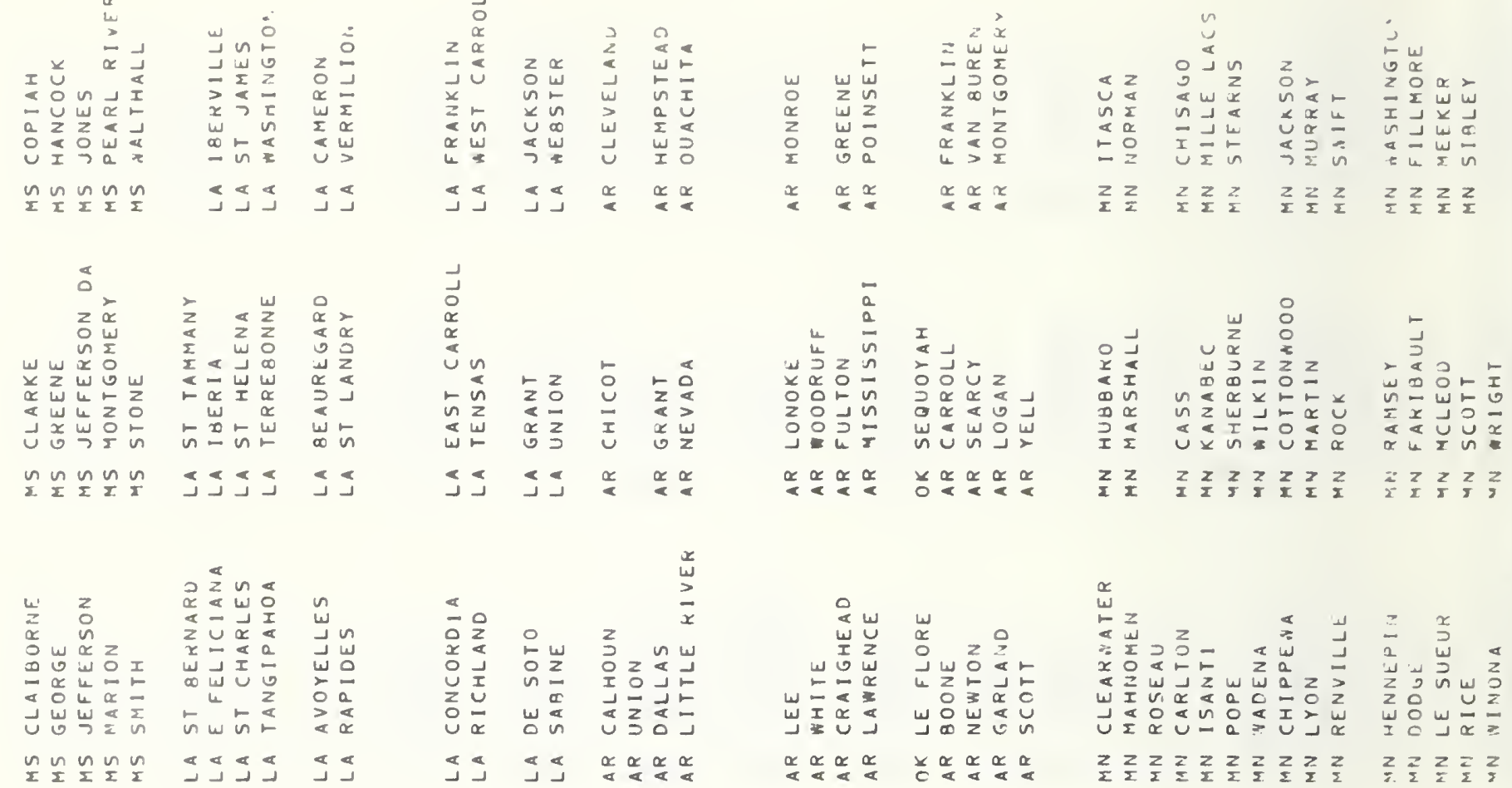

$2 \stackrel{z}{2} \underset{2}{2} z^{2}$

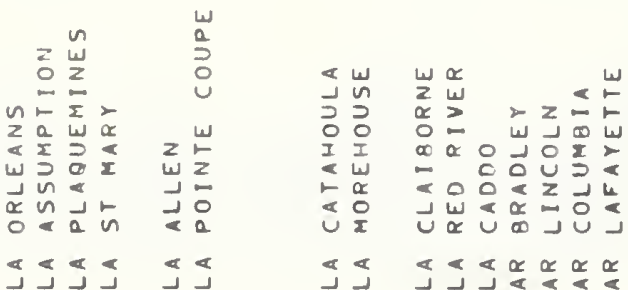

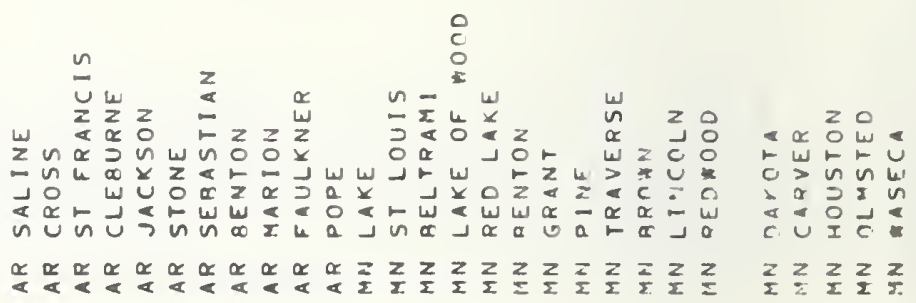

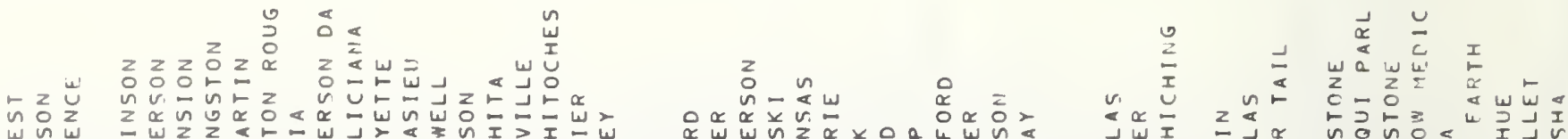

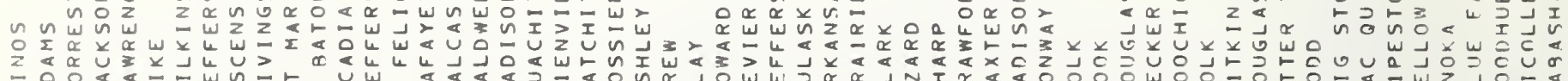

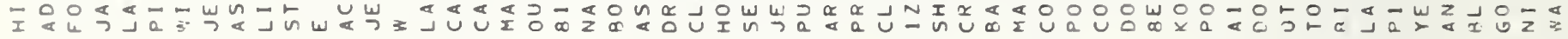

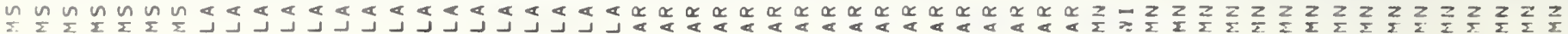




\begin{tabular}{|c|c|c|c|c|c|c|c|c|c|c|c|c|c|c|c|}
\hline 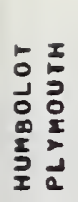 & $\begin{array}{l}: \\
0 \\
0 \\
0 \\
0 \\
\frac{\pi}{2} \\
\frac{\pi}{2} \\
\vdots\end{array}$ & 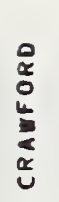 & 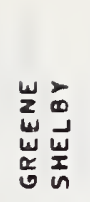 & $\begin{array}{l}a \\
w \\
a \\
n \\
\vdots \\
j\end{array}$ & 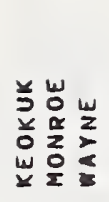 & 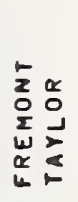 & 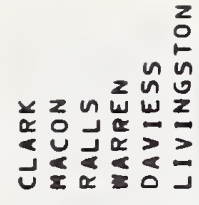 & $\begin{array}{l}\omega \\
5 \\
\circ \\
0 \\
\vdots \\
0\end{array}$ & 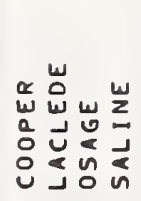 & 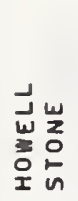 & 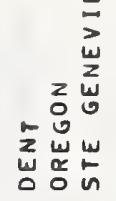 & $\begin{array}{l}n \\
0 \\
0 \\
\vdots \\
\text { n }\end{array}$ & 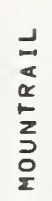 & 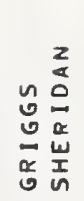 & 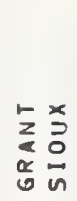 \\
\hline$<<$ & $\leq$ & $\leq$ & $\leq \leq$ & $\leq$ & $\leq \leq \leq$ & $\leq \leq$ & 웃오올올올 & $\underline{n}$ & 옾옾올오 & 옾오 & 울울 & 웊 & i & 울 & 울 \\
\hline
\end{tabular}

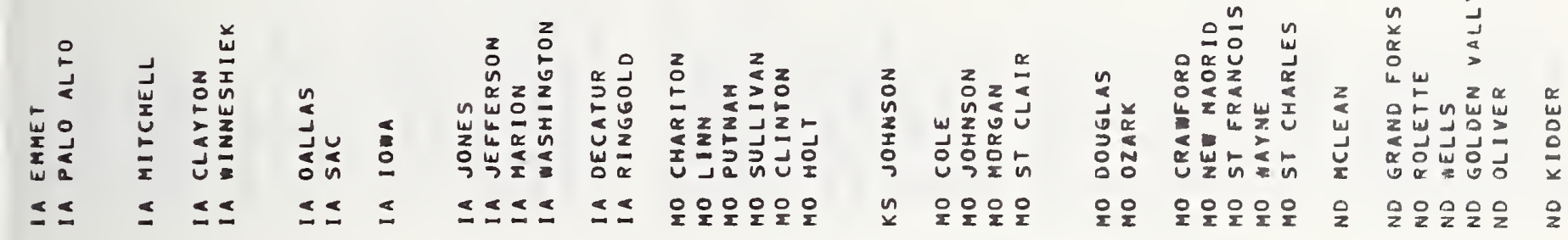

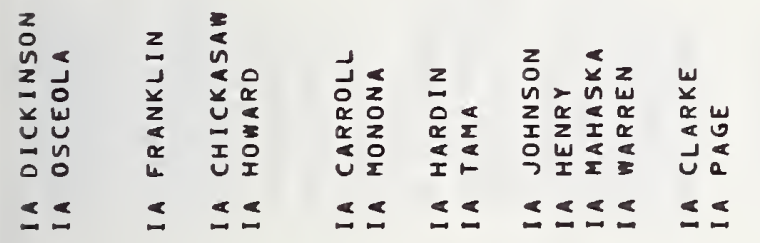

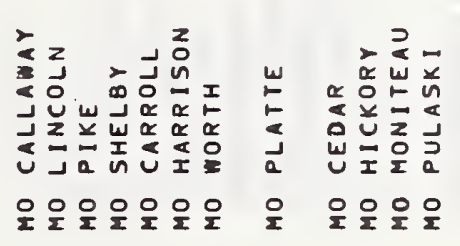

$\vec{a} \quad z$

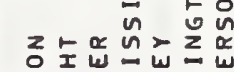

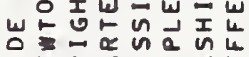

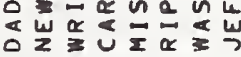

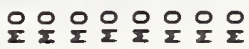

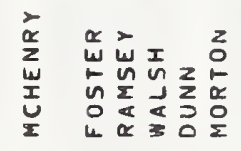

$n$
$z$
0
$\sum_{2}^{n}$
w
i

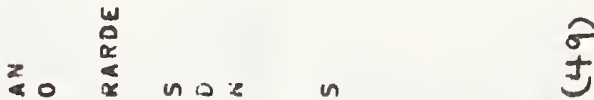

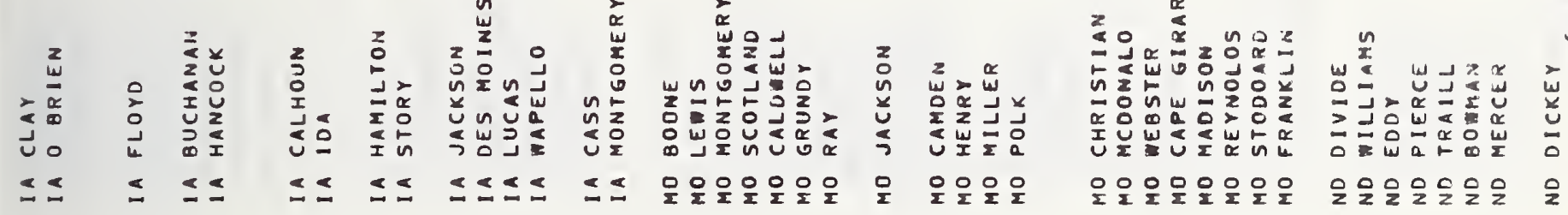

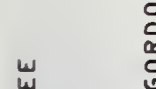

$\circ$
$\therefore$
0

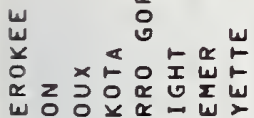

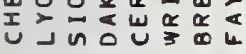

$\leq \leq \leq W \leq \leq \leq \leq$

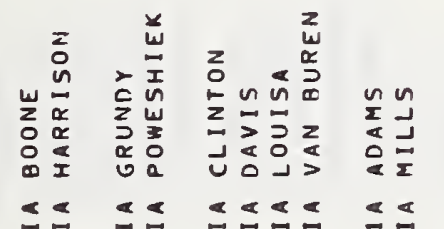

$z$
$a$
0

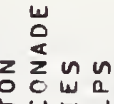

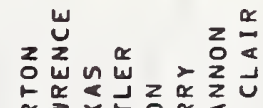

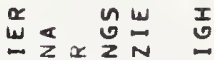

之出市岕

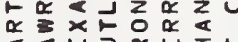

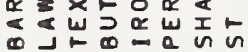

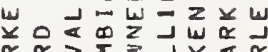

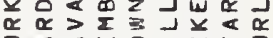

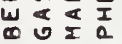

올오올오올일이

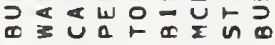

올오올오

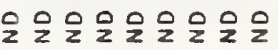

n

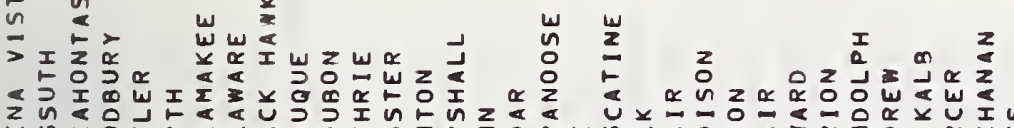

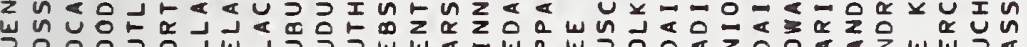

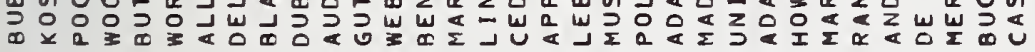

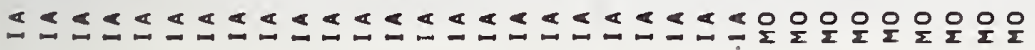

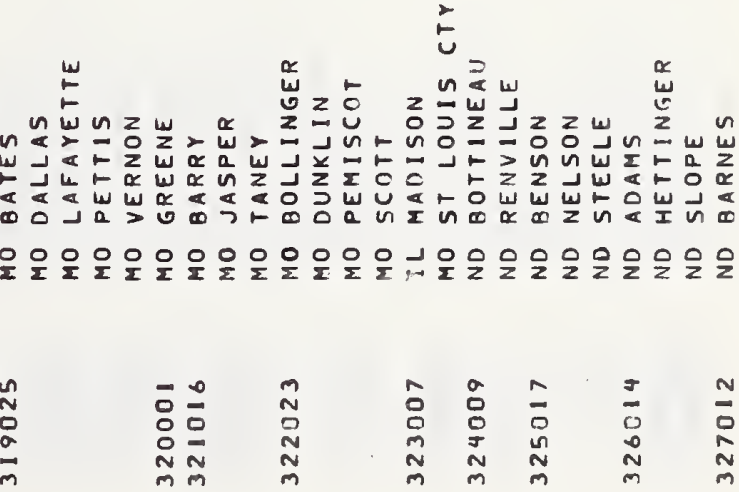

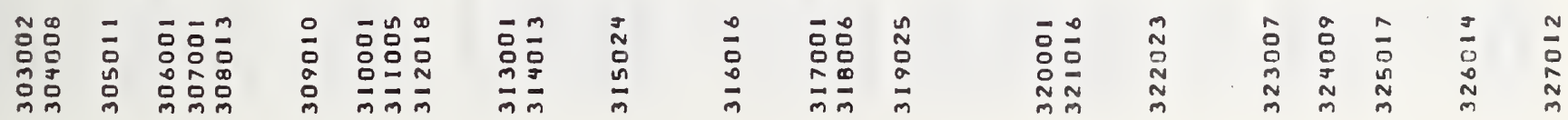



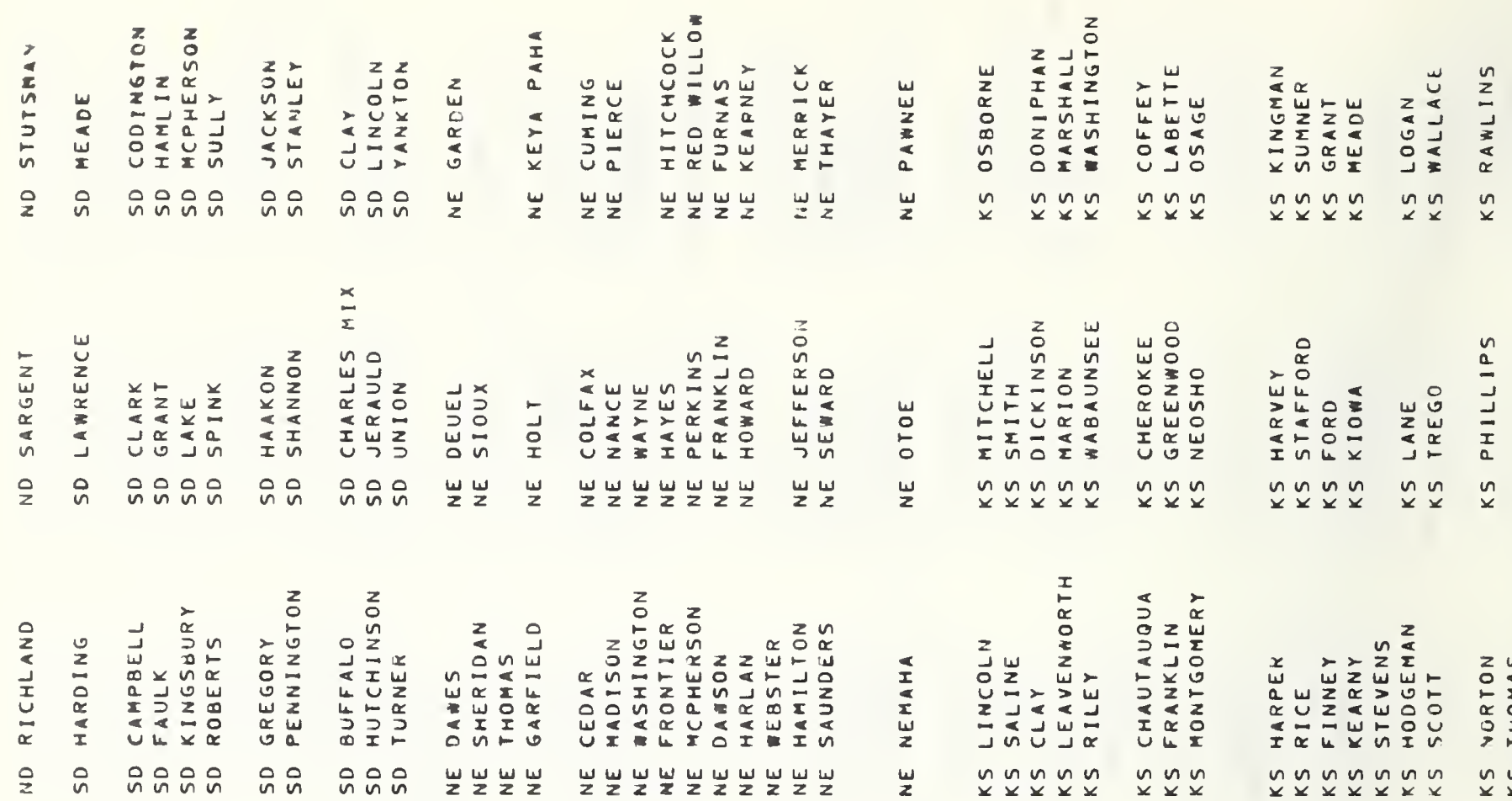

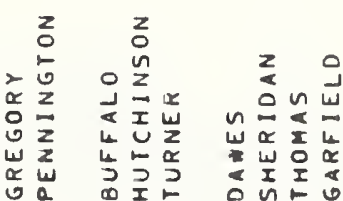

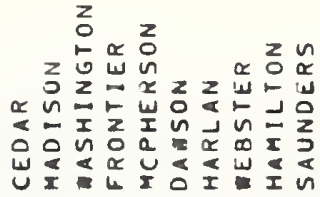

응 in 0 i $\underset{z}{w} \frac{w}{2} \frac{w}{2}$

$\frac{w}{z} \frac{w}{z} \sum \frac{w}{z} \frac{w}{z} z \frac{w}{z}$

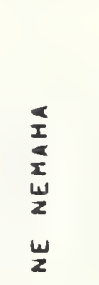

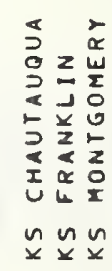

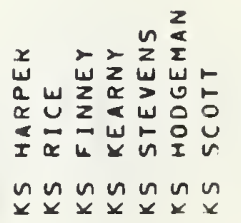

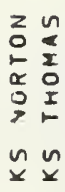

o

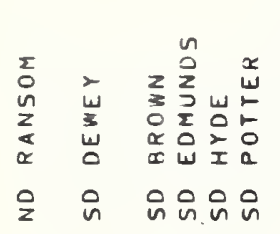

$\simeq \quad I$

$\stackrel{r}{\mathrm{w}} \stackrel{\mathrm{I}}{\mathrm{s}}$

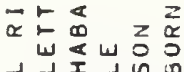

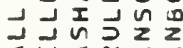

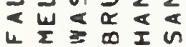

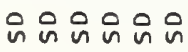

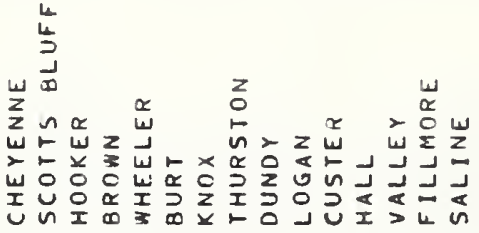

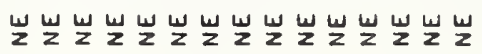

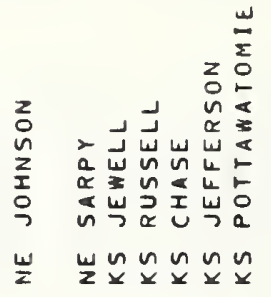

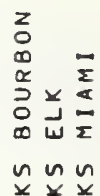

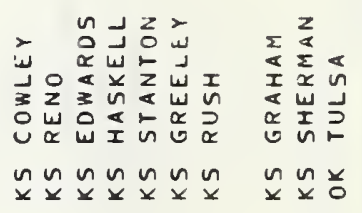

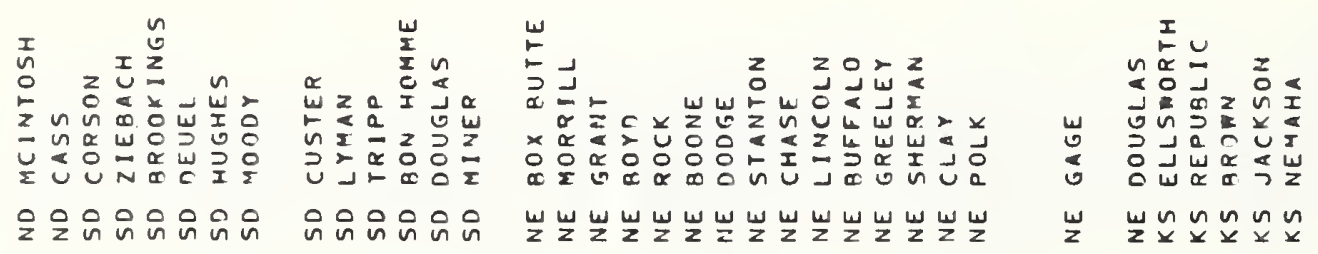

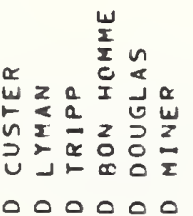
$Z Z Z Z Z Z=\Sigma Z Z Z Z Z Z$

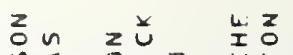

n⿺ 山心

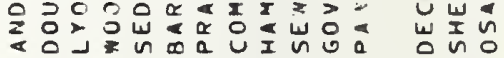

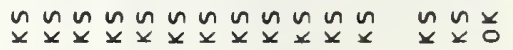

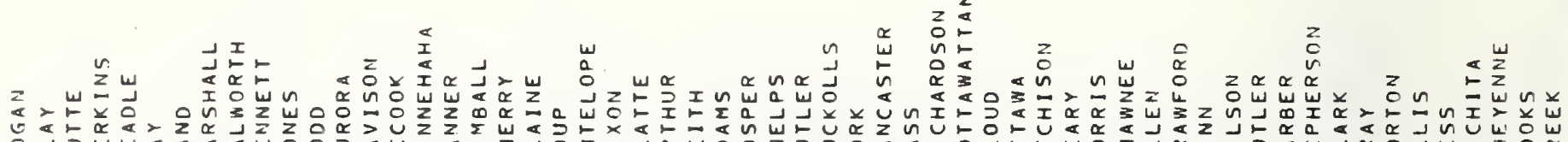

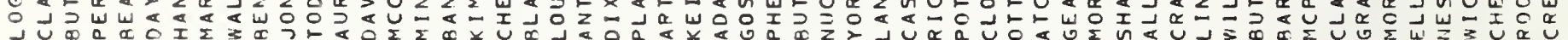

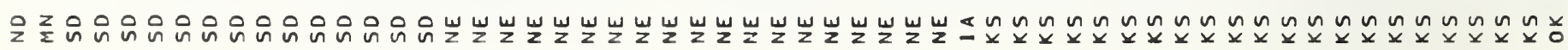

\begin{tabular}{|c|c|c|c|c|c|c|c|c|c|c|c|c|c|c|c|c|}
\hline $\begin{array}{ll}N & \infty \\
0 & 0 \\
0 & 0 \\
\infty & a \\
N & N \\
m & m\end{array}$ & $\frac{n}{a}$ & $\begin{array}{l}\frac{\infty}{0} \\
\stackrel{N}{N} \\
m \\
m\end{array}$ & $\begin{array}{l}\bar{c} \\
0 \overline{0} \\
0 \\
m \\
m \\
m\end{array}$ & $\begin{array}{ll}J & a \\
0 & 0 \\
0 & c \\
\text { M } & 0 \\
m & m \\
m & m\end{array}$ & $\begin{array}{l}\frac{n}{c} \\
\text { c. } \\
\text { m } \\
\text { m }\end{array}$ & $\begin{array}{l}N \\
0 \\
0 \\
a \\
m \\
m\end{array}$ & $\begin{array}{l}0 \\
\vec{c} \\
a \\
m \\
m\end{array}$ & $\begin{array}{l}m \\
5 \\
0 \\
j \\
m\end{array}$ & 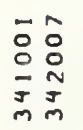 & $\begin{array}{l}m= \\
0 \\
0 \\
m \\
m \\
\bar{J} \\
m\end{array}$ & $\begin{array}{l}\frac{\infty}{5} \\
\tilde{J} \\
\vdots \\
m\end{array}$ & $\begin{array}{l}-0 \\
0 \stackrel{N}{0} \\
0 \\
0 \\
J \\
\text { J }\end{array}$ & $\begin{array}{ll}N & N \\
0 & \bar{c} \\
\omega & 0 \\
\sigma & \sigma \\
m & j\end{array}$ & $\begin{array}{l}\frac{0}{0} \\
0 \\
\text { un } \\
m\end{array}$ & $\frac{m}{\bar{c}}$ & $\begin{array}{l}\frac{0}{E} \\
N \\
N \\
n\end{array}$ \\
\hline
\end{tabular}




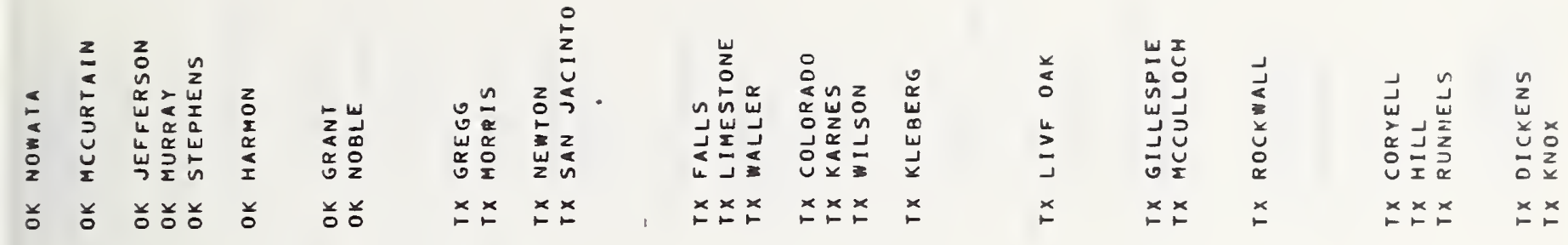

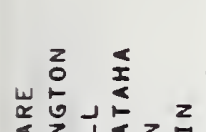

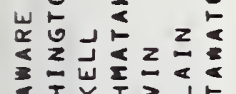

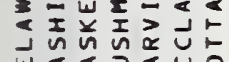

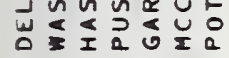

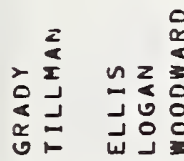

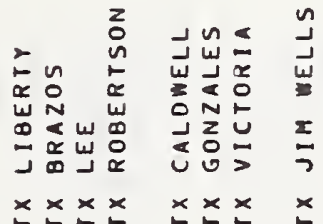

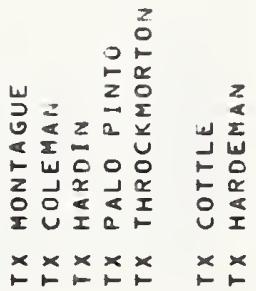

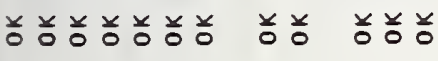

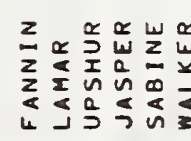

땀ㅉํำ

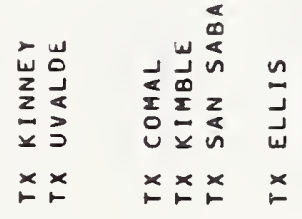

$x \times x \times x$

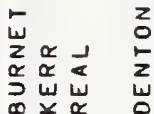

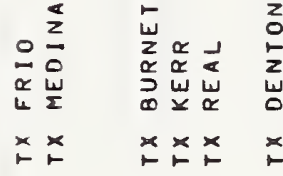

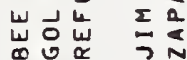

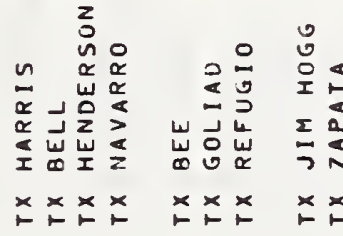

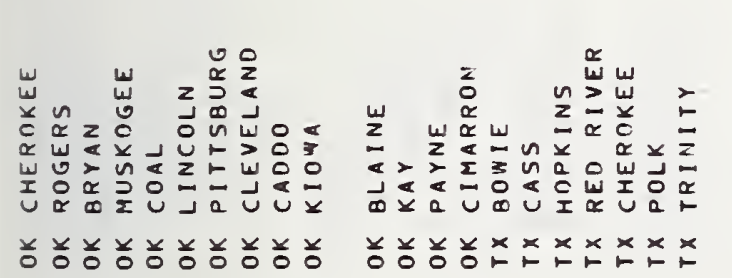

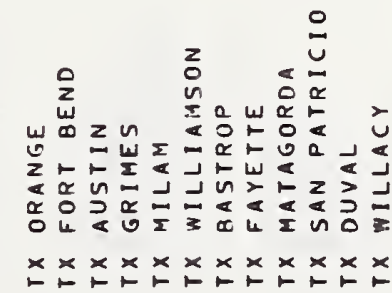

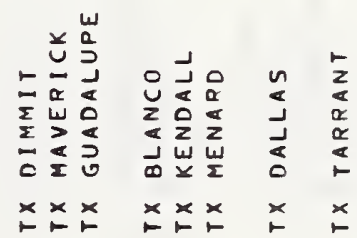

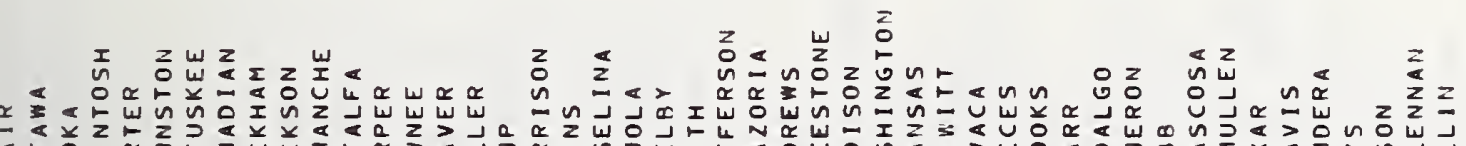

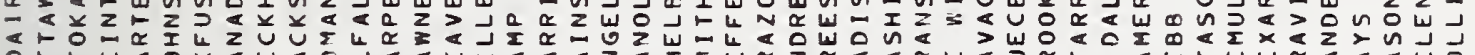

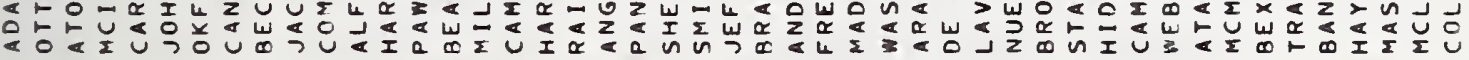

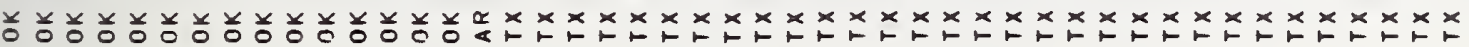

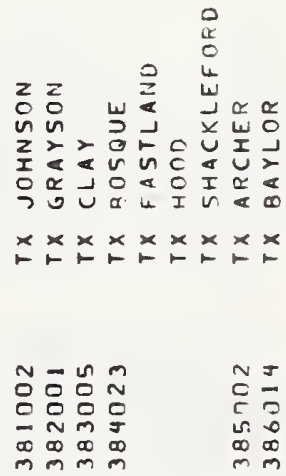

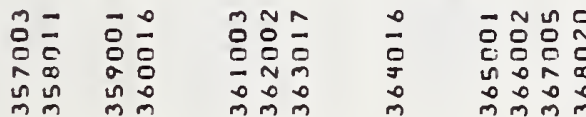

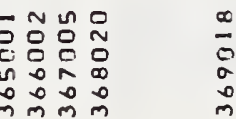

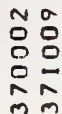
莫员员官 象: 응

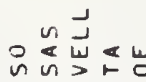
w $<\& \alpha$ 过 $\frac{a}{2} \sum^{2} u$ 원

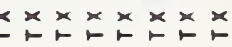
过的岌 。 造造点至求

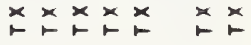




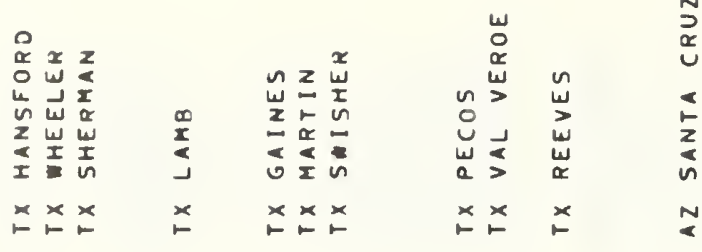

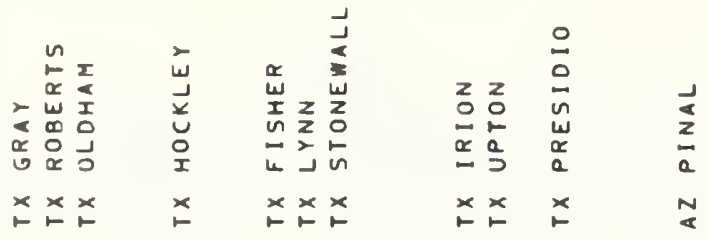
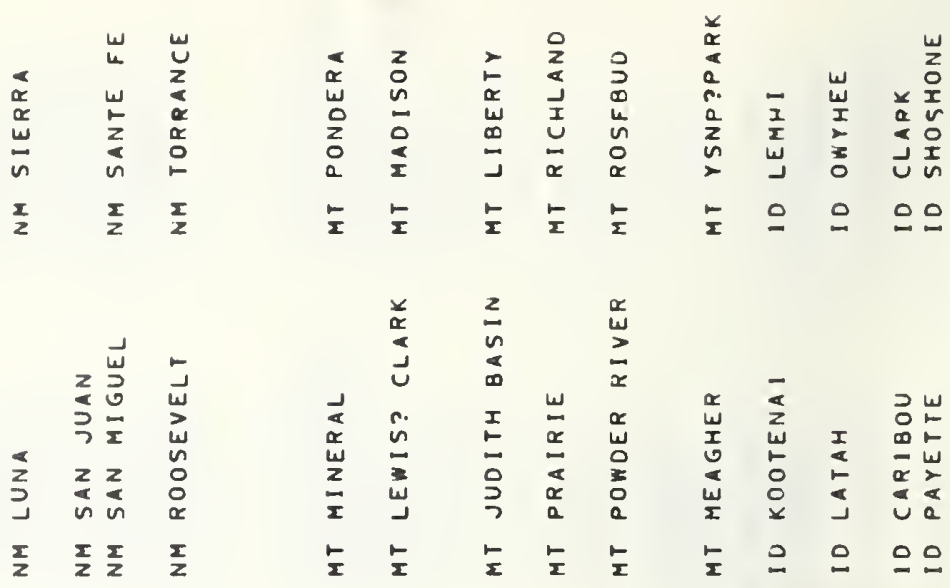

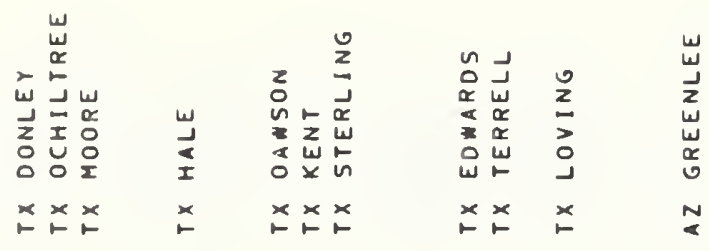

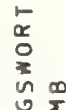

蕰岂志

古鱼

$x \times x$

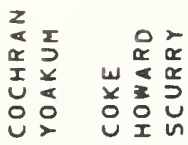

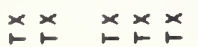

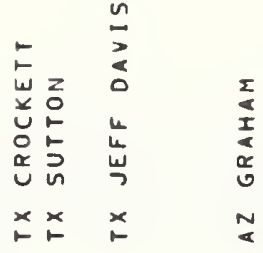

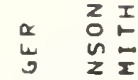
\& $z \sum^{2} x^{2}$

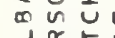

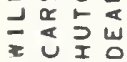
$x \times x x$

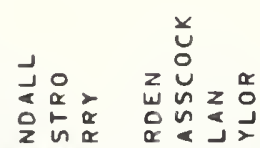

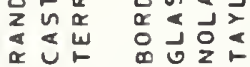
$x \times x \times x x$
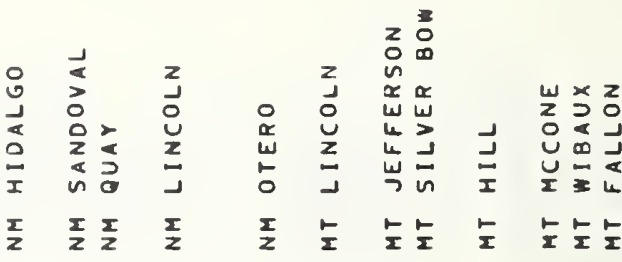

2.

$\cup \infty$

I

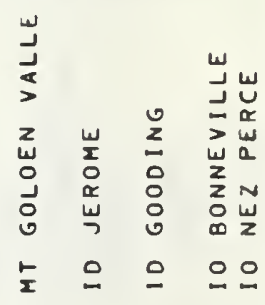

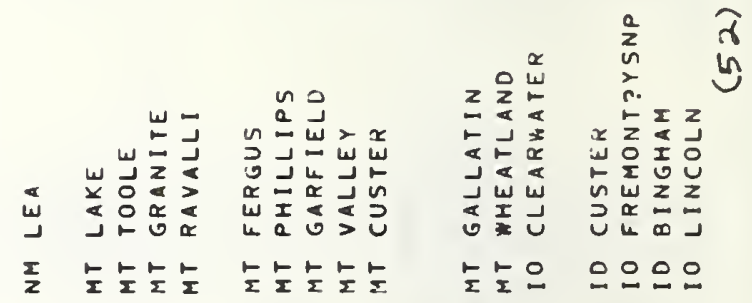

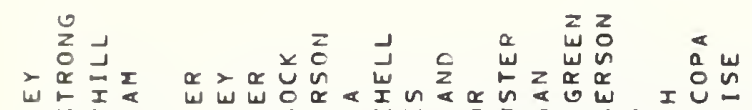
出是」5

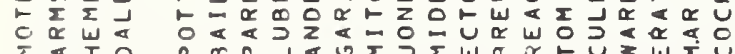

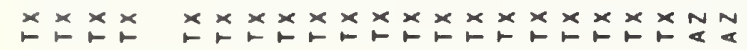

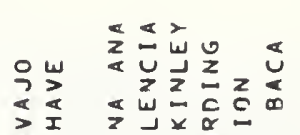

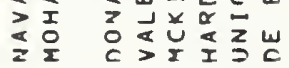
NN $\sum_{2}^{2} \sum \frac{\pi}{2} \frac{\pi}{2} \frac{\pi}{2}$

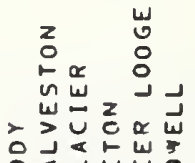

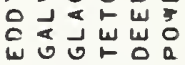
攵希它占占

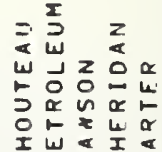

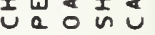
㝊宝卡尗

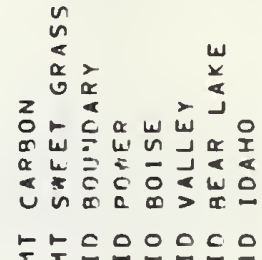

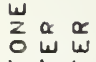
돋ㅇㅇㅇㅇㅇ으은

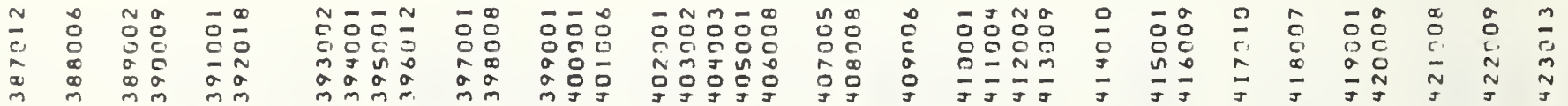

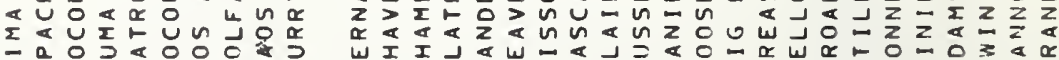

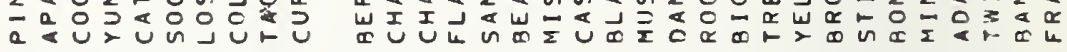

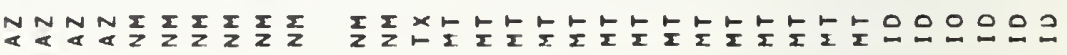




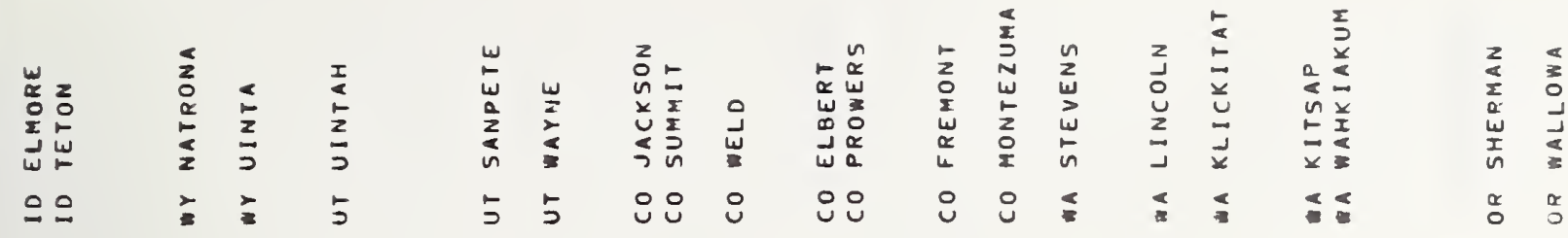

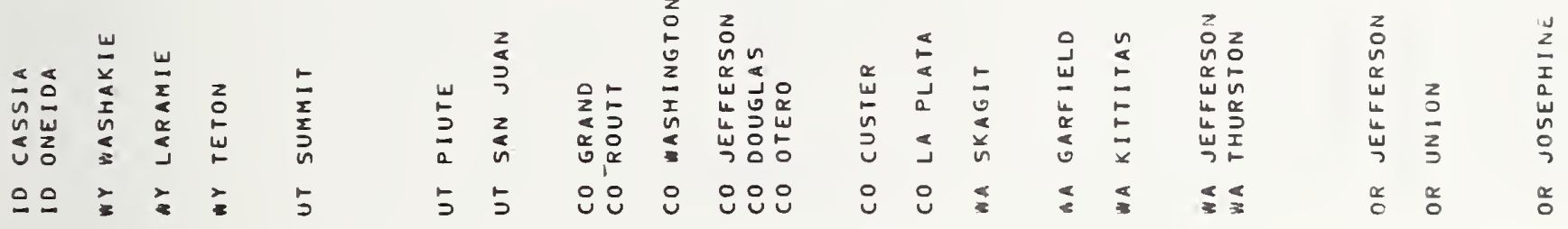

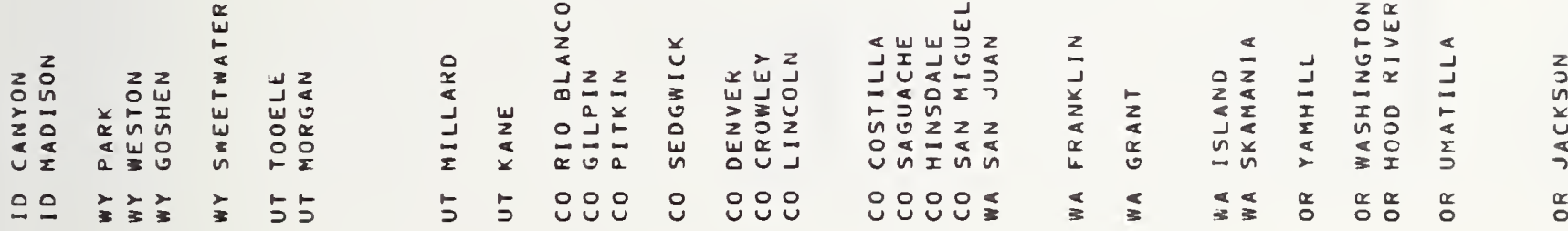

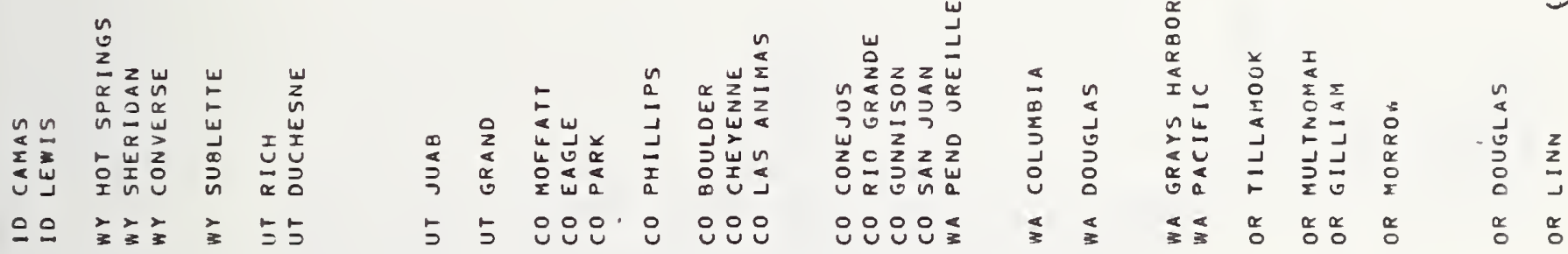

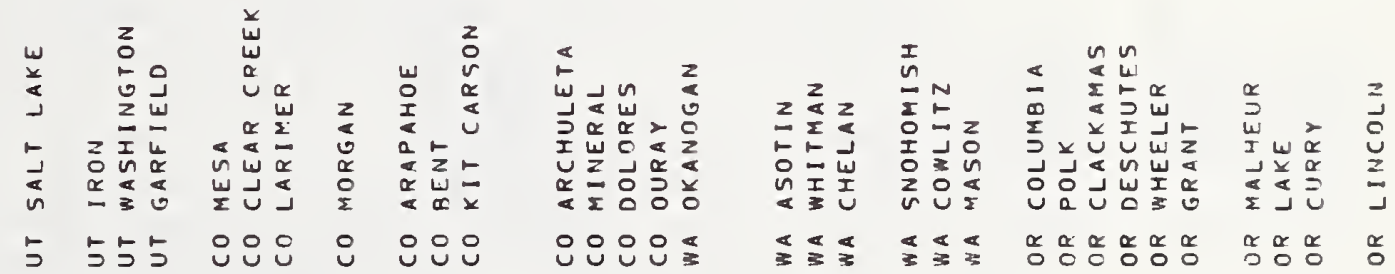

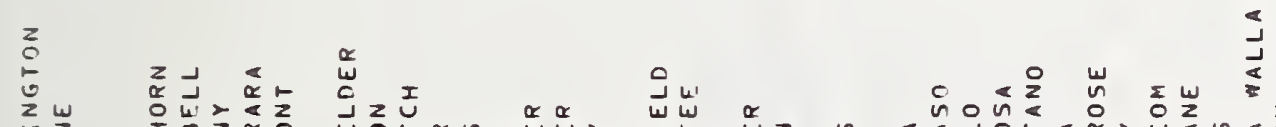

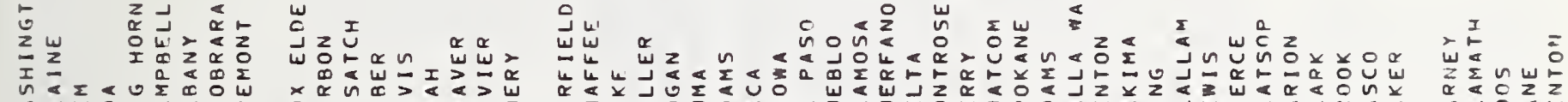

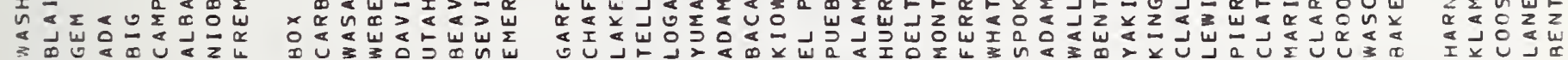

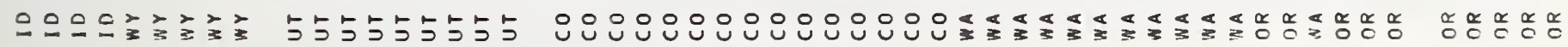

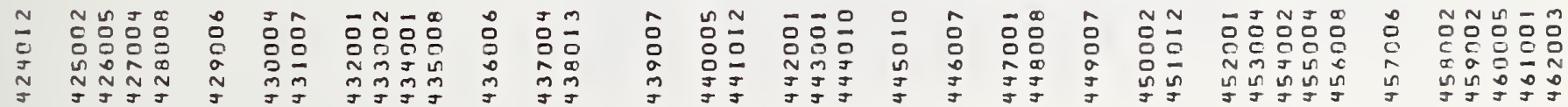




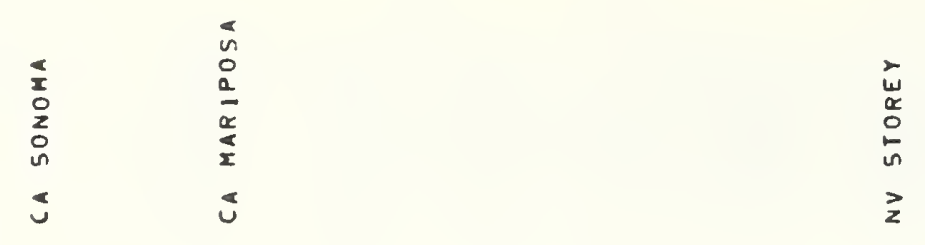

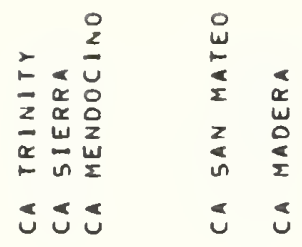

2
5
$z$
0
in
$\alpha$
$\vdots$
$z$
$z$

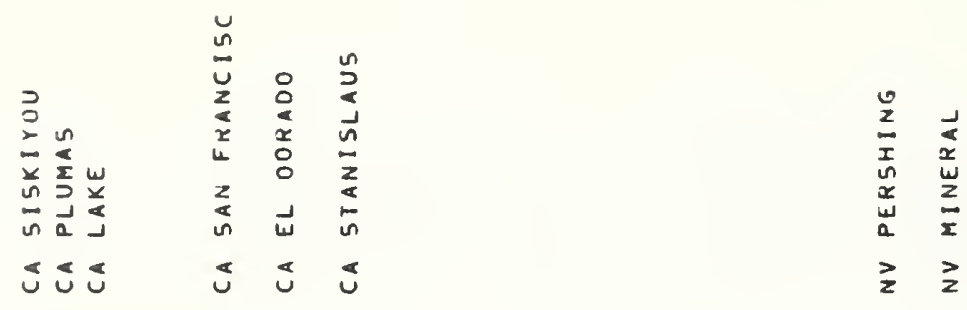

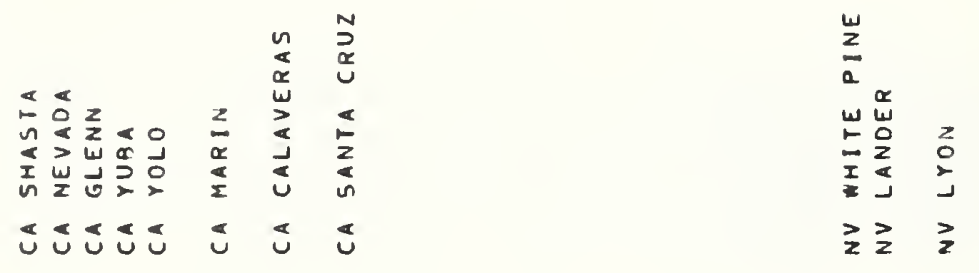

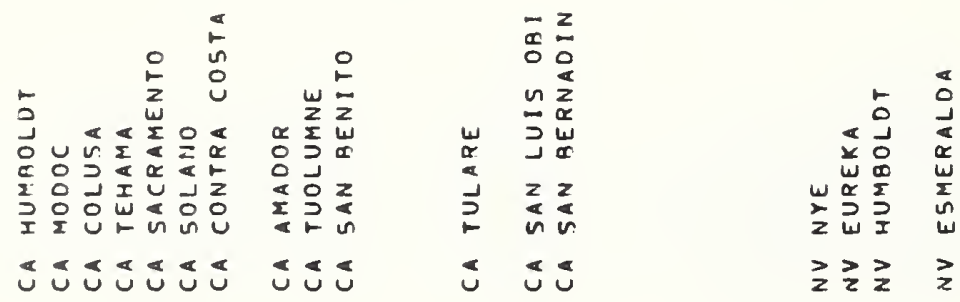

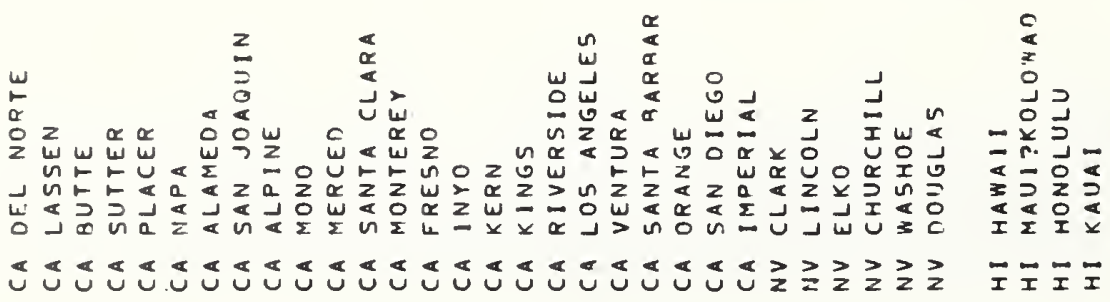

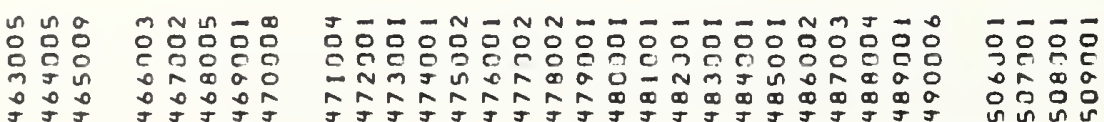

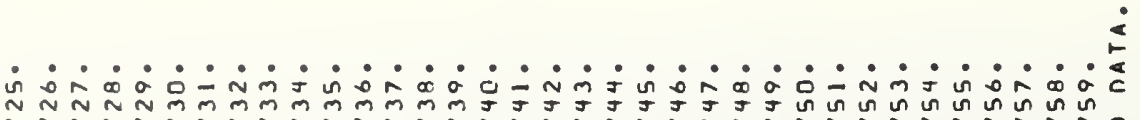
N 
Appendix 4

Data Set BEA

The first column gives the BEA zone number times 1000 plus the number of counties in the zone. In the next six columns, for as many lines as are needed, the county names (with state abbreviations) are listed. For example, lines 17 and 18 ist the 12 counties that comprise BEA zone 7. The error messages and strings of asterisks that appear in place of some county names for BEA zones 1-6 and 14 do not detract from the validity of the listing for other BEA zones. These BEA zones are the only ones affected by the first 40 NNS zones for which the NNS to BEA zone mapping was manually determined. 


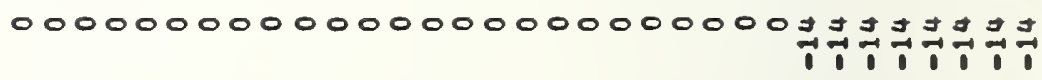

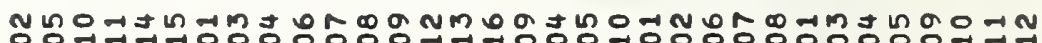

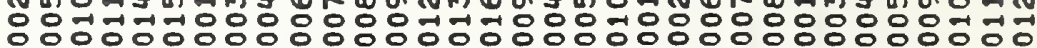
언

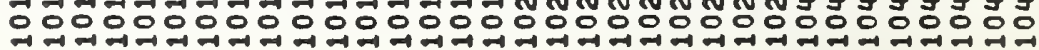

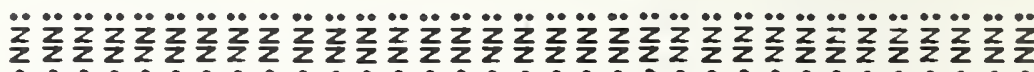

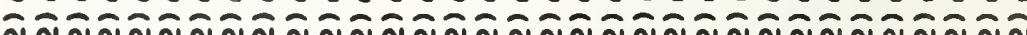

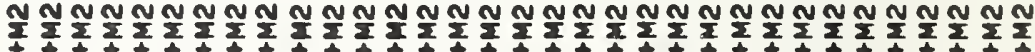

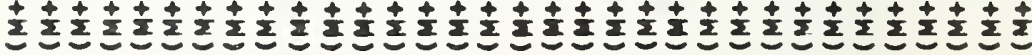

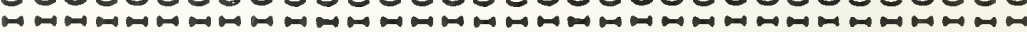

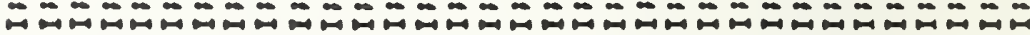

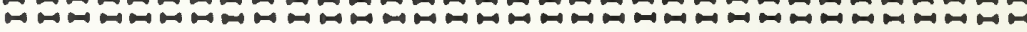

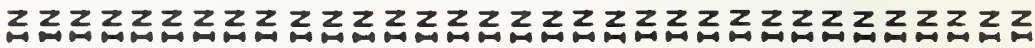

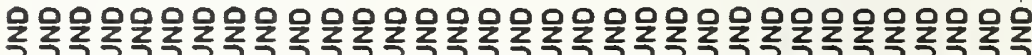

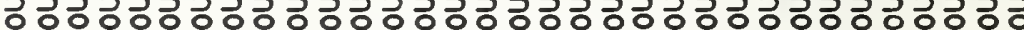

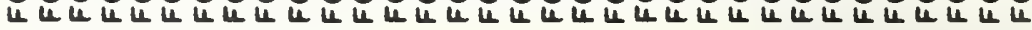

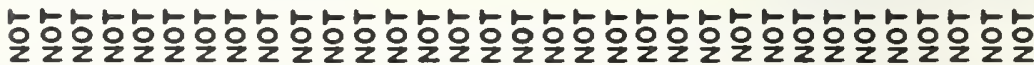
点

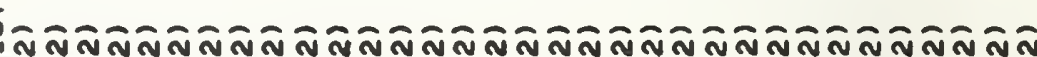

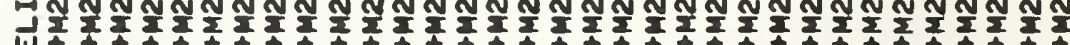

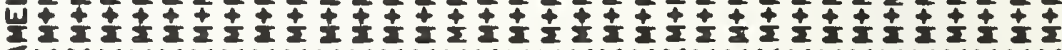

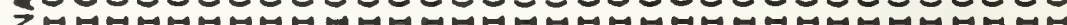
:

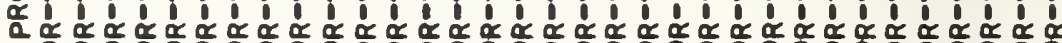

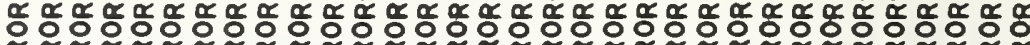

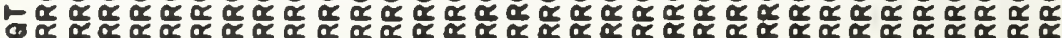

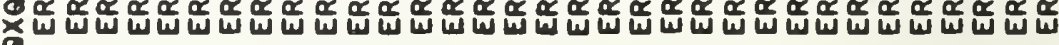




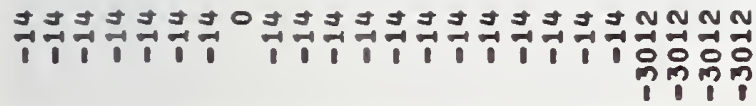

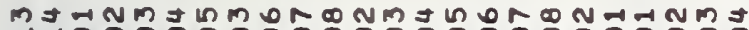

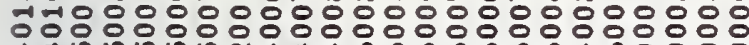

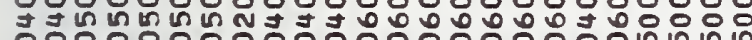

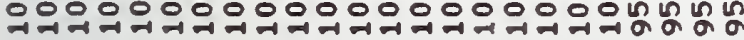

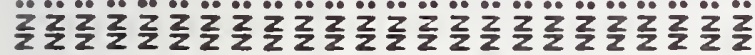
जิ

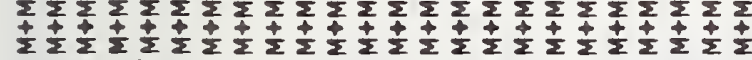

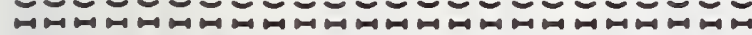

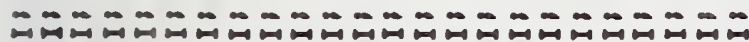

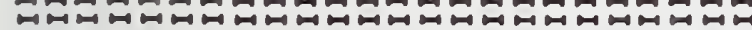

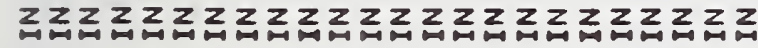

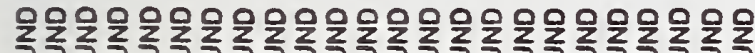

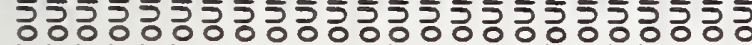

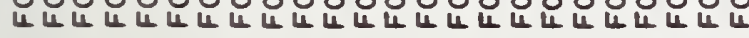

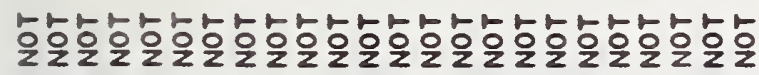

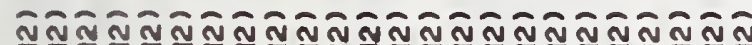
2

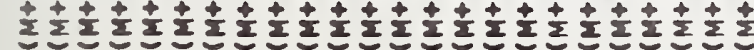

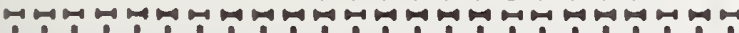

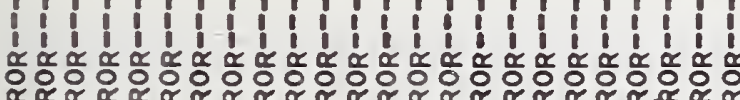

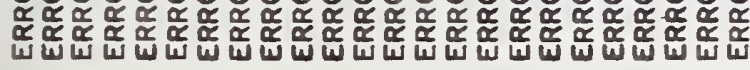

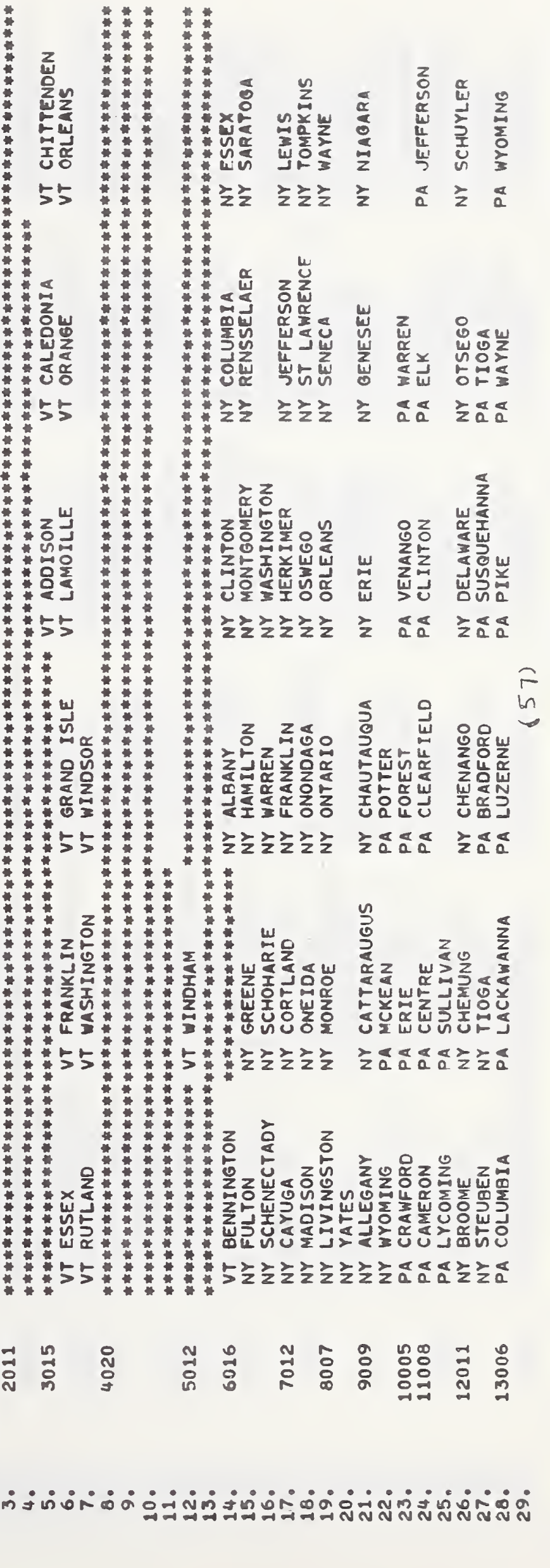




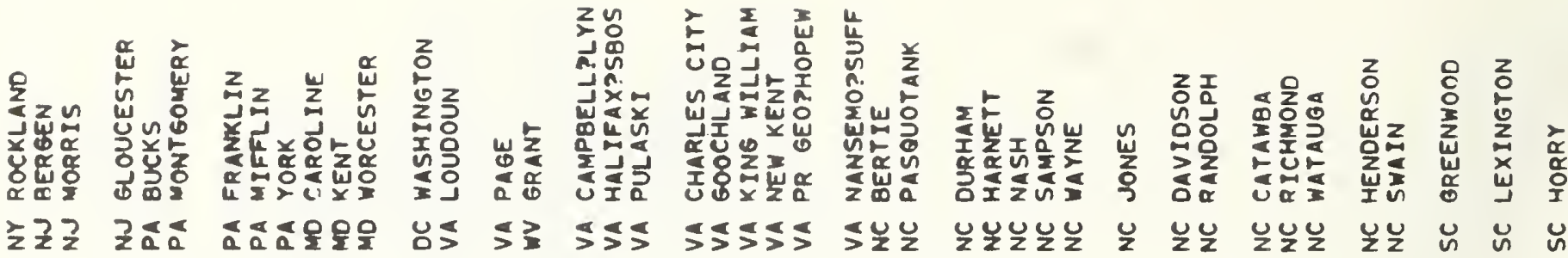

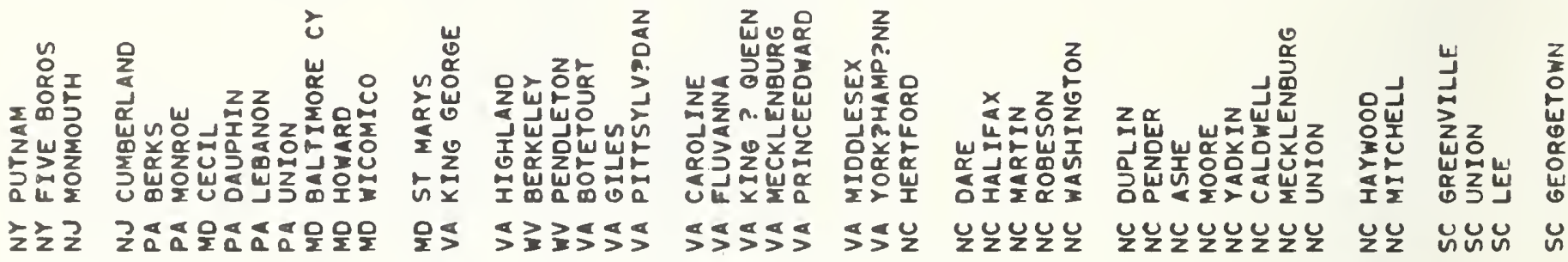

竎文 w

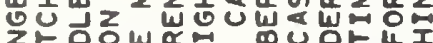

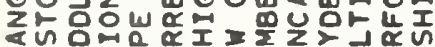

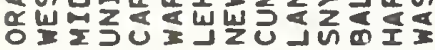

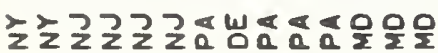

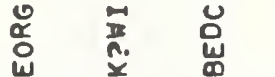

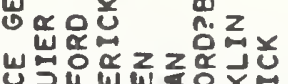

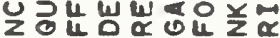

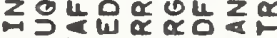

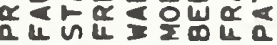

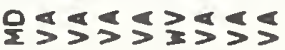

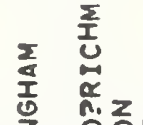

z - $x$ un

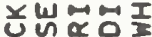

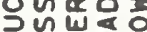

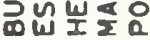
\\タ⿱亠⿻⿰丿亅八阝

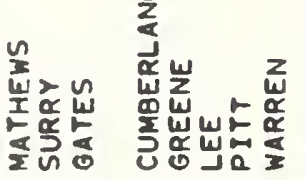
$\$ \$$
登离

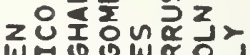

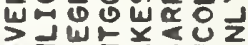

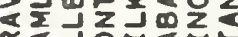

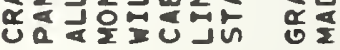

움 z $w_{0}^{w} \sum_{x}$ s

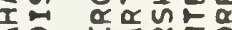

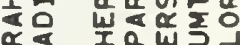

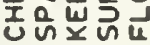

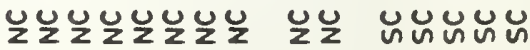

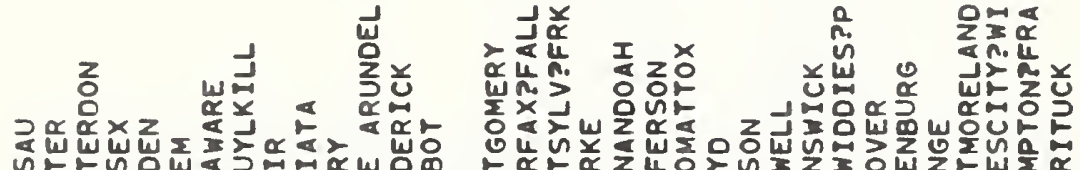

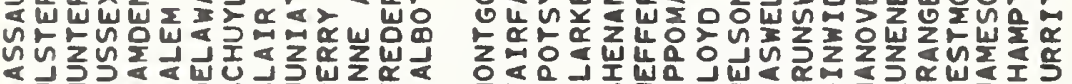

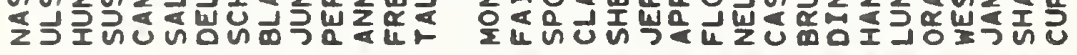

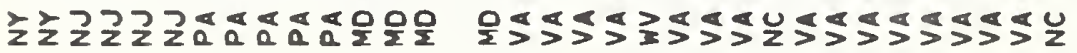

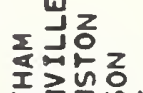

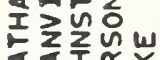

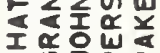

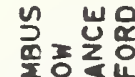
골

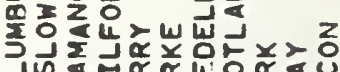

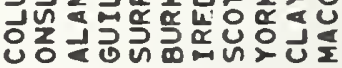

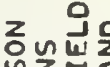
败业之
出

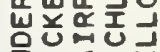
$\sum_{<0}$

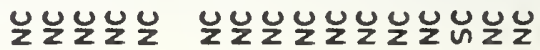
uuuuuㅛ

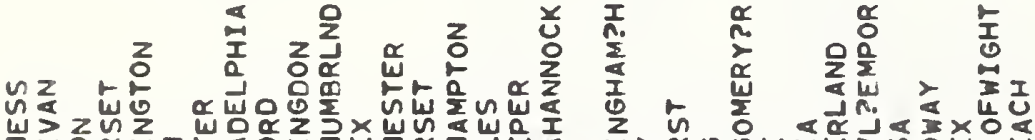

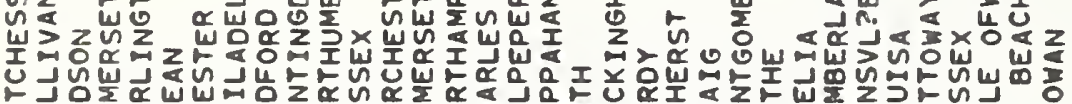

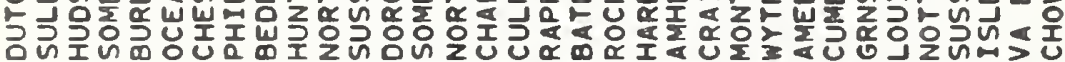

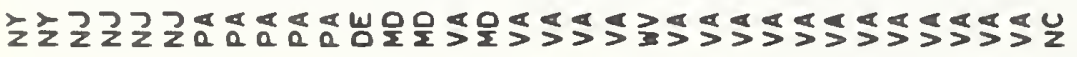

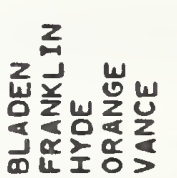

总

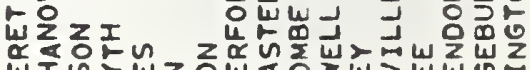

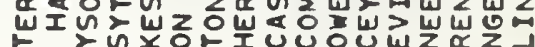

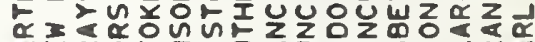

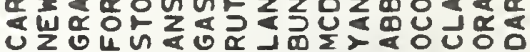

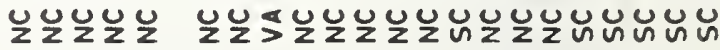

t. *

z $\quad$ w $\quad$ w

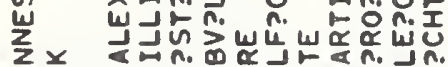

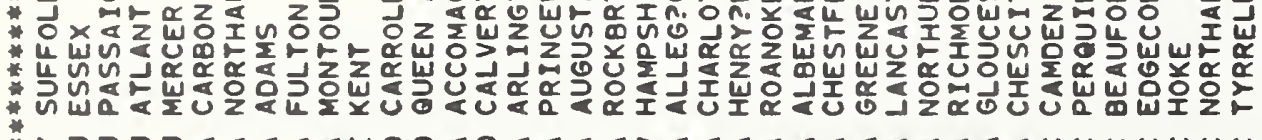

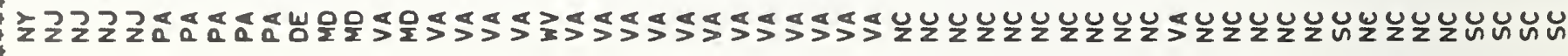

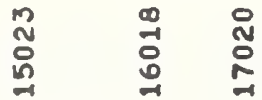

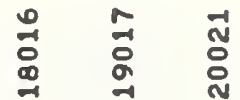

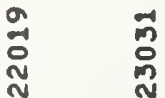

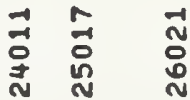

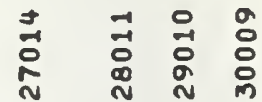




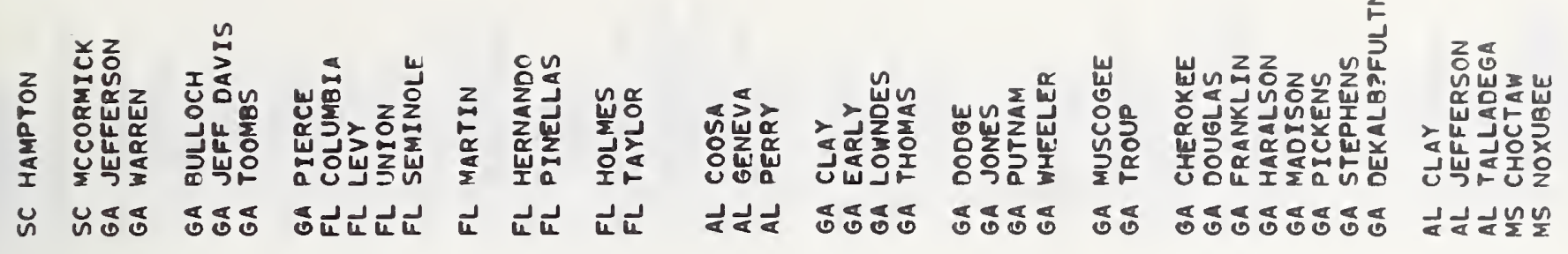

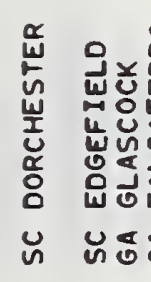

닌

0

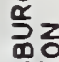

象占

ป.

武高

जน

\section{$\frac{0}{2}$}

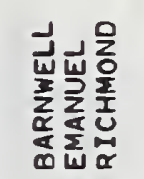

z

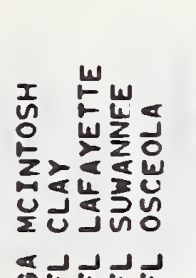

$\sum_{\substack{a \\ \alpha}}^{\infty}$

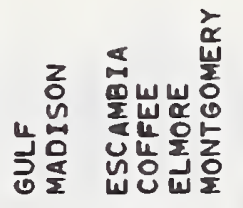

2゙

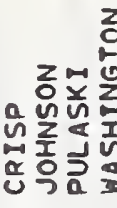

2

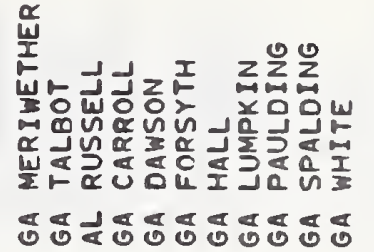

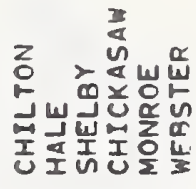

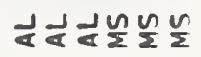

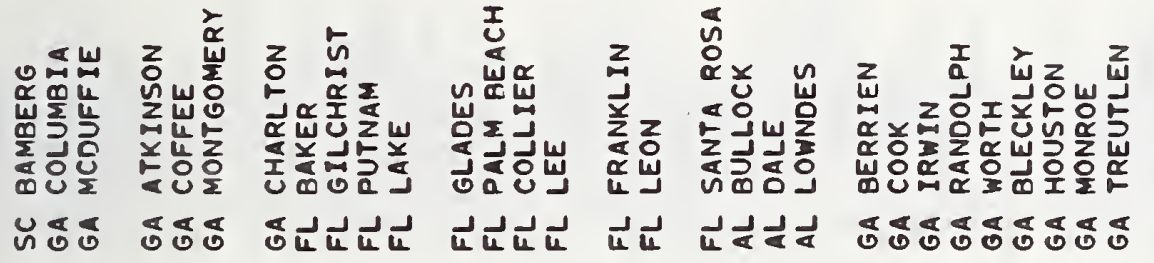

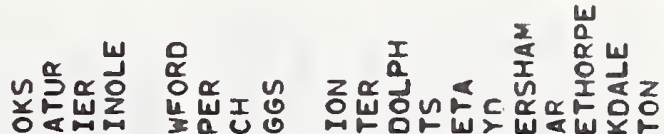

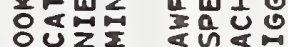

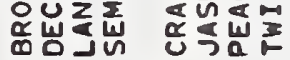

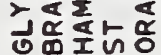
2 넌은 올 岌的改京

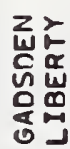
인 खे मد

دـ

近造

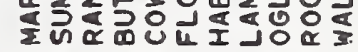

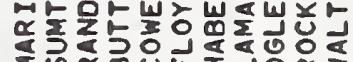

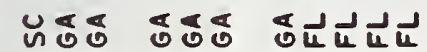

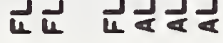

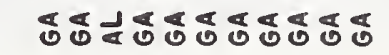

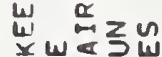

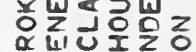

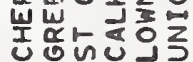

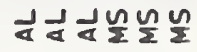
峞

unu

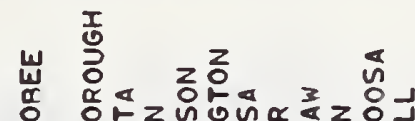

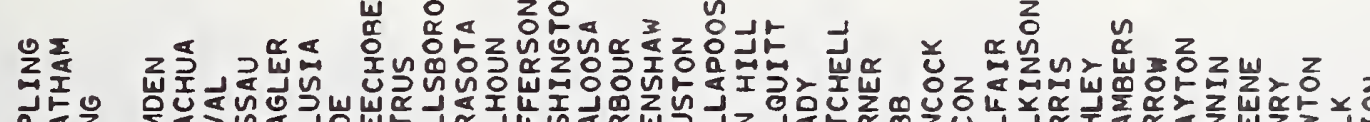

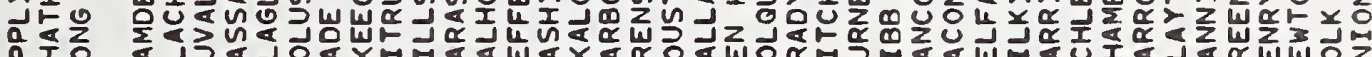

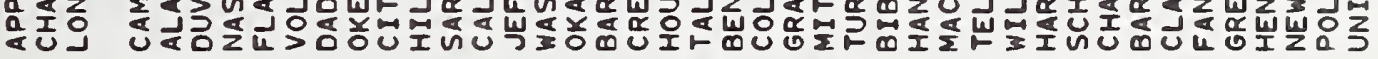
过导灾
党

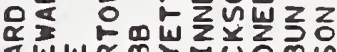

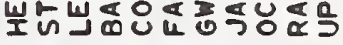

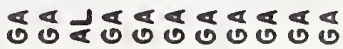

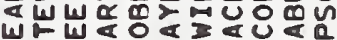

zwwn 원른

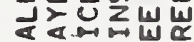

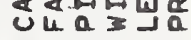

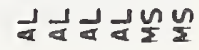

닌

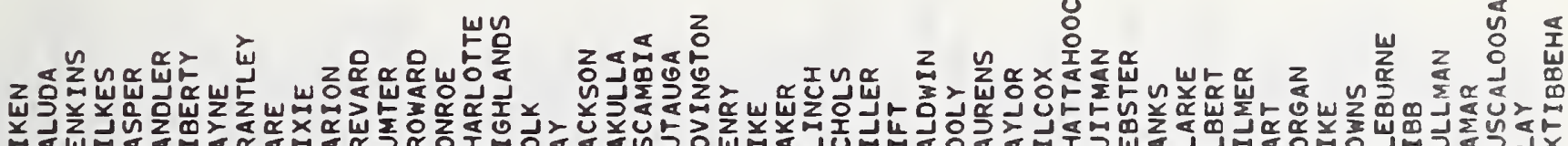

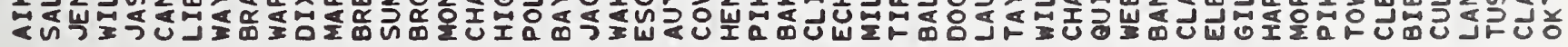

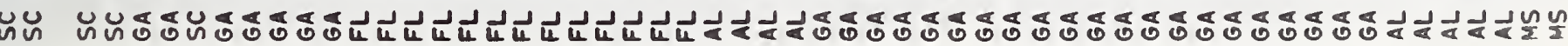

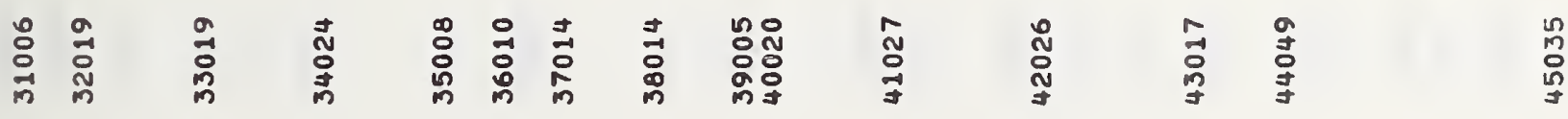




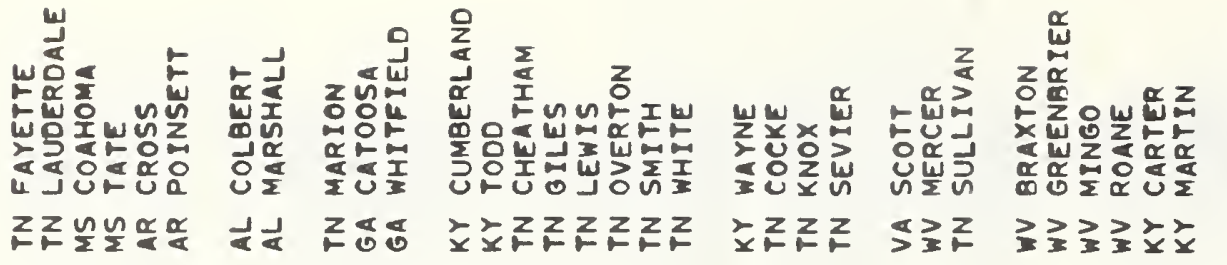

上z

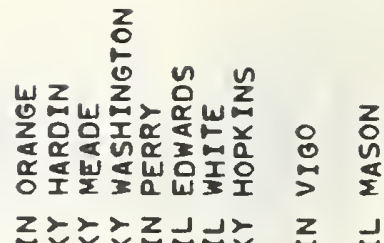

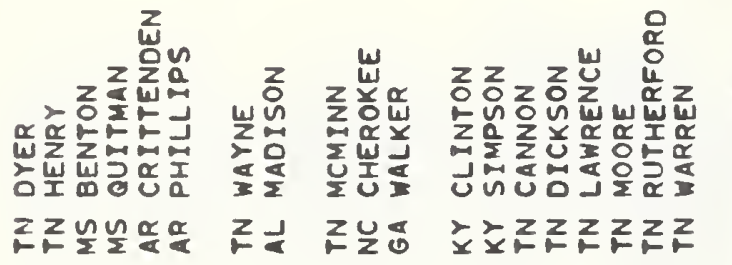

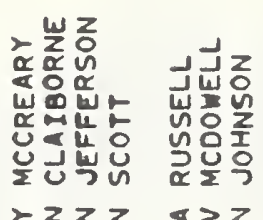

嵌岕志㤝

wำ

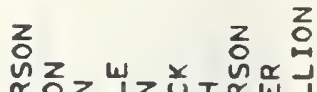

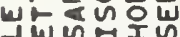

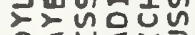

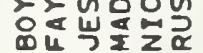

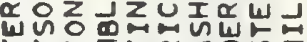

4

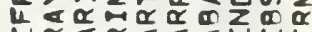

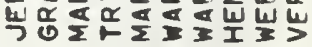

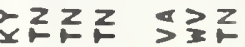

至主主至文

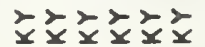

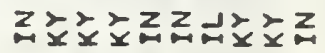

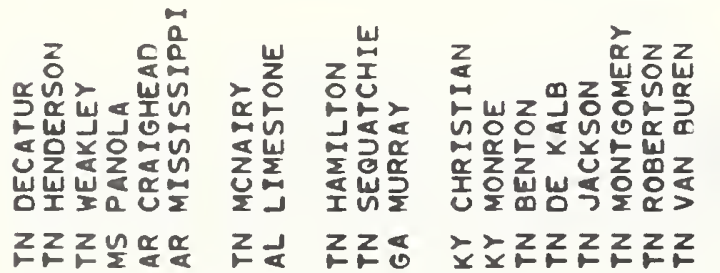

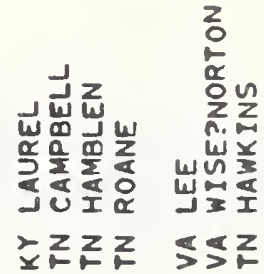

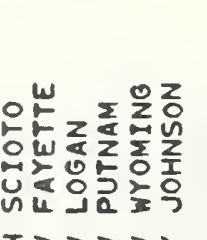

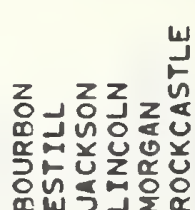

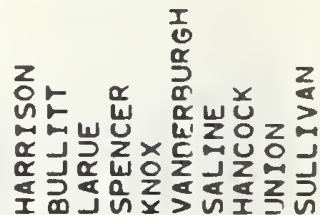

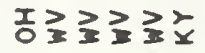

ンンンンンン

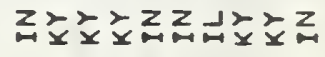

능을

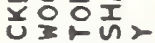

웅ำ

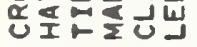

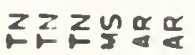

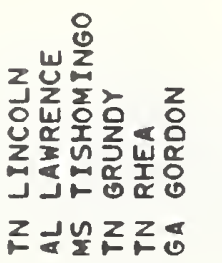

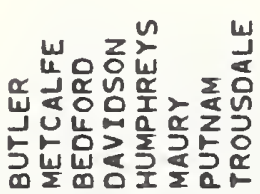

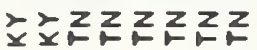

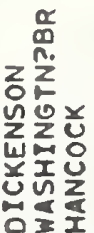

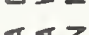

\&SZ

\author{
2 \\ $z \sum^{5} \alpha 0$

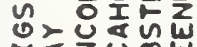

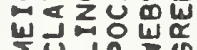

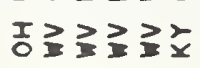

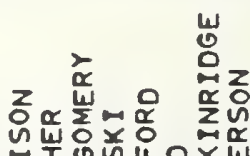

w

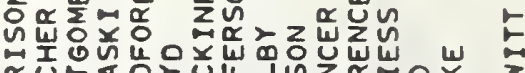

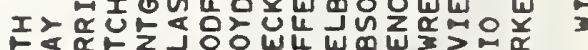

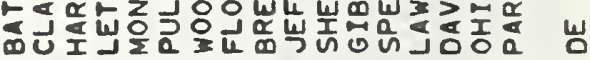

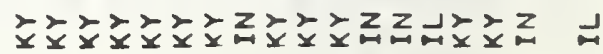

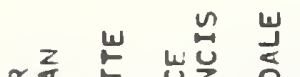

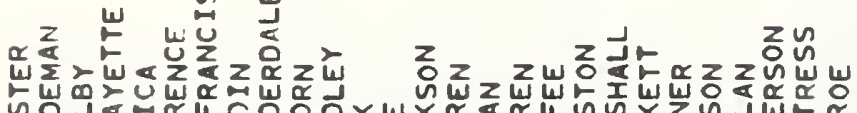

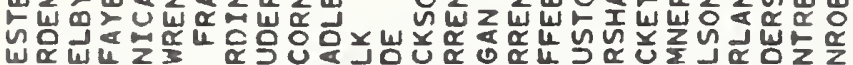

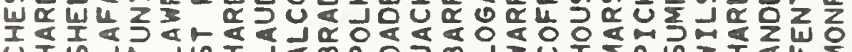

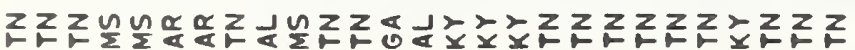

ż山 z

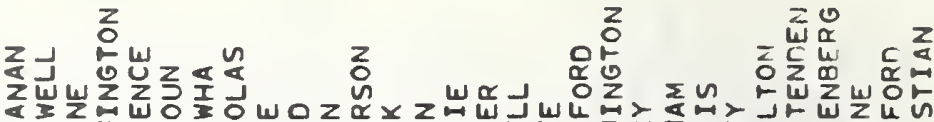

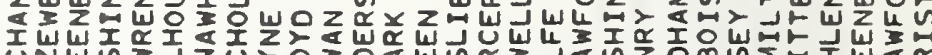

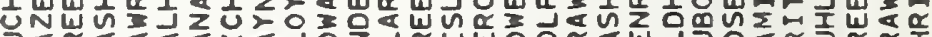

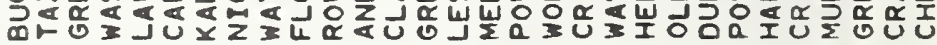

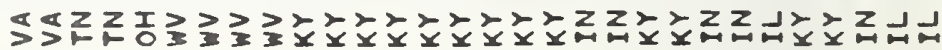

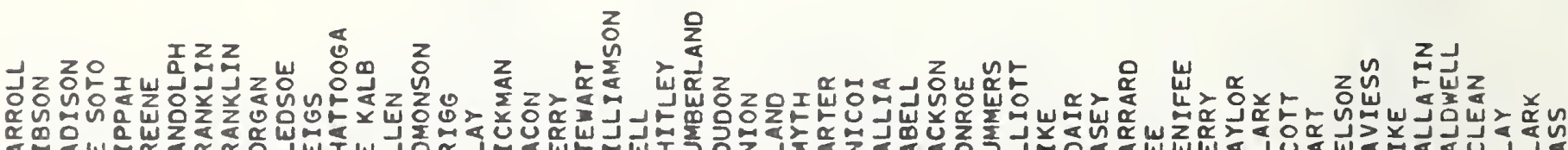

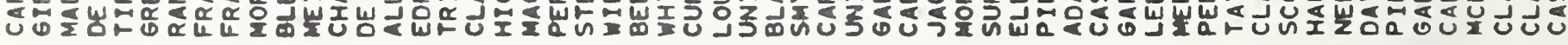

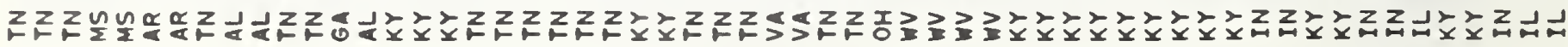

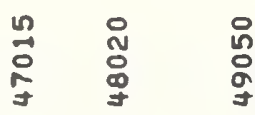

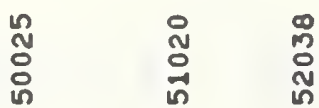

量

Nٌ
苟

岕

$\begin{array}{lll}\infty & 0 \\ : & 0 \\ : & 0 & 0 \\ \text { in }\end{array}$ 


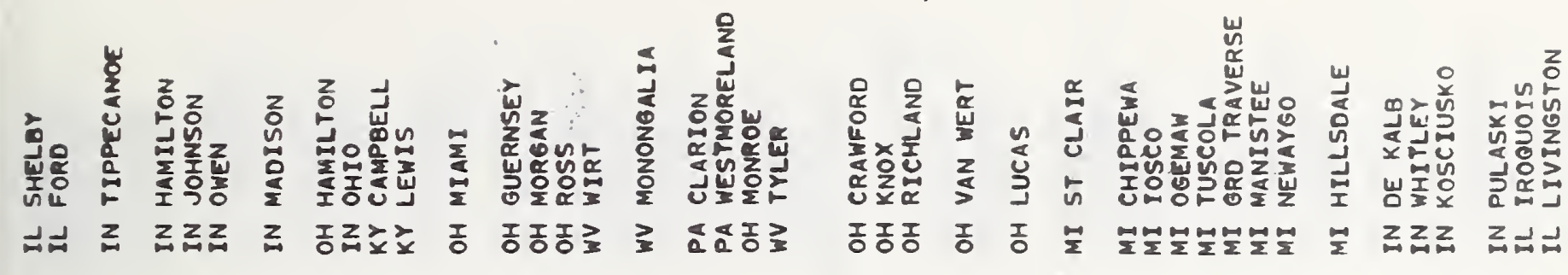

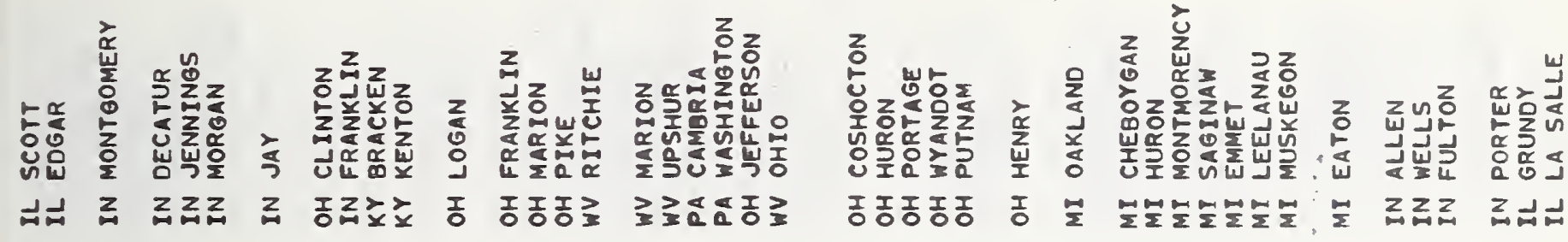

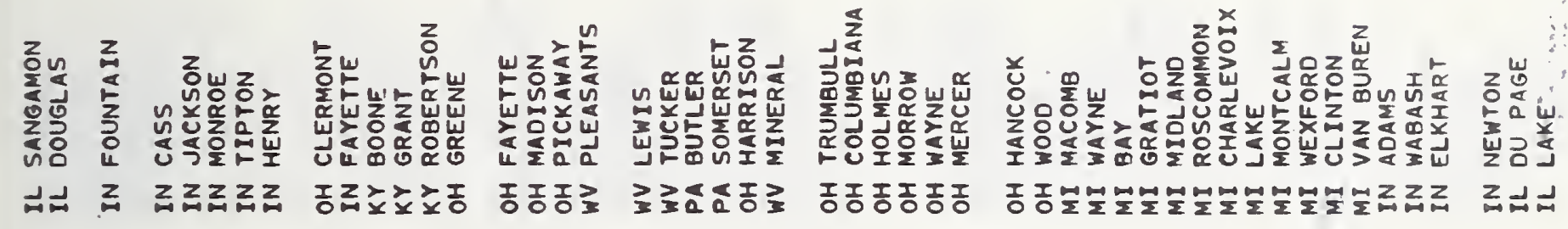

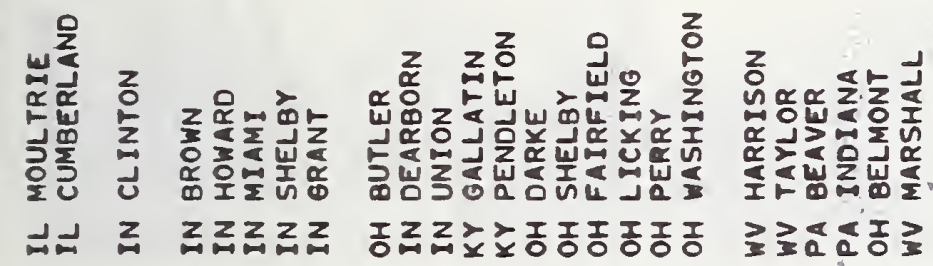

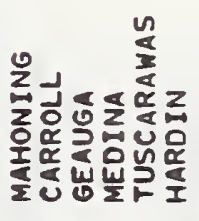

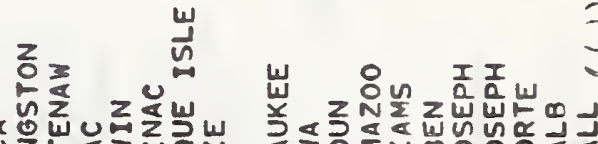

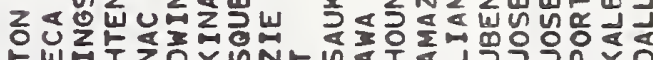

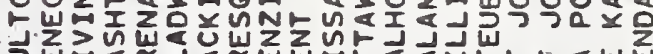

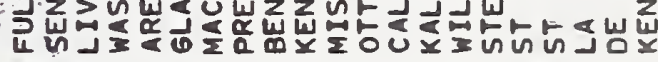

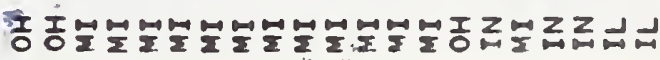

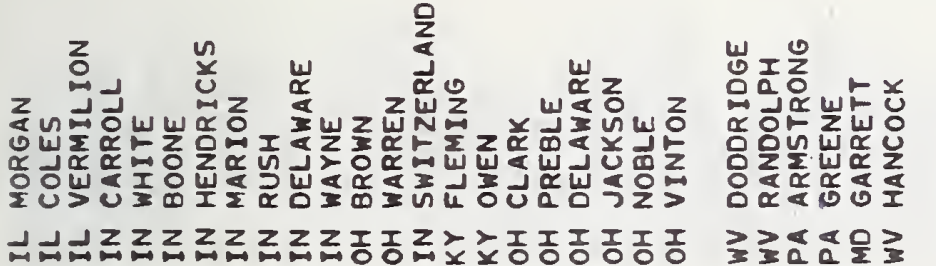

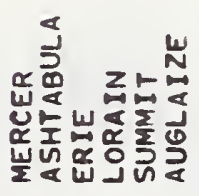

뜸동종동중

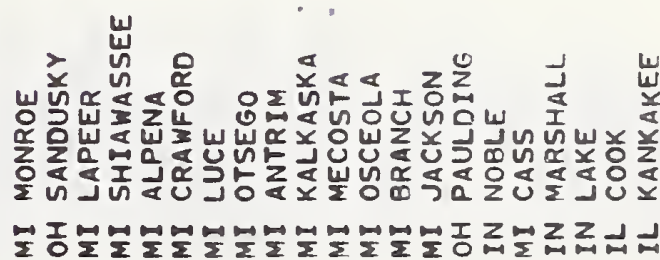

z

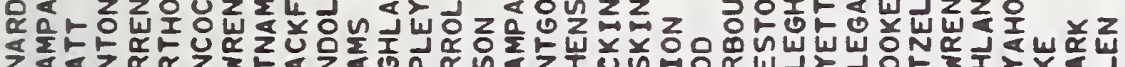

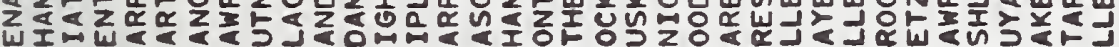

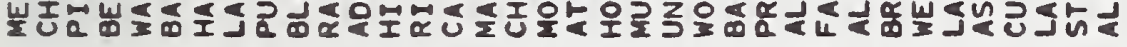

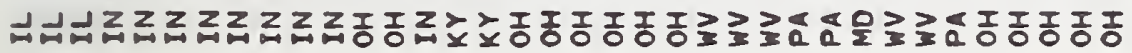

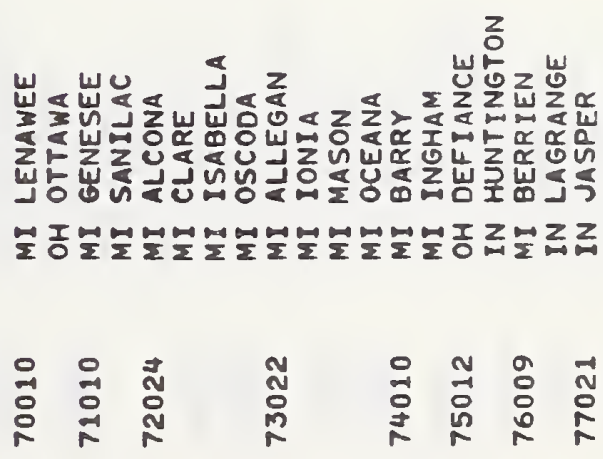

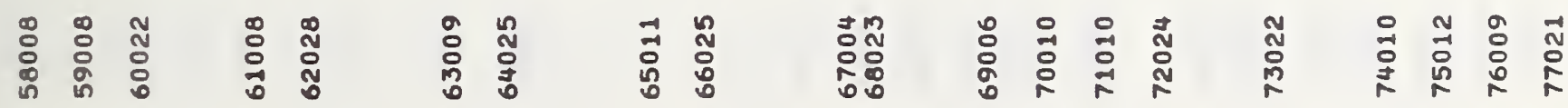

Iம0ல் ำ 


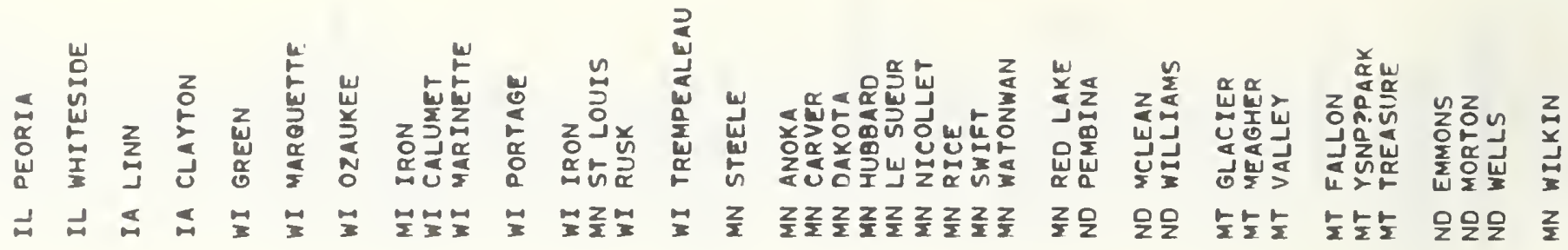

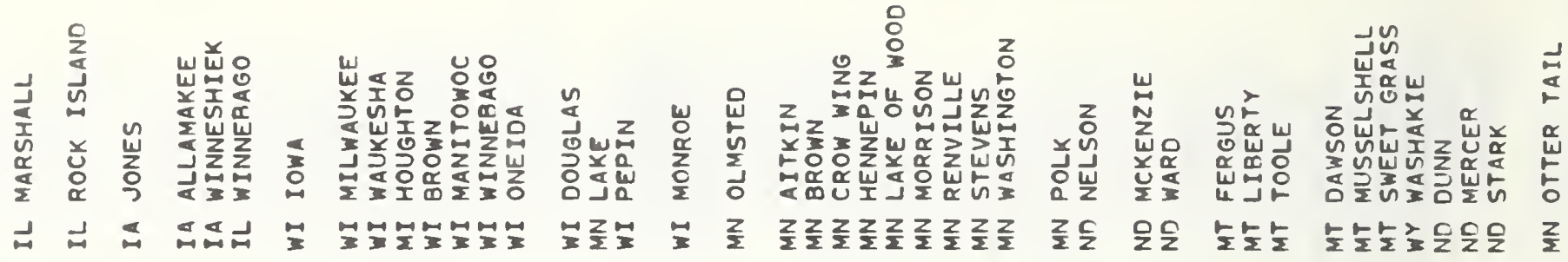

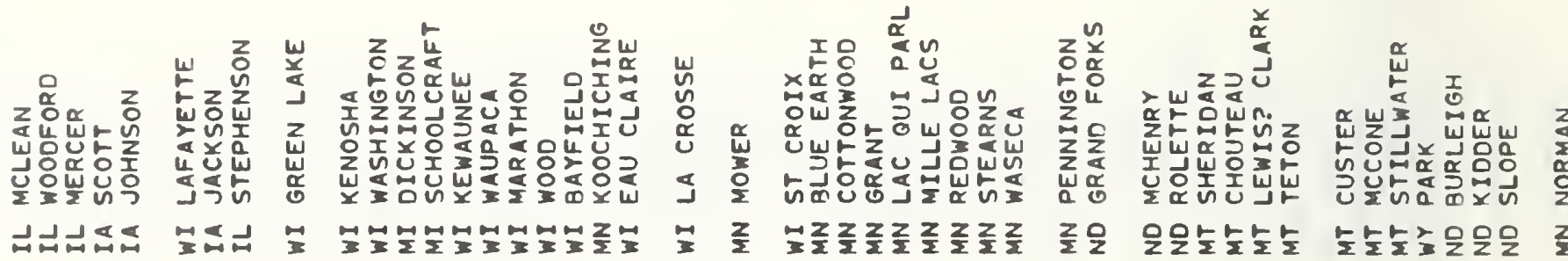

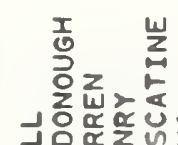

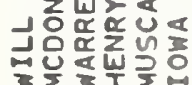
II

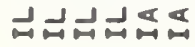

乏虽以

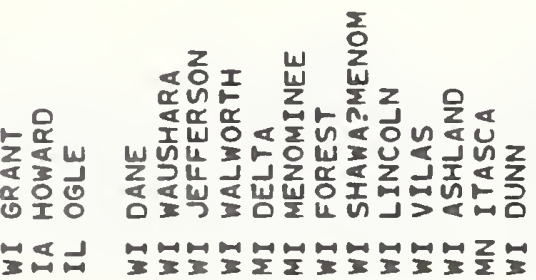

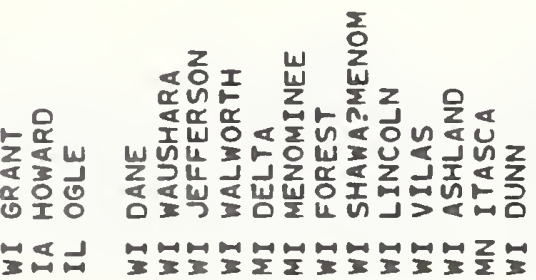

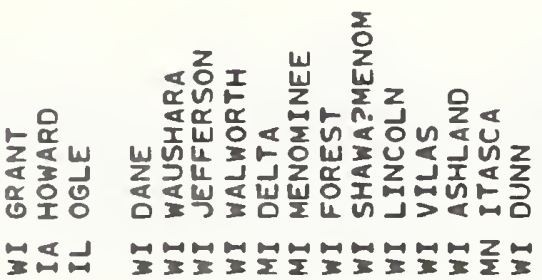

닝용농

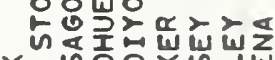

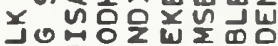

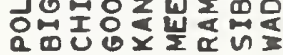

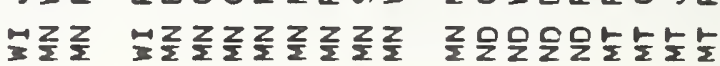

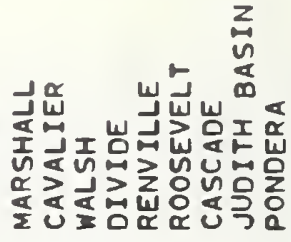

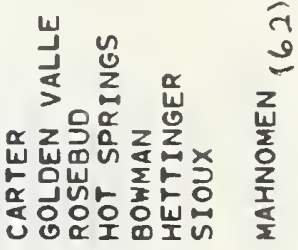

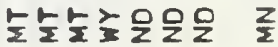

Iz

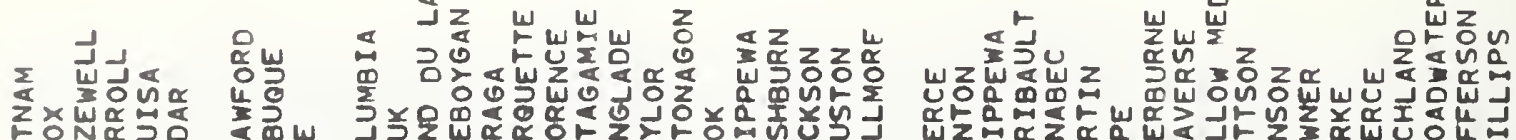

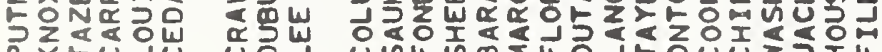
åu」U

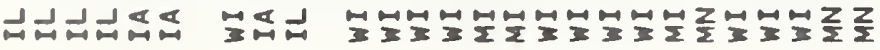

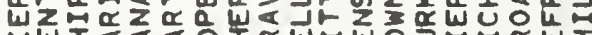

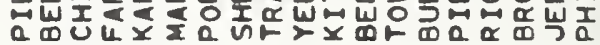

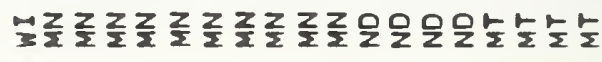

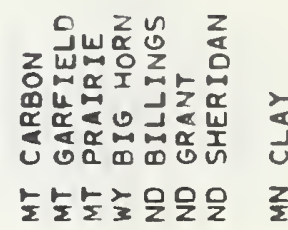

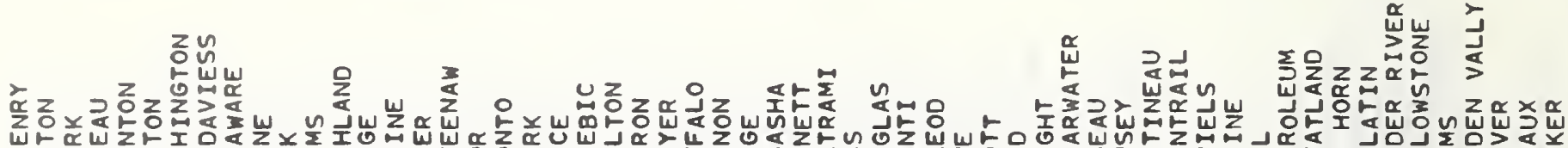

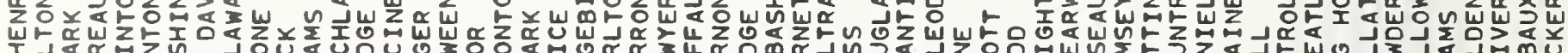

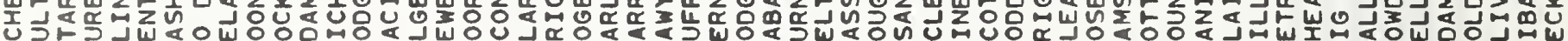

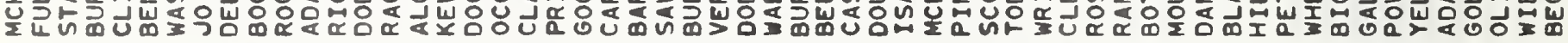

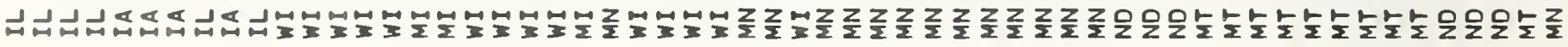

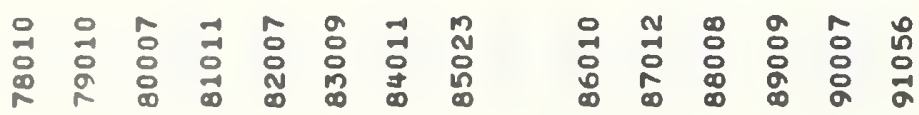

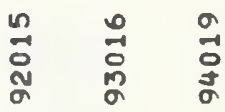

$\stackrel{m}{\sim}$ 


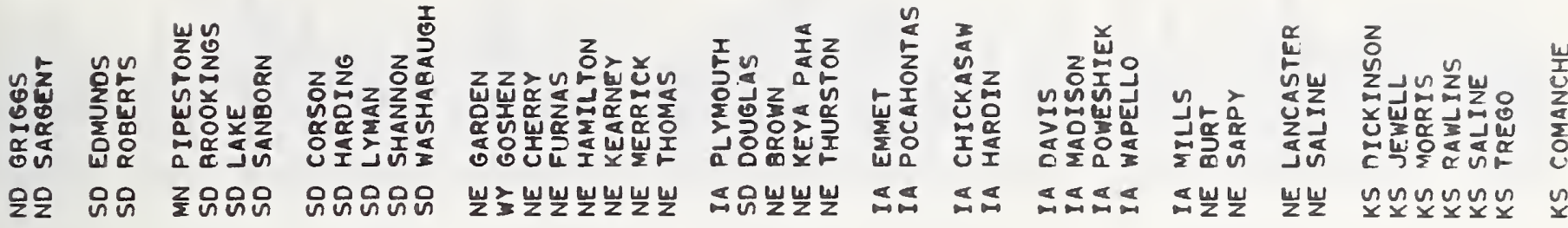

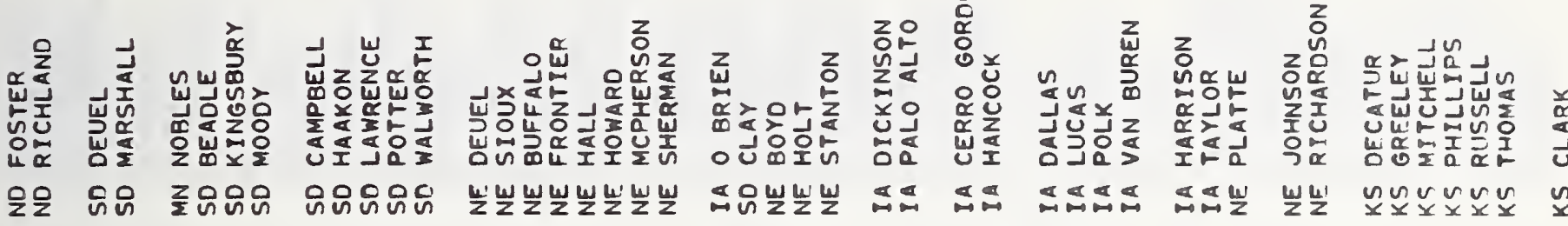

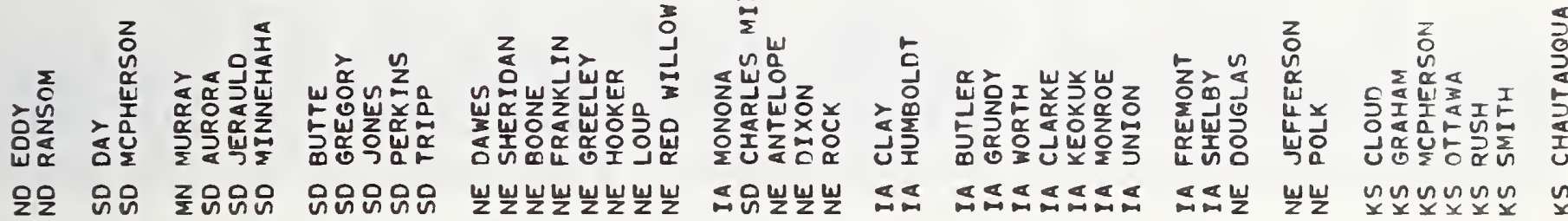

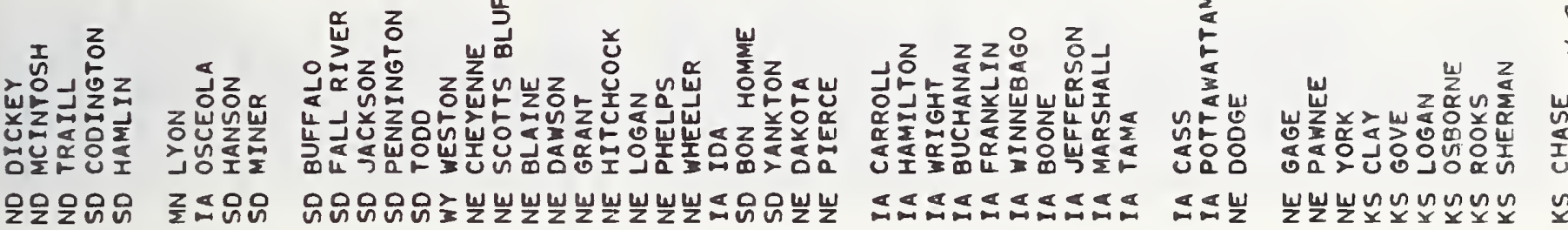

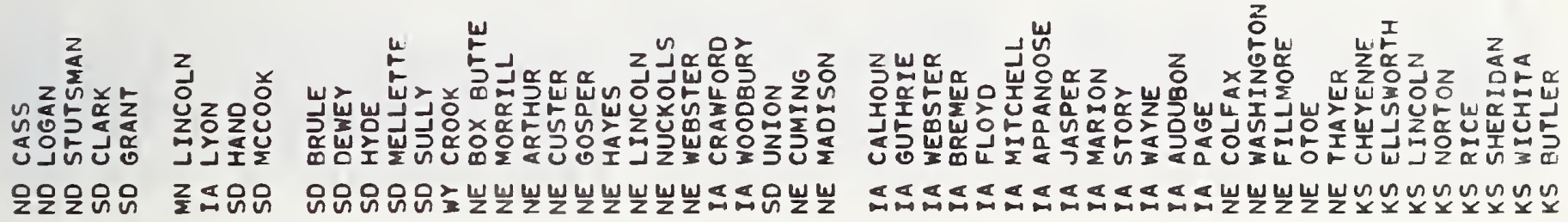

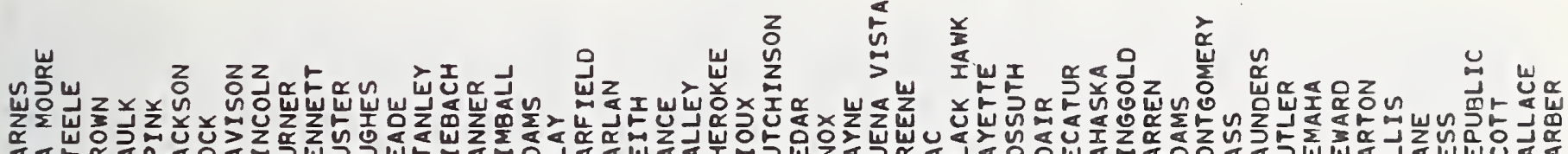

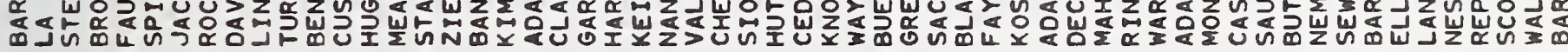

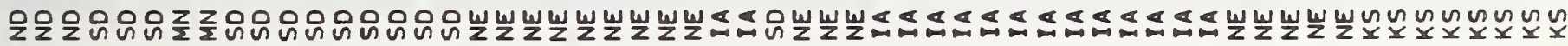

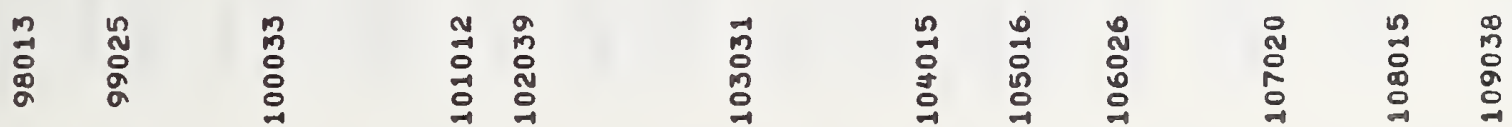




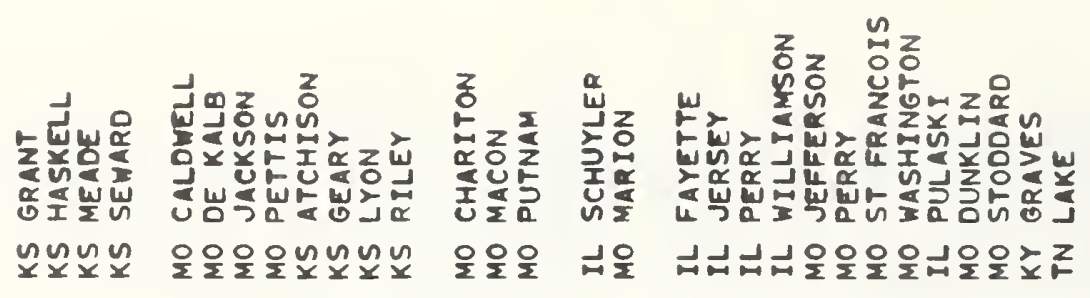

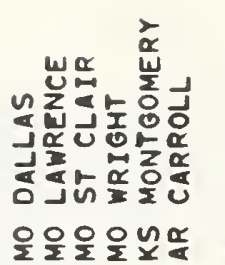

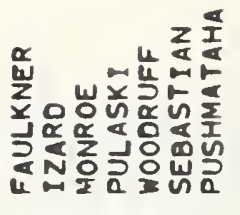

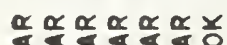

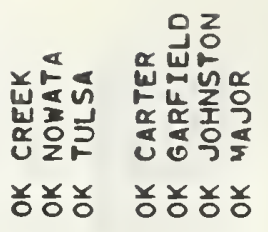

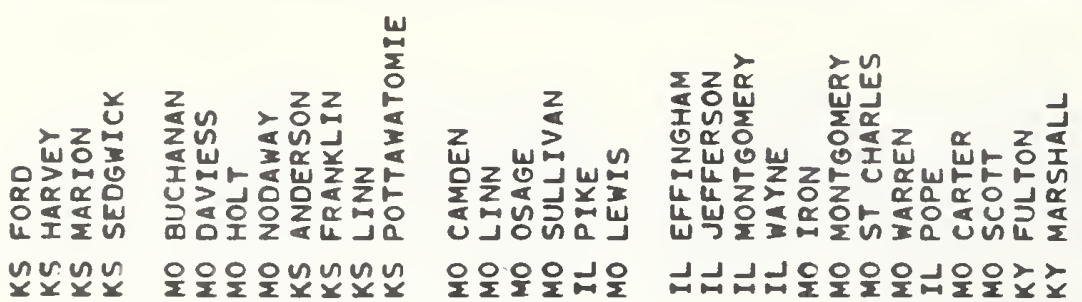

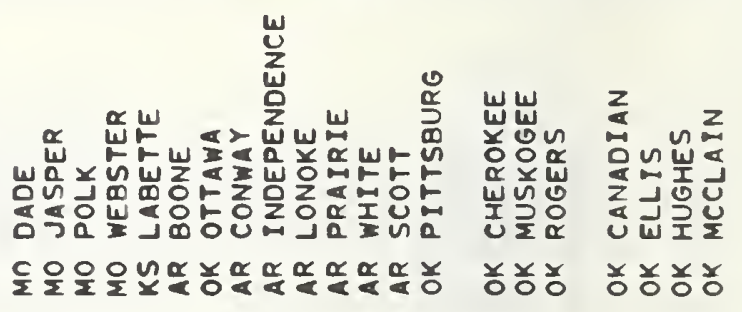

$I$

$\frac{1}{\frac{1}{\alpha}}$

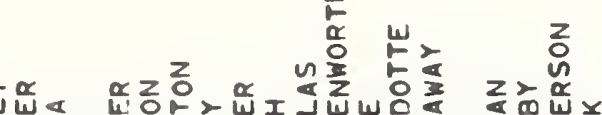

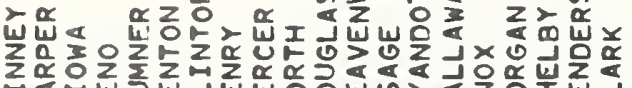

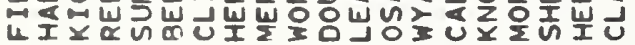

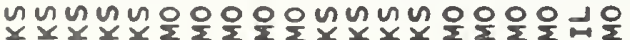

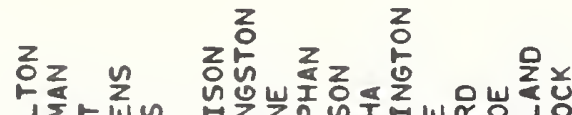

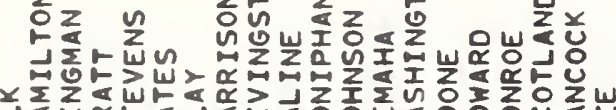

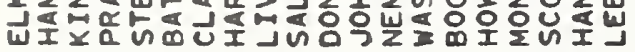

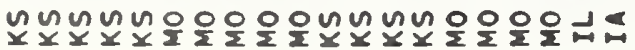

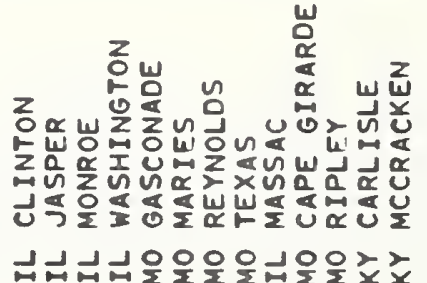

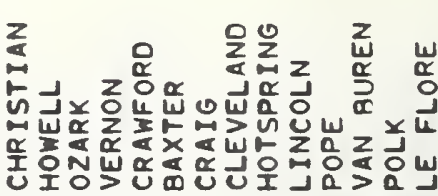

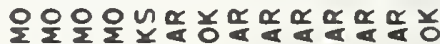

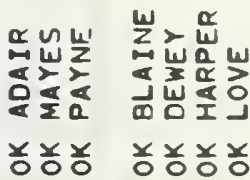

\begin{abstract}
$\vec{w}$

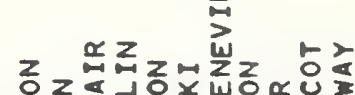

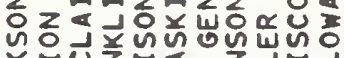

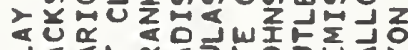

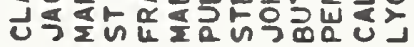

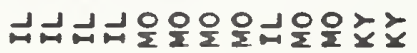

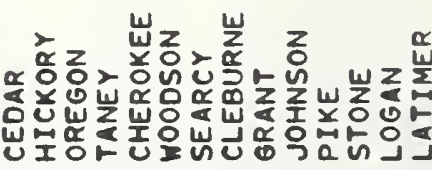

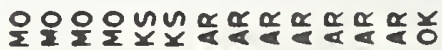

z

I 인요

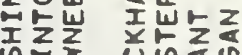

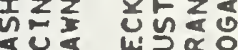

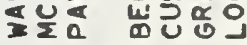

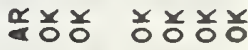

응 z zo

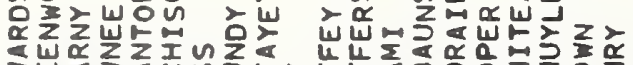

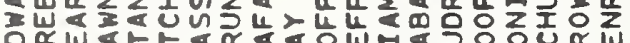

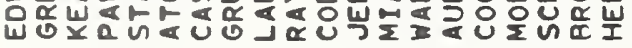

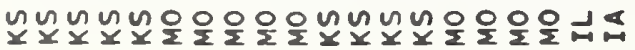

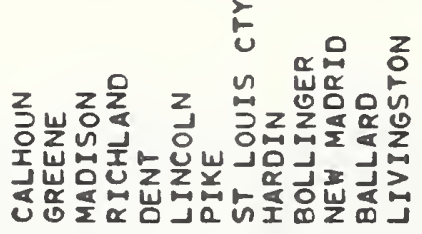

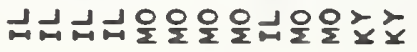

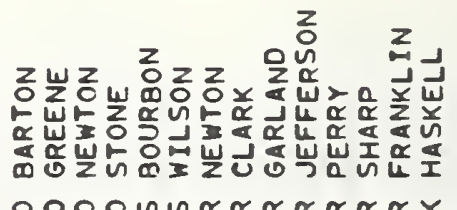

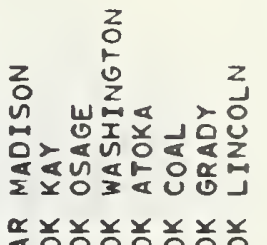

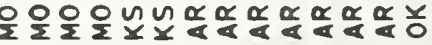

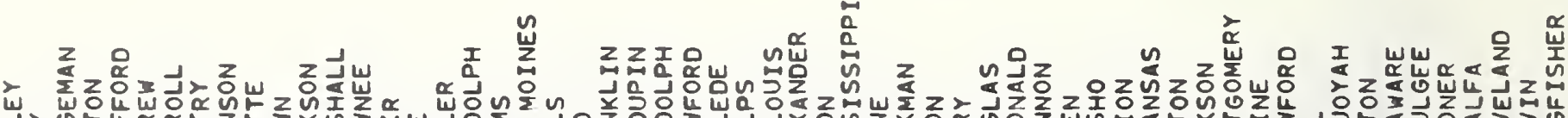

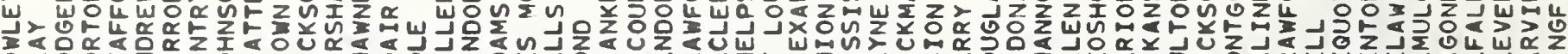

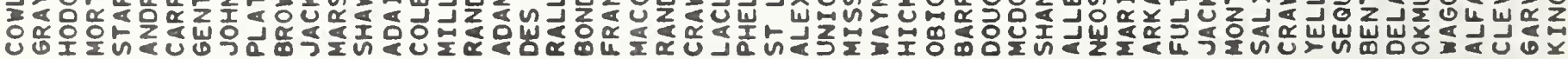

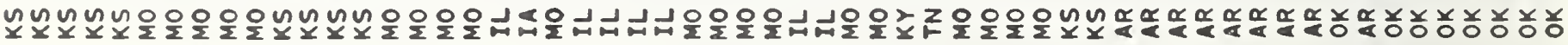

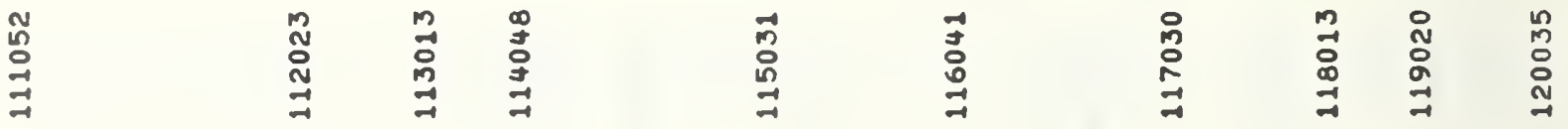




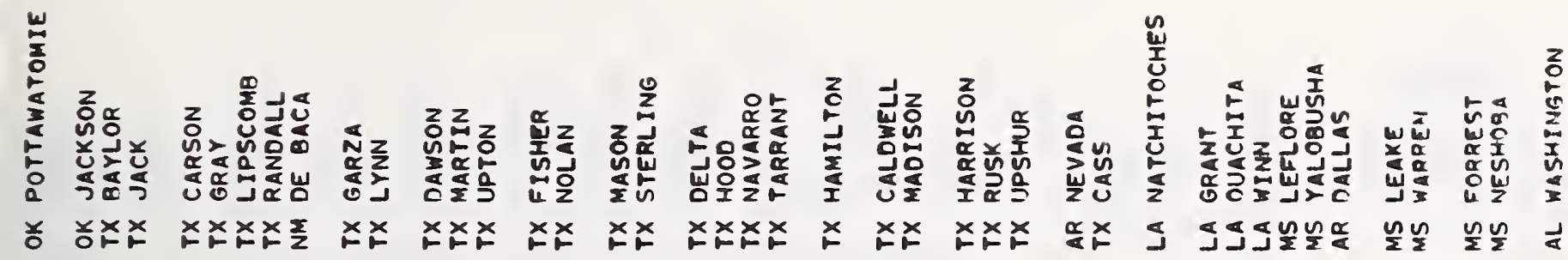

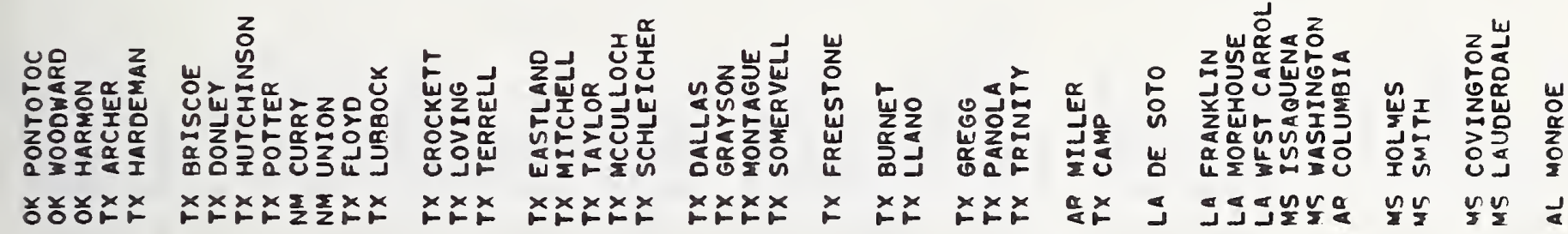

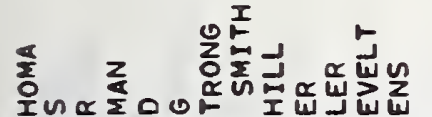

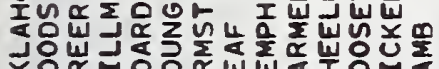

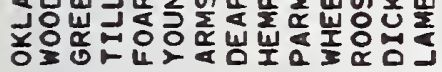

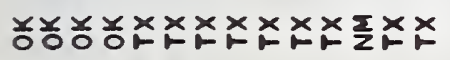

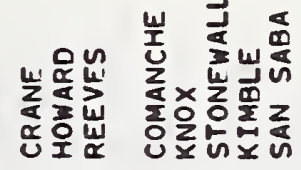

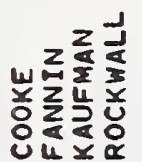

zz

xx不

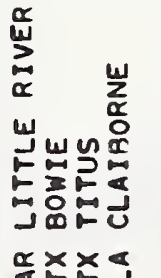

J

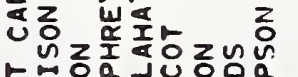

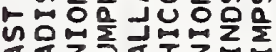

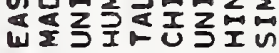
ปs wo

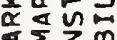
$\sum_{i} \sum_{i=1}^{\infty}$ Uృ nก⿻上丨丶

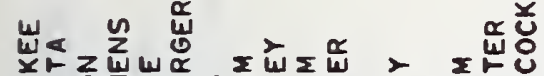

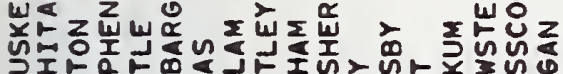

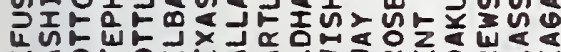

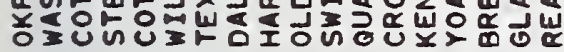

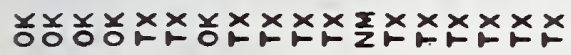

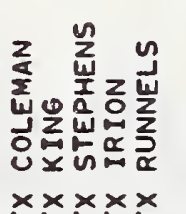

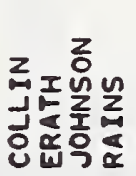

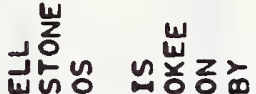

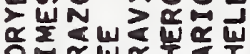

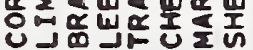

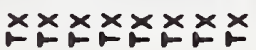

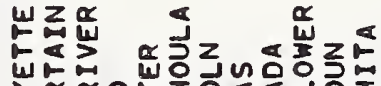

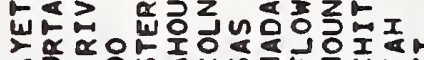

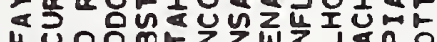

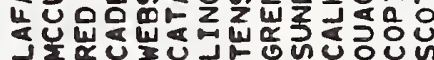

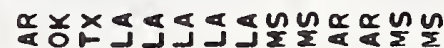

$\alpha \propto \frac{T}{5}$ w出

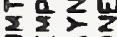

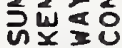
d $\frac{n}{\Sigma} \frac{n}{\Sigma} d$

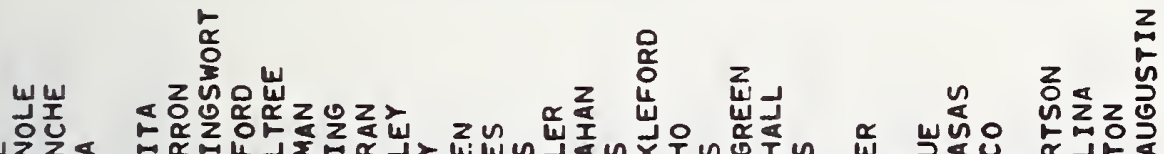

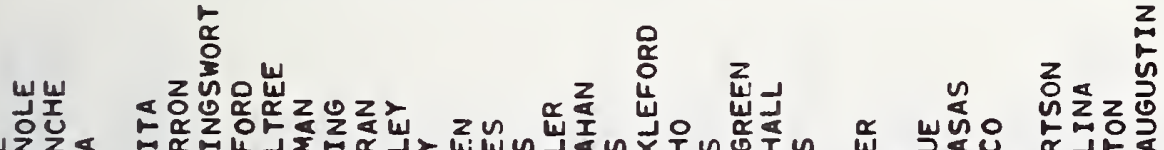

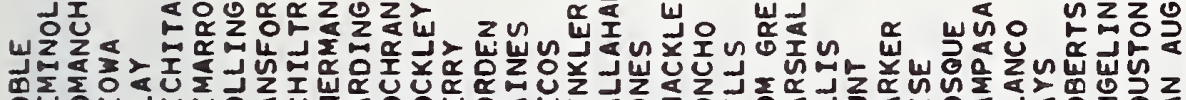

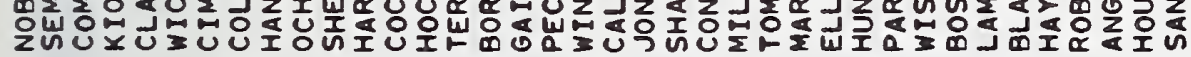

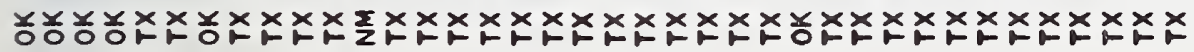

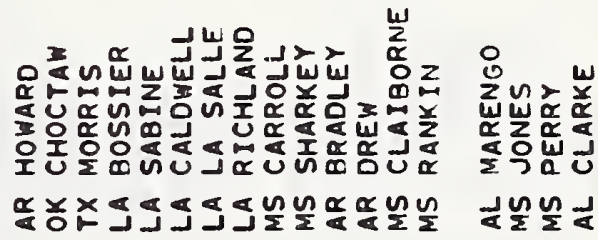

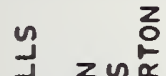

$z$ 고웡

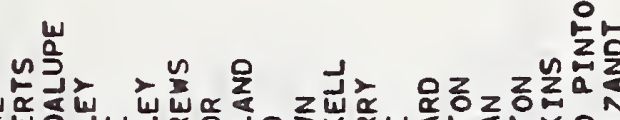
a $z$ zo

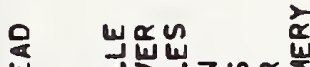
$\frac{\alpha}{\frac{\alpha}{2}}$

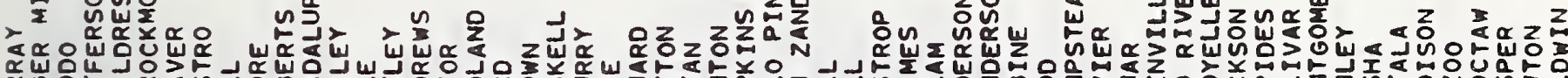

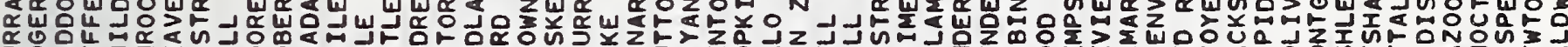

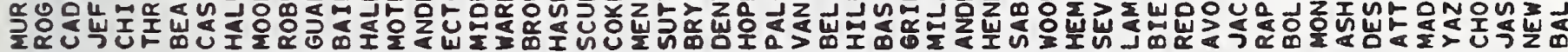

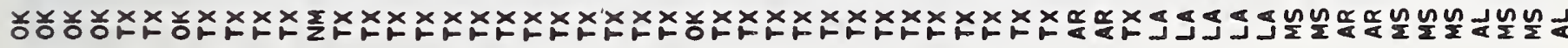

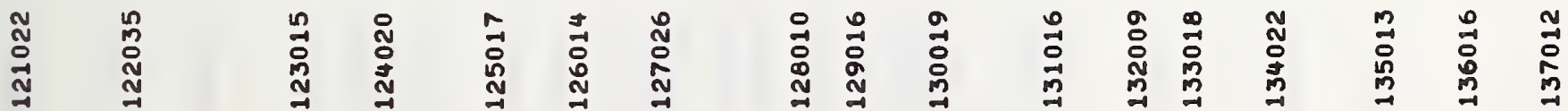




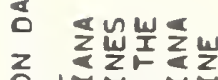

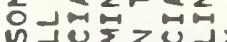

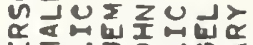

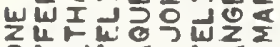
o

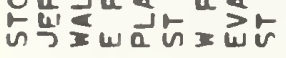

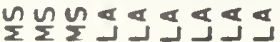

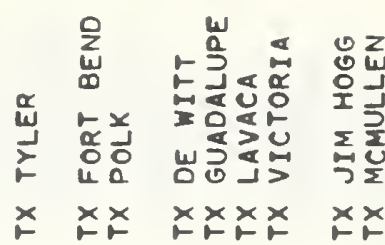

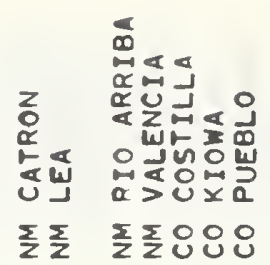

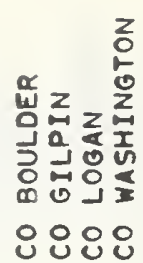

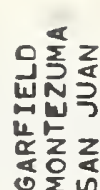

\section{(0)}

웅

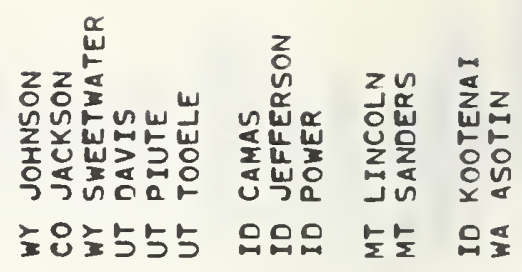

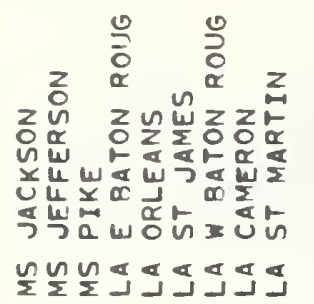

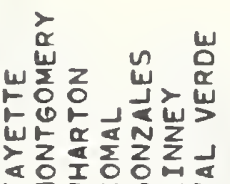

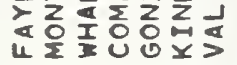

xxxxxx

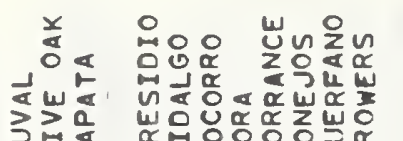

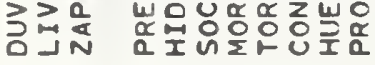

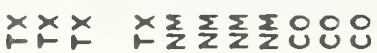

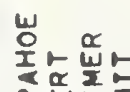
$\frac{w}{\alpha} \frac{\sum}{\alpha}$ $\propto$ แ⿺ 丶 웅ㅇㅇㅇ

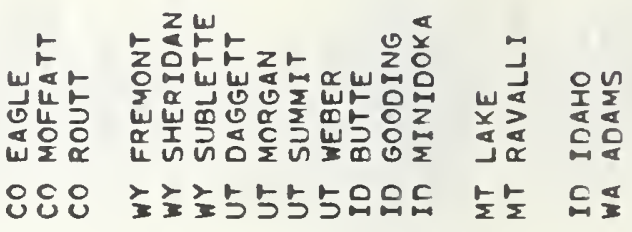

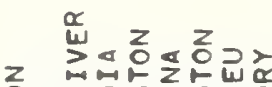

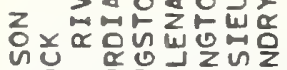

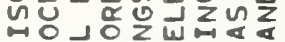

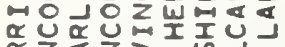

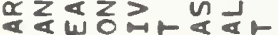

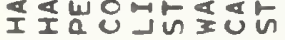

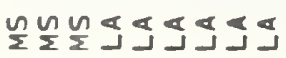

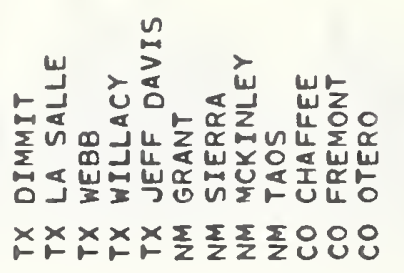

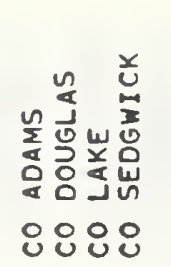

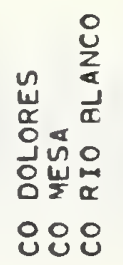

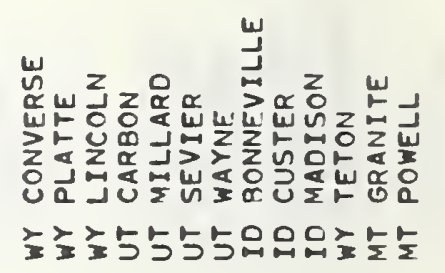

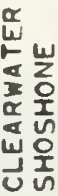
오요

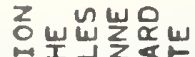 Z

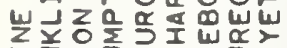

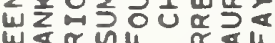

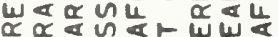

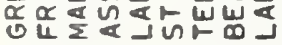

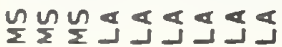

$\stackrel{0}{0}$ ๔⿻

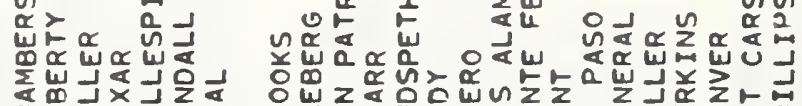

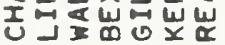

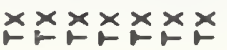

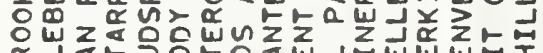

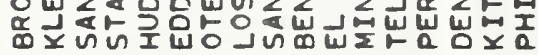

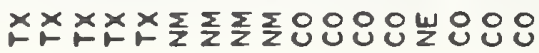

$\sum_{\substack{n \\ \frac{2}{n}}}^{n}$ 2

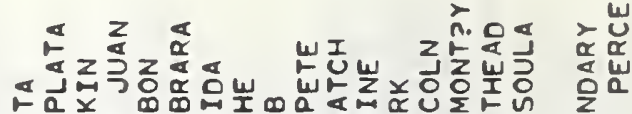

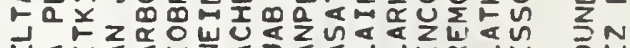

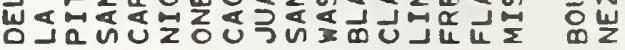

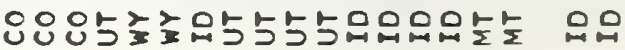

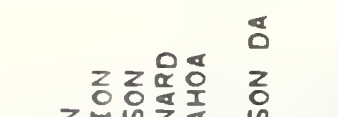

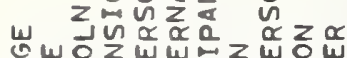

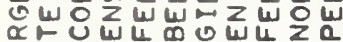 ○一

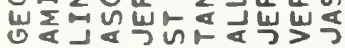

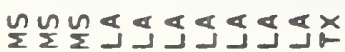

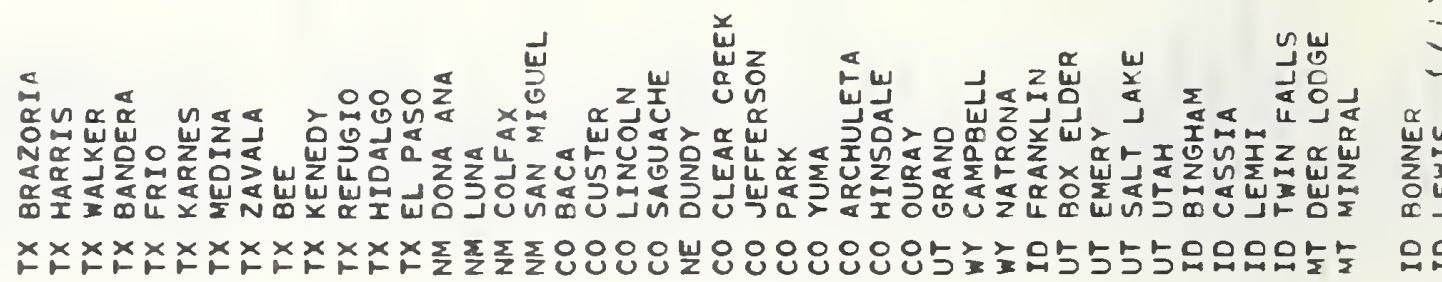

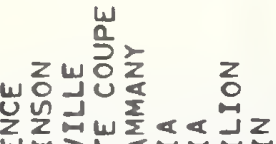

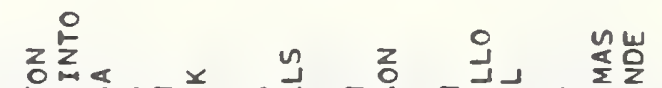

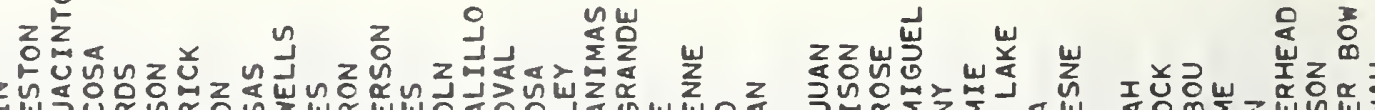

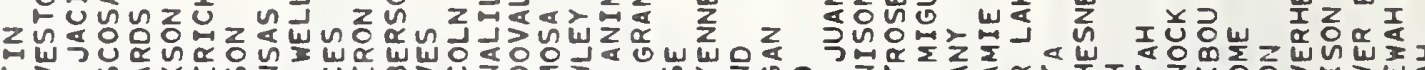

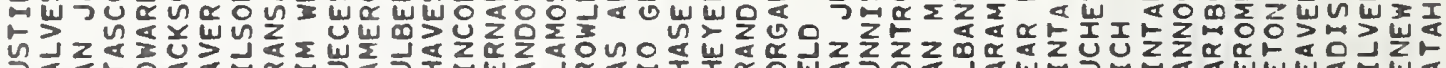

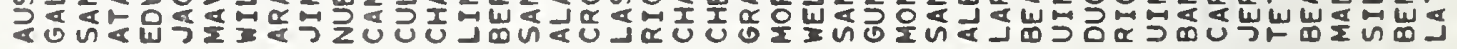

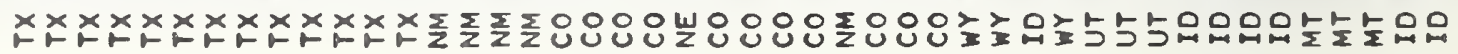

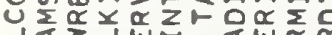

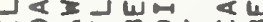

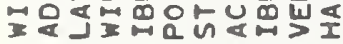

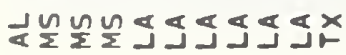

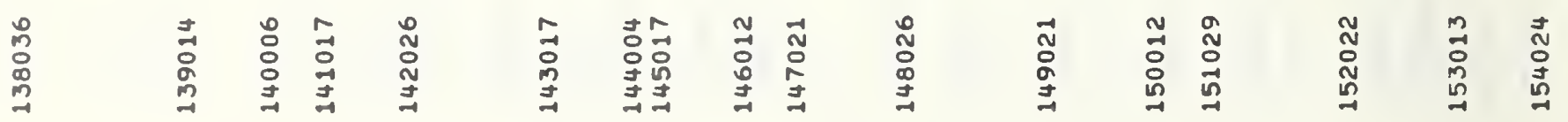

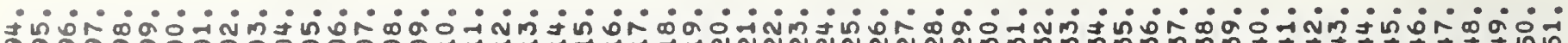

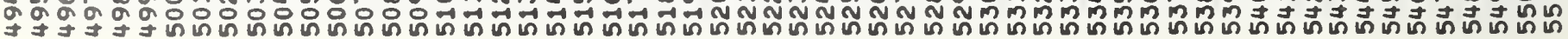




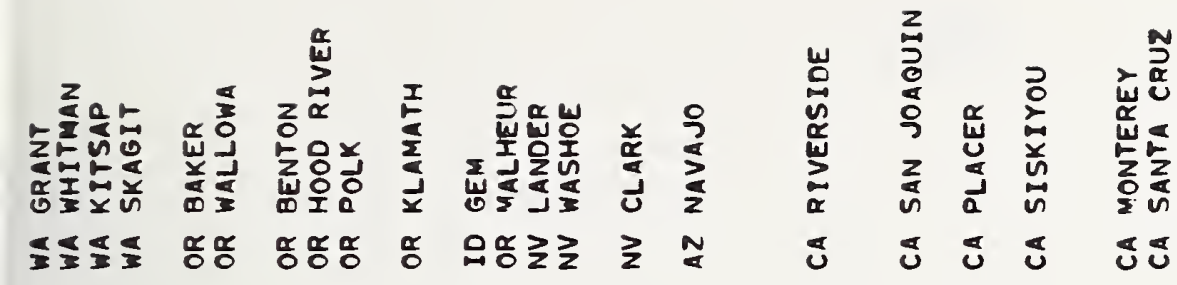

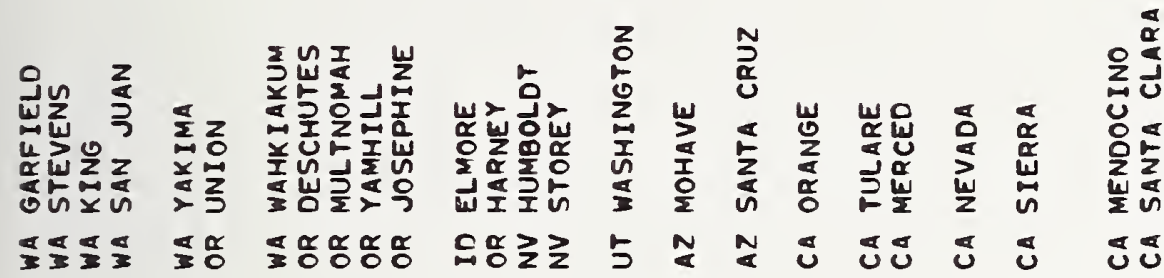

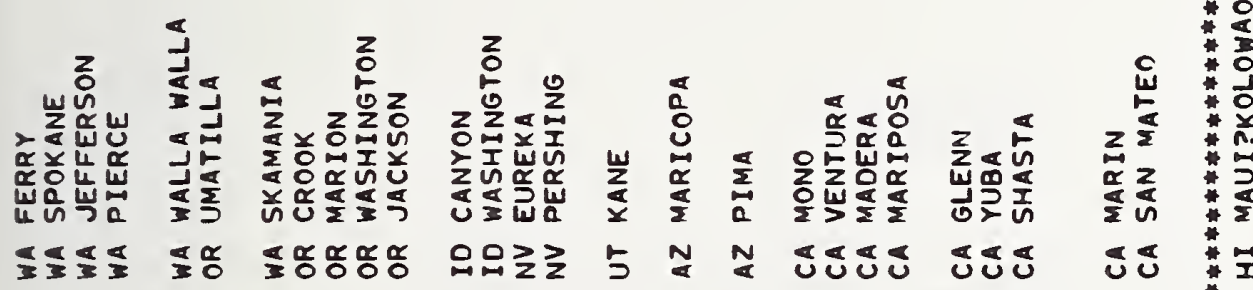

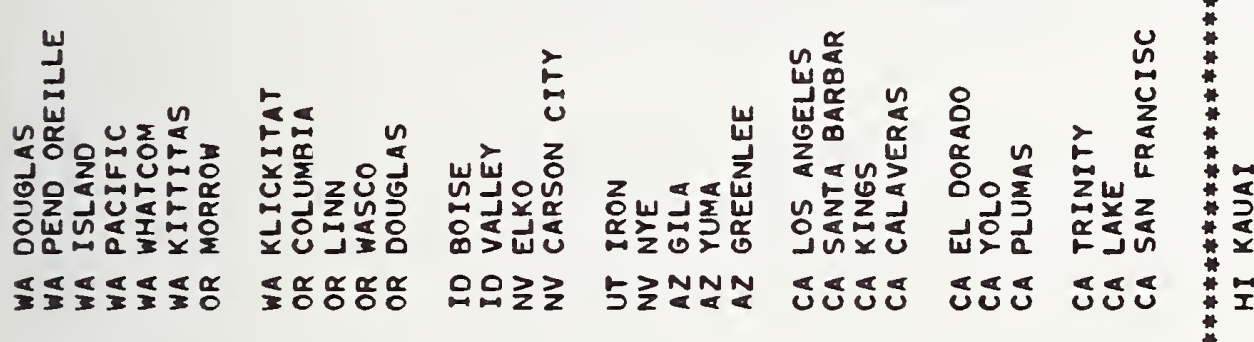
总

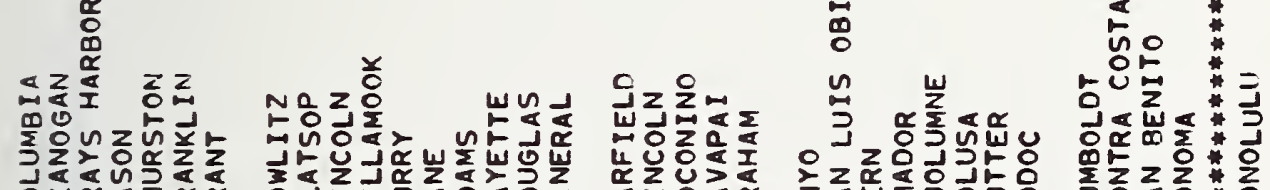

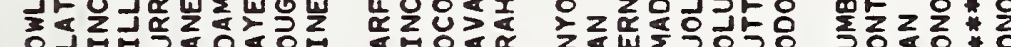

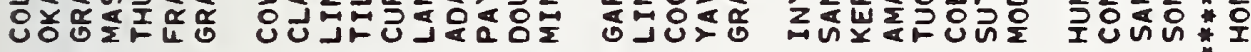

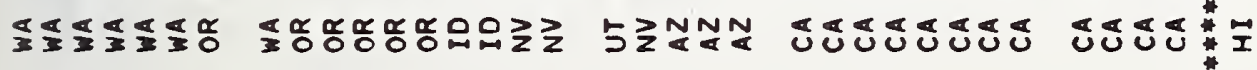

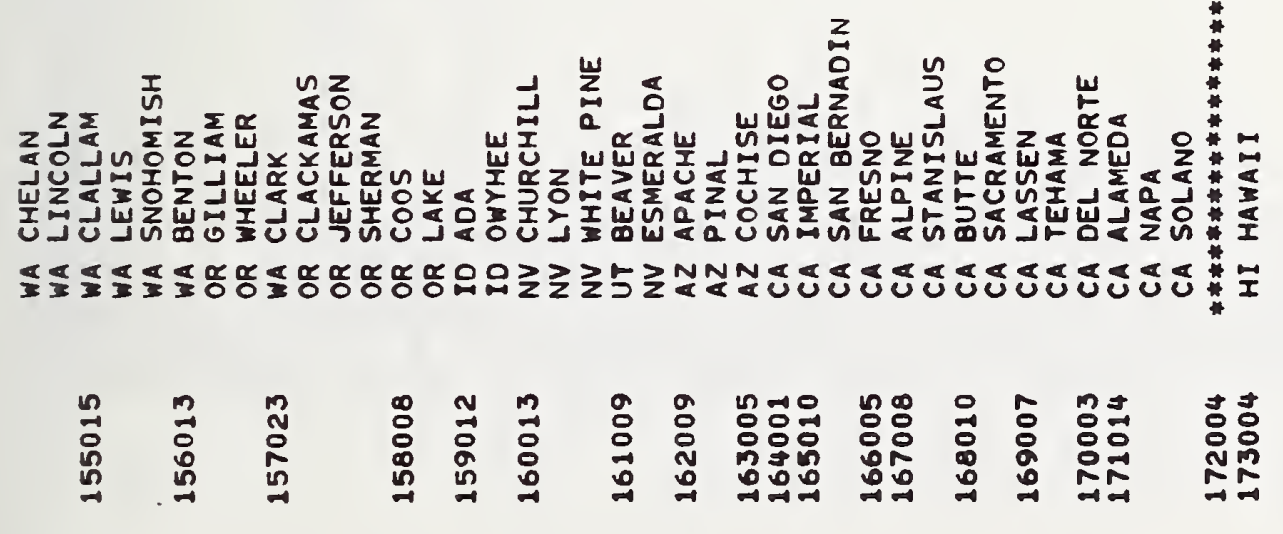

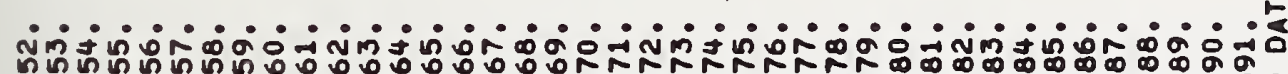

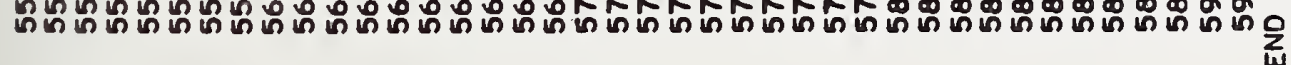


Appendix 5

Listings of Programs CNTYLIST and INDX 


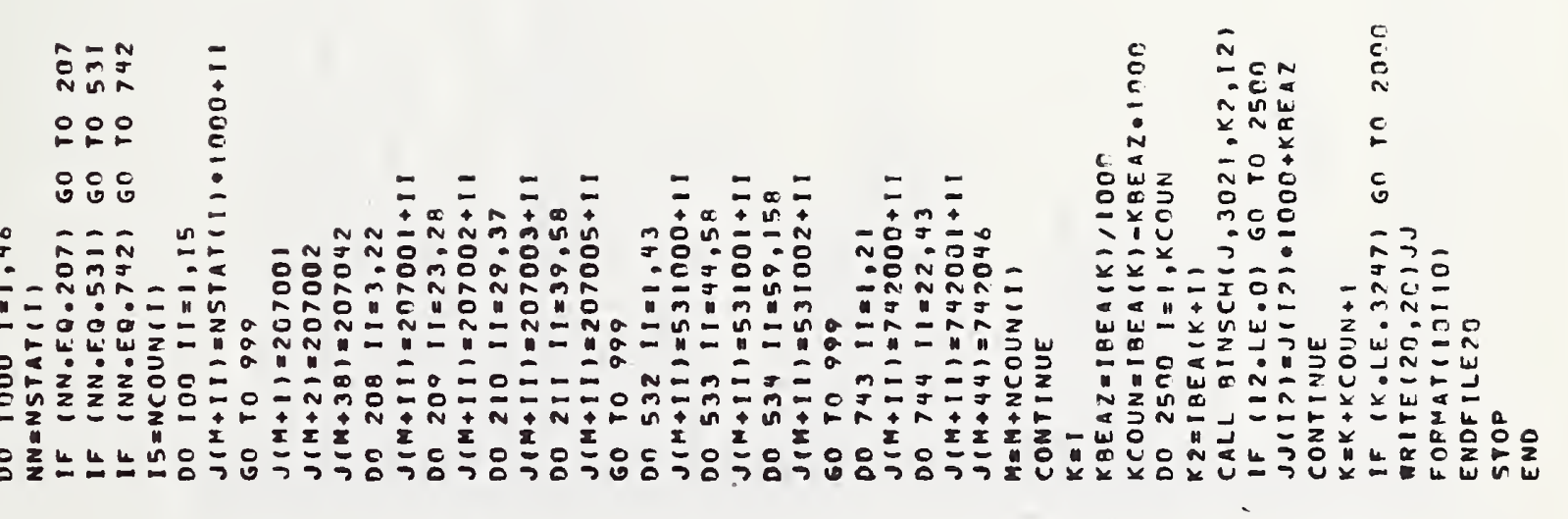
$\underline{0}$
$\stackrel{0}{0}$
造
它导 


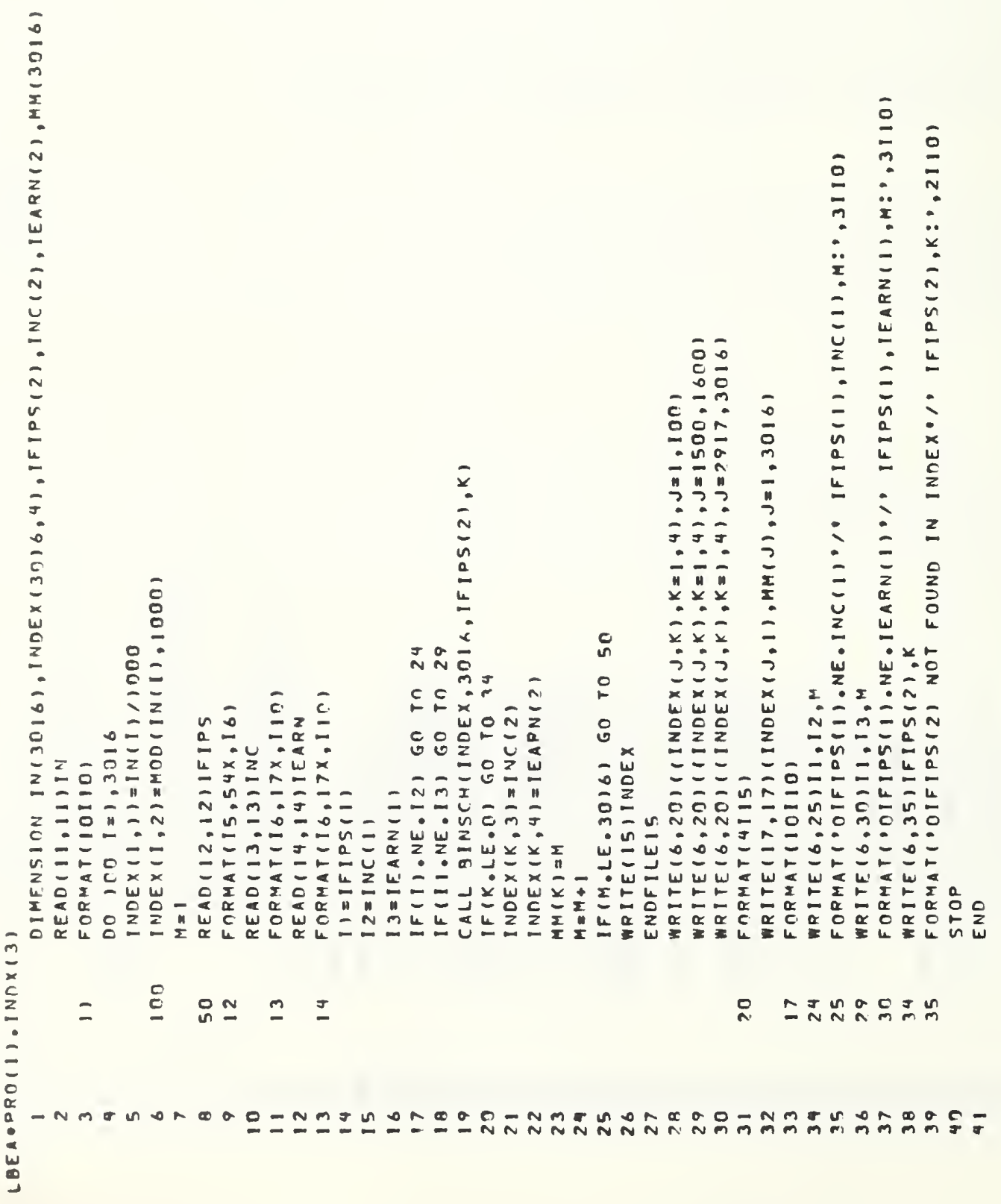

$\hat{0}$ 


\section{Appendix 6}

Listings of Programs NAMELIST and FBBFC 


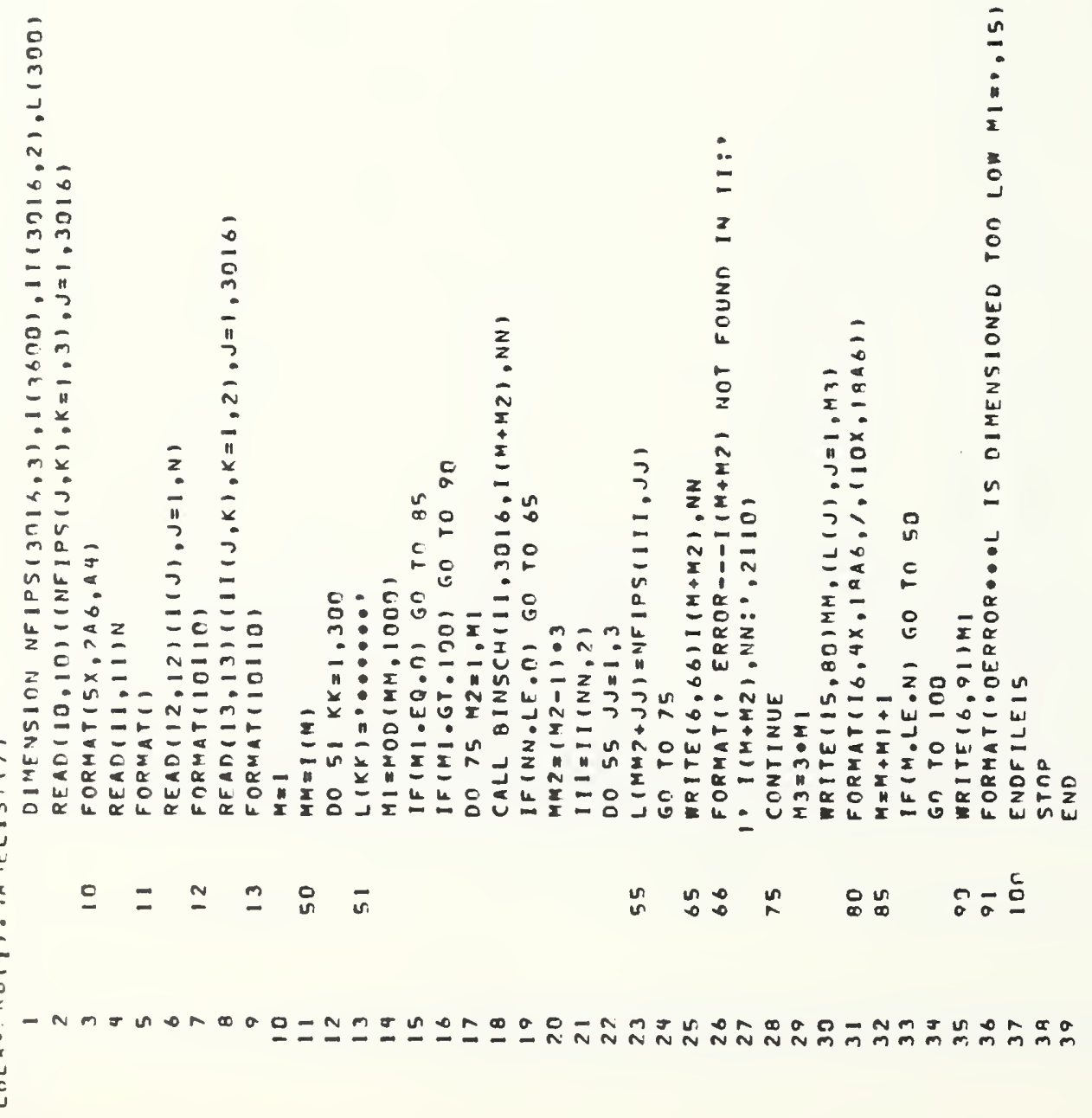




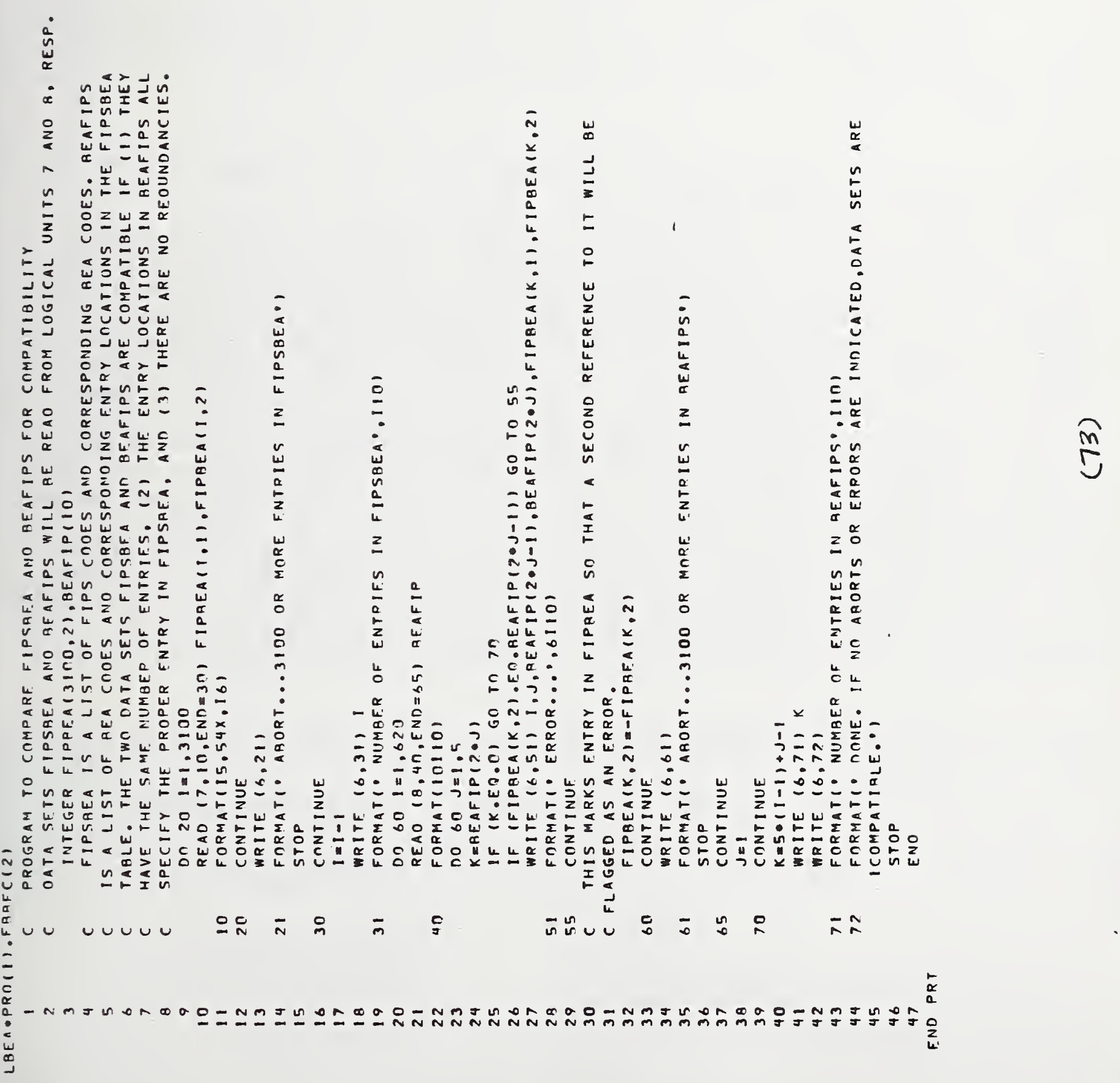


NBS.I14A (REV. 7.73)

\begin{tabular}{|c|c|c|c|}
\hline $\begin{array}{l}\text { U.S. DEPT. OF COMM. } \\
\text { BIBLIOGRAPHIC DATA } \\
\text { SHEET }\end{array}$ & $\begin{array}{l}\text { 1. PUIBL.K.ATION OR RIEPORT NO. } \\
\text { NBSIR 75-918 }\end{array}$ & $\begin{array}{l}\text { 2. Gov't Accession } \\
\text { No. }\end{array}$ & 3. Recipient's Accession No. \\
\hline \multirow{2}{*}{\multicolumn{3}{|c|}{$\begin{array}{l}\text { 4. TITI.F AND SUBTITI. } \\
\text { Machine-Readable Mapping from National Network Simulation (NNS) } \\
\text { Zones to Bureau of Ficonomic. Analysis (BEA) Areas }\end{array}$}} & $\begin{array}{l}\text { 5. Publication Date } \\
\text { Sept. } 1975\end{array}$ \\
\hline & & & 6. Performing Organization Code \\
\hline \multicolumn{3}{|c|}{ 7. AUTHOR(S) Daniel W. Lozier and John R. Stiehler } & 8. Performing Organ. Report No. \\
\hline \multirow{2}{*}{\multicolumn{3}{|c|}{$\begin{array}{l}\text { 9. PERFORMING ORGANIZATION NAME AND ADDRESS } \\
\text { NATIONAL BUREAU OF STANDARDS } \\
\text { DEPARTMENT OF COMMERCE } \\
\text { WASHINGTON, D.C. } 20234\end{array}$}} & $\begin{array}{l}\text { 10. Project/Task/Work Unit No. } \\
2050141\end{array}$ \\
\hline & & & 11. Contract/Grant No. \\
\hline \multirow{2}{*}{\multicolumn{3}{|c|}{ 12. Sponsoring Organization Name and Complete Address (Street, City, State, ZIP) }} & $\begin{array}{l}\text { 13. Type of Report \& Period } \\
\text { Covered } \\
\text { Final }\end{array}$ \\
\hline & & & 14. Sponsoring Agency Code \\
\hline
\end{tabular}

15. SUPPLEMENTARY NOTES

16. ABSTRACT (A 200-word or less factual summary of most significant in formation. If document includes a significant bibliography or literature survey, mention it here.)

This report describes the allocation of freight flow data from the National Network Simulation (NNS) zone system to the Bureau of Economic Analysis (BEA) area system. The NNS zone system was developed for use in the analysis of national modal freight flows. The BEA area system was primarily developed for the allocation of national economic data to regions of the United States. The BEA area system contains approximately 175 distinct areas and the NNS zone system, approximately 500. Assuming flows of commodities are known among the NNS zones, the NNS zone to BEA area mapping enables the determination of flows among the BEA areas. When an NNS zone is completely contained in one BEA area, flows entering and leaving the NNS zone accrue entirely to that BEA area. When an NNS zone overlaps more than one $\mathrm{BEA}$ area, the mapping specifies the allocation of incoming and outgoing flows among the affected BEA areas. This report presents the NNS zone to BEA area mapping which utilizes 1970 economic data as the basis for allocating flows when an NNS zone overlaps more than one BEA area. It also presents computer programs that could be used to generate a mapping using economic data from some other year. Closely related reports are $\mathbb{R}$. Sehofer, "Final Report on the National Network Simulation", NBS Internal Report 75-912 and R.H.F. Jackson, "A National Network Data Base System", NBS Interna1 Report 75-911.

17. KEY WORDS (six to twelve entries; alphabetical order; capitalize only the first letter of the first key word unless a proper name; separated by semicolons)

Commodity flow analysis, Economic analysis, National Network Simulation System.

18. AVAILABILITY Xnlimited

For Official Distribution. Do Not Release to NTIS

Order From Sup. of Doc., U.S. Government Printing Office Washington, D.C. 20402, SD Cat. No. C13

\begin{tabular}{|l|c|}
$\begin{array}{l}\text { 19. SECURITY CLASS } \\
\text { (THIS REPURT) }\end{array}$ & 21. NO. OF PAGES \\
UNCL ASSIFIED & 77 \\
\hline $\begin{array}{l}\text { 20. SECURITY CLASS } \\
\text { (THIS PAGE) }\end{array}$ & 22. Price \\
UNCLASSIFIED & $\$ 5.00$ \\
\hline
\end{tabular}

Order From National Technical Information Service (NTIS Springfield, Virginia 22151 
see target for $75-919$ 
